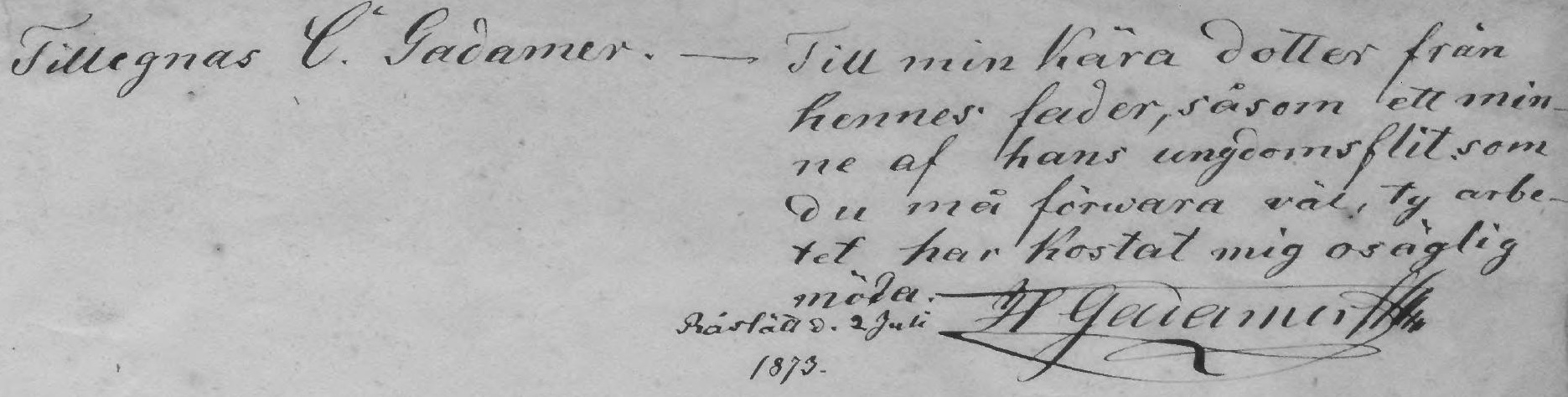



Esoloutern

Scanica. ) on 


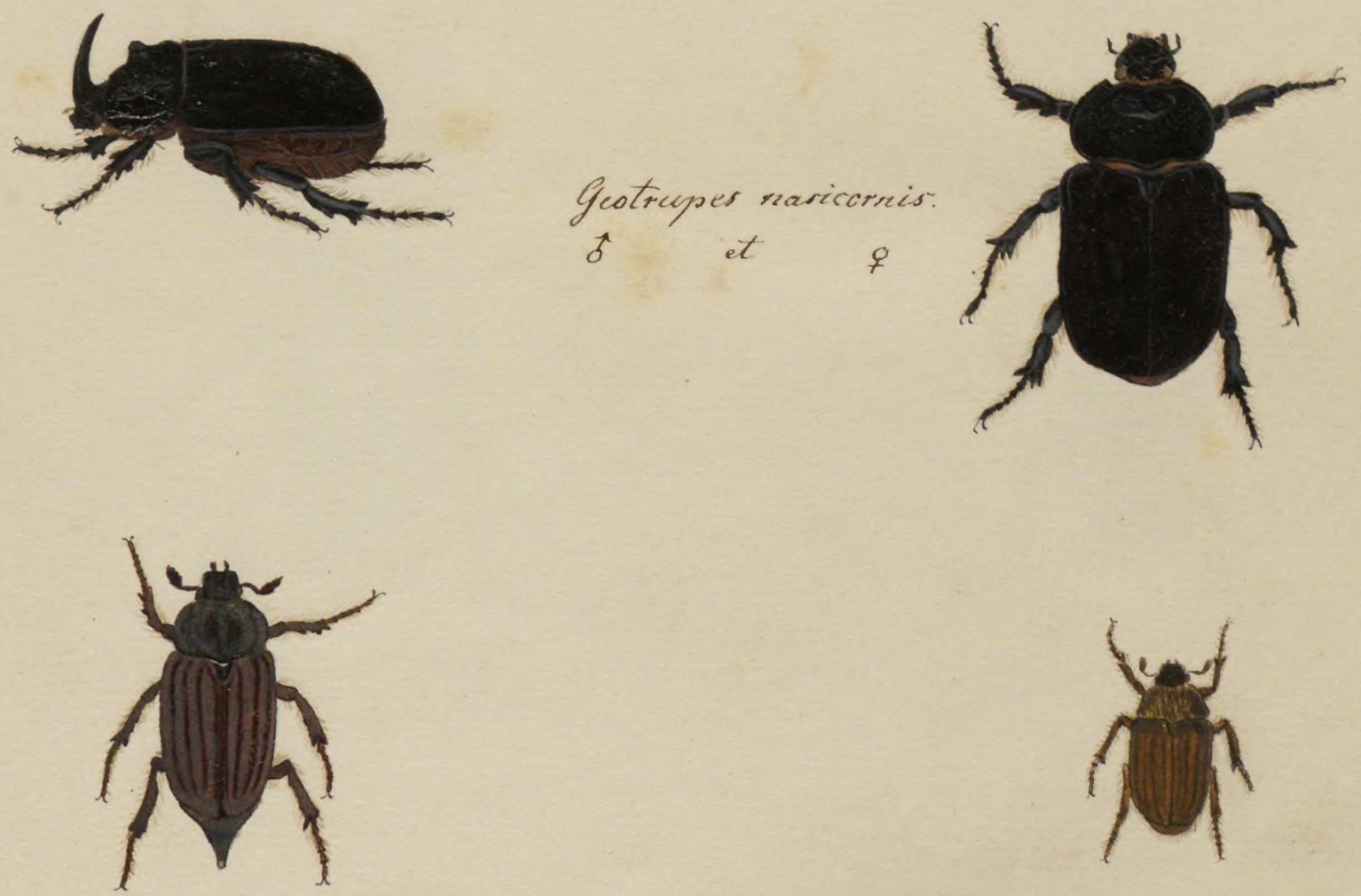

Mzdolontha valgaris.

$$
\text { medolontha solstitiatis. }
$$

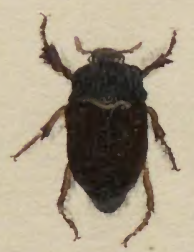

incloloritha falleric
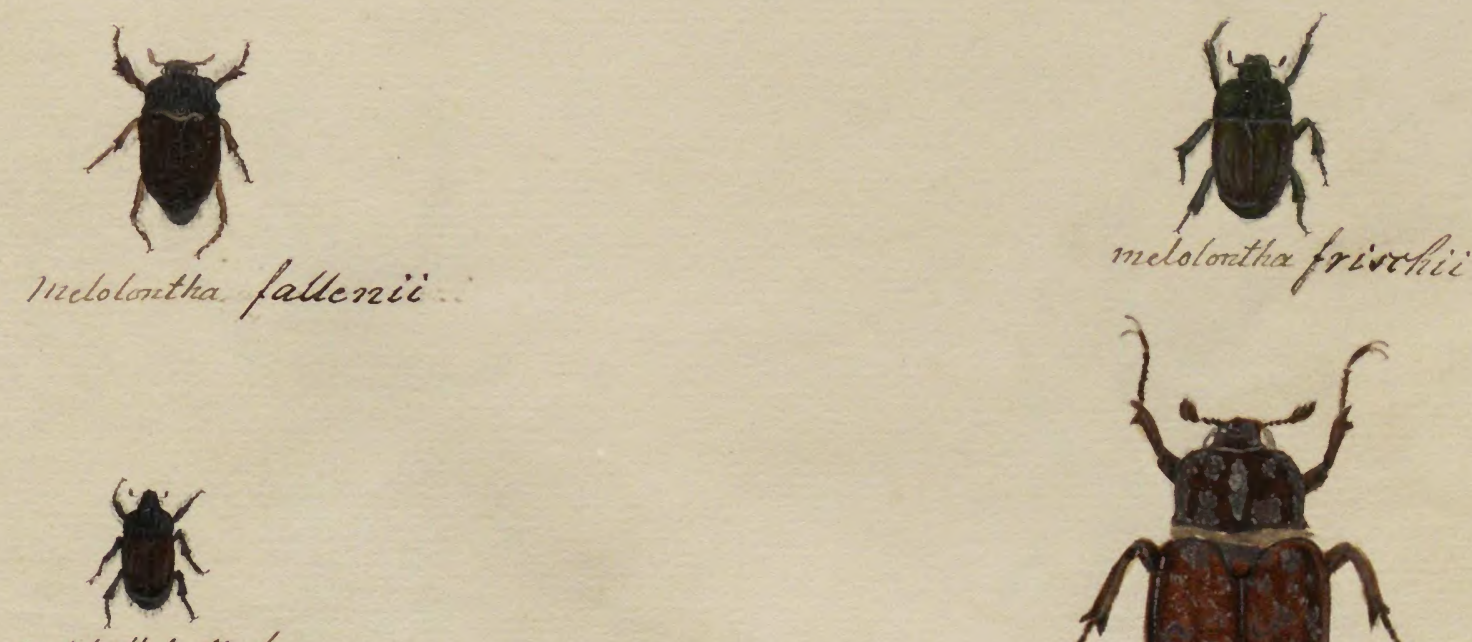

mulolonth horticala.

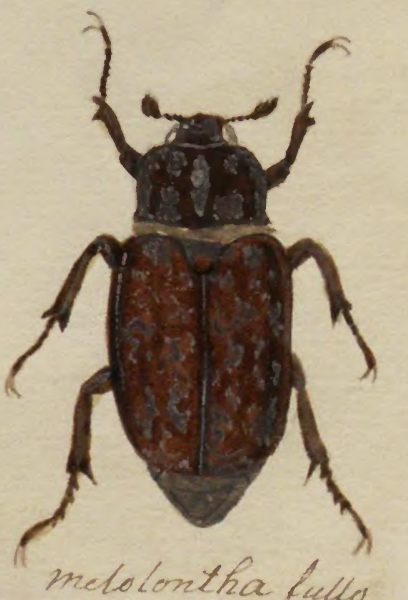



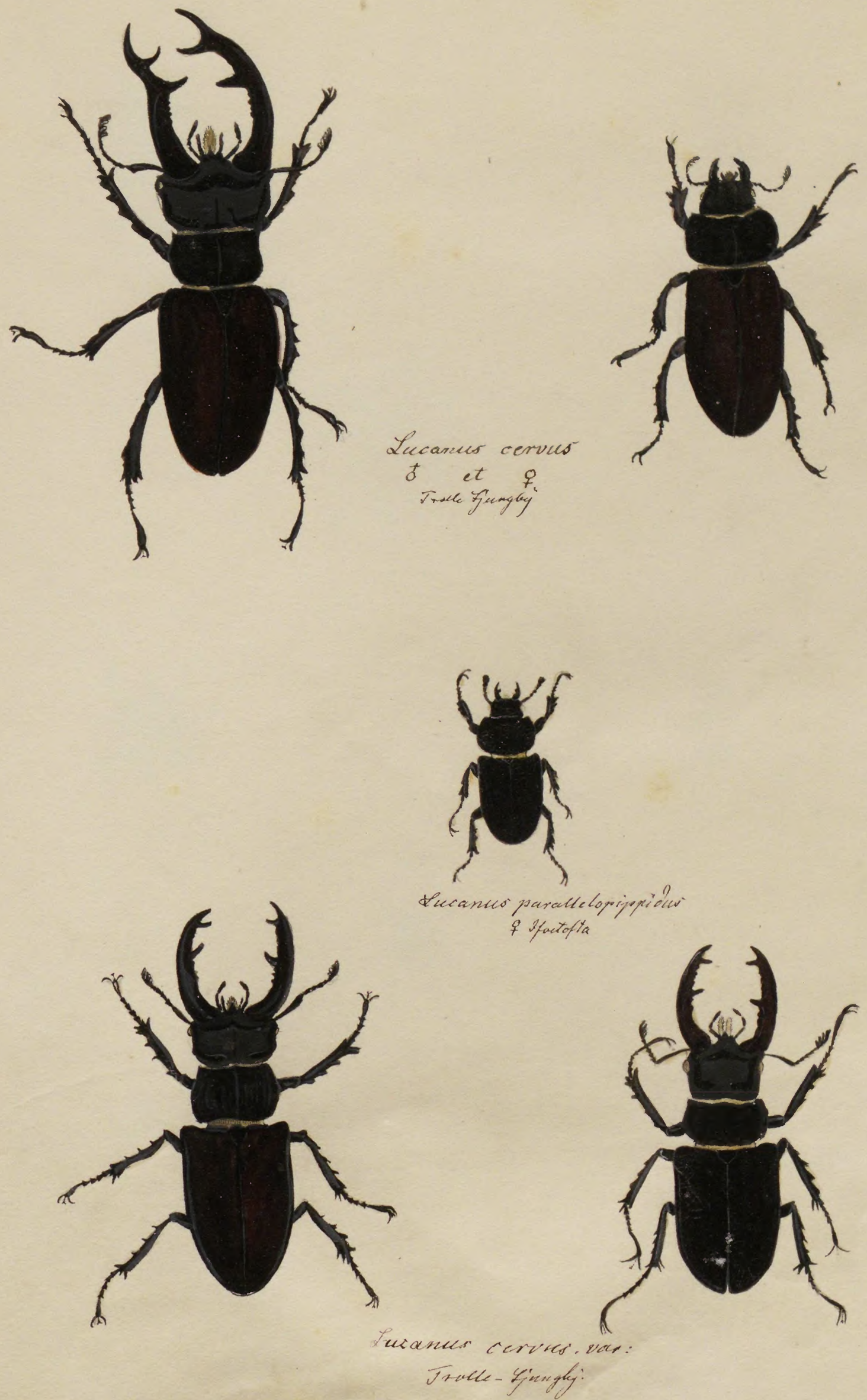

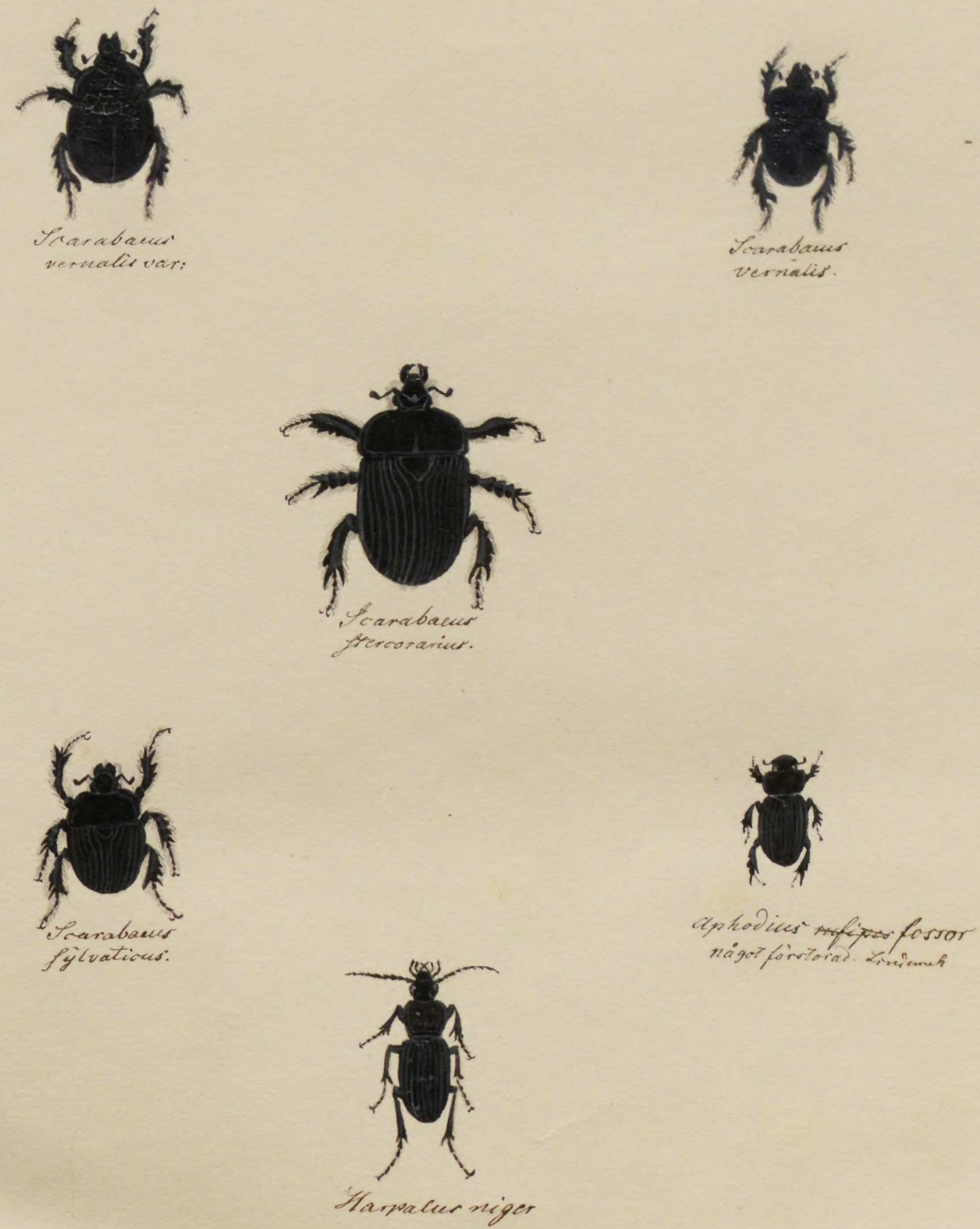



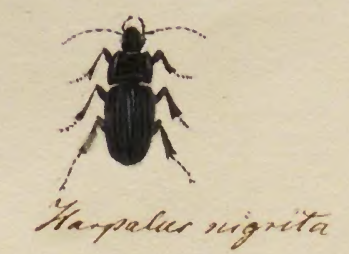



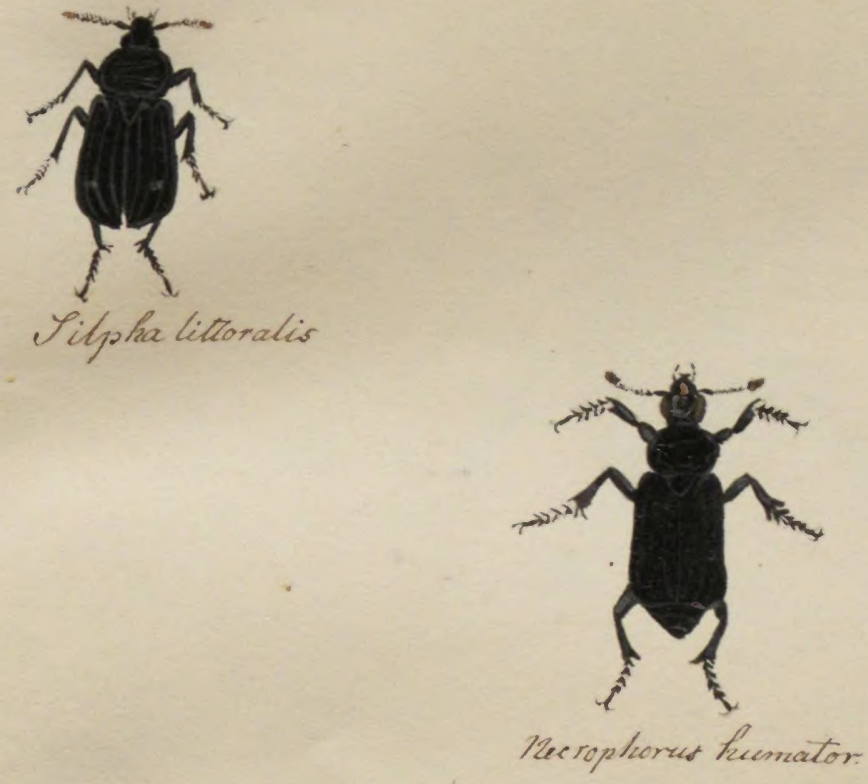

1eeropluorus feemator:

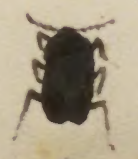

Tilphe opaca

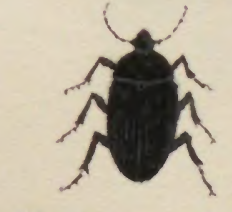

Keloposter

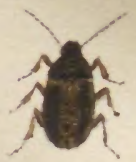

Atopa arvina

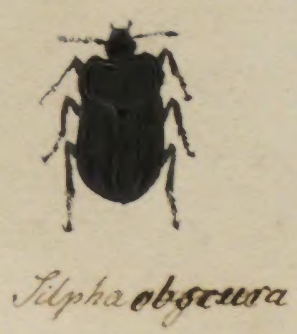

\section{Tipha obsceura}
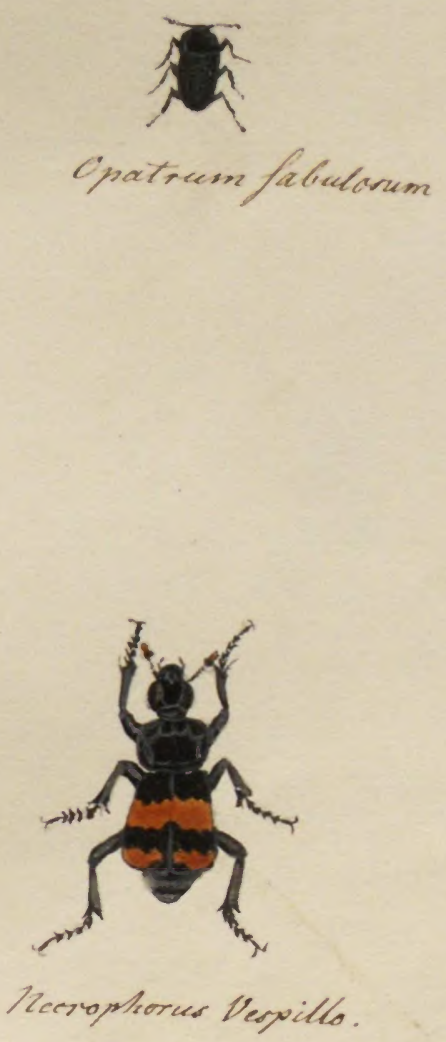


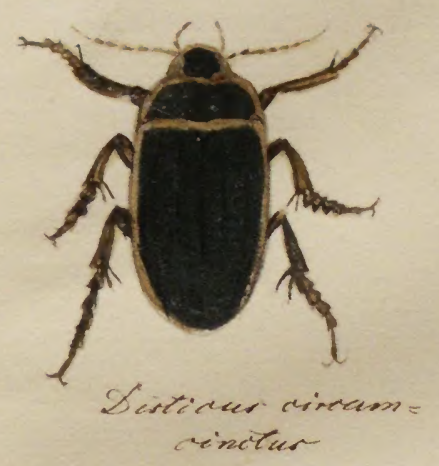

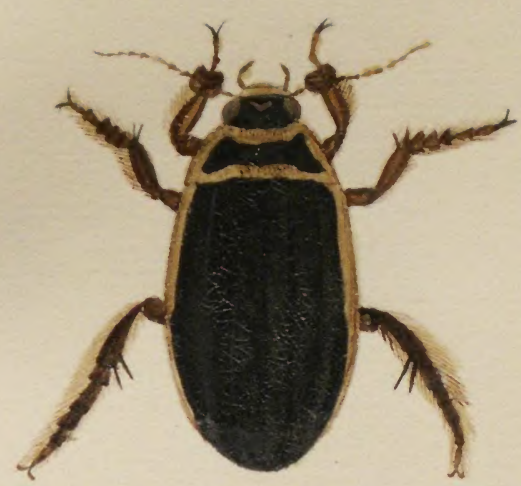

Distiras mangi:
nalis.

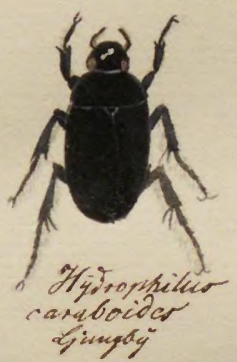

xy

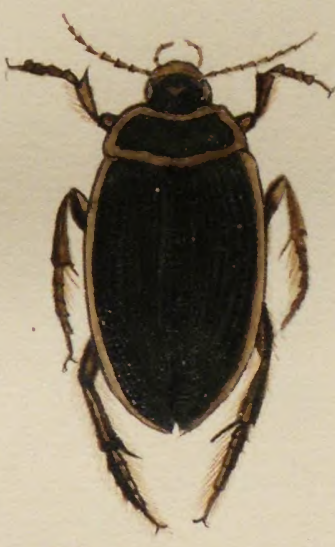

Dirticur manginalirg

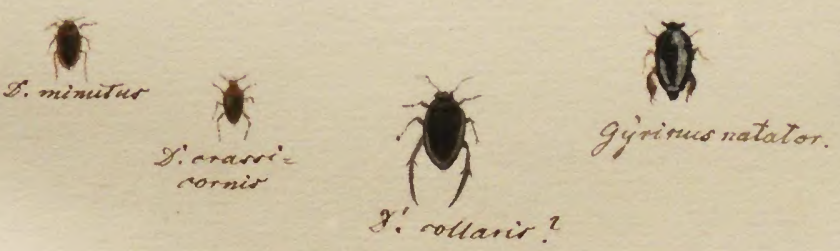

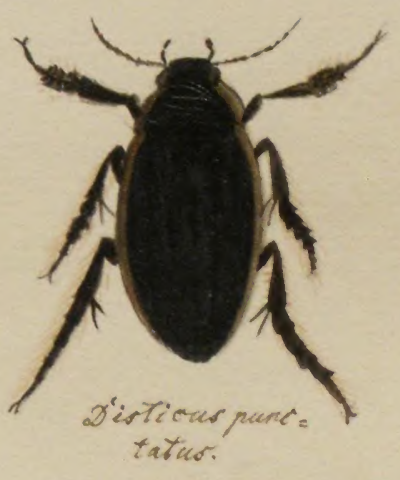

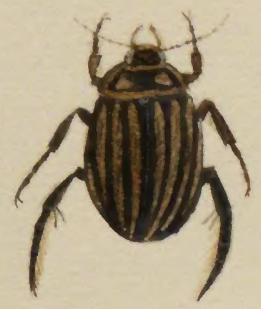

Distines fulcatar

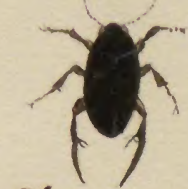

Distinuer carbonarieer 
$+11$

$1+1$

111 


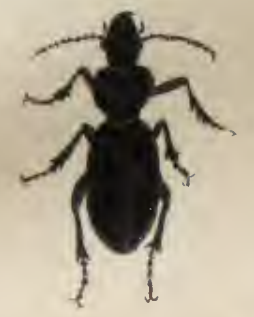

Horpaluer repota coter.
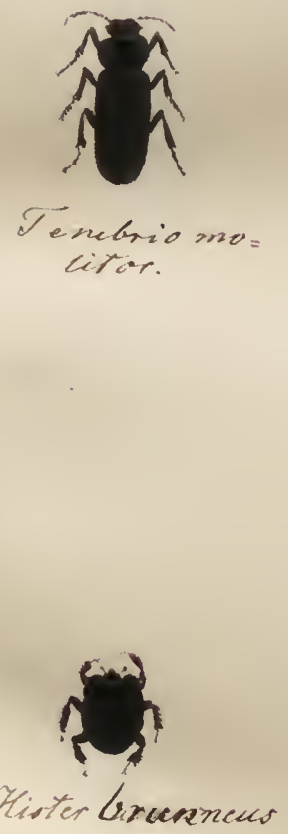
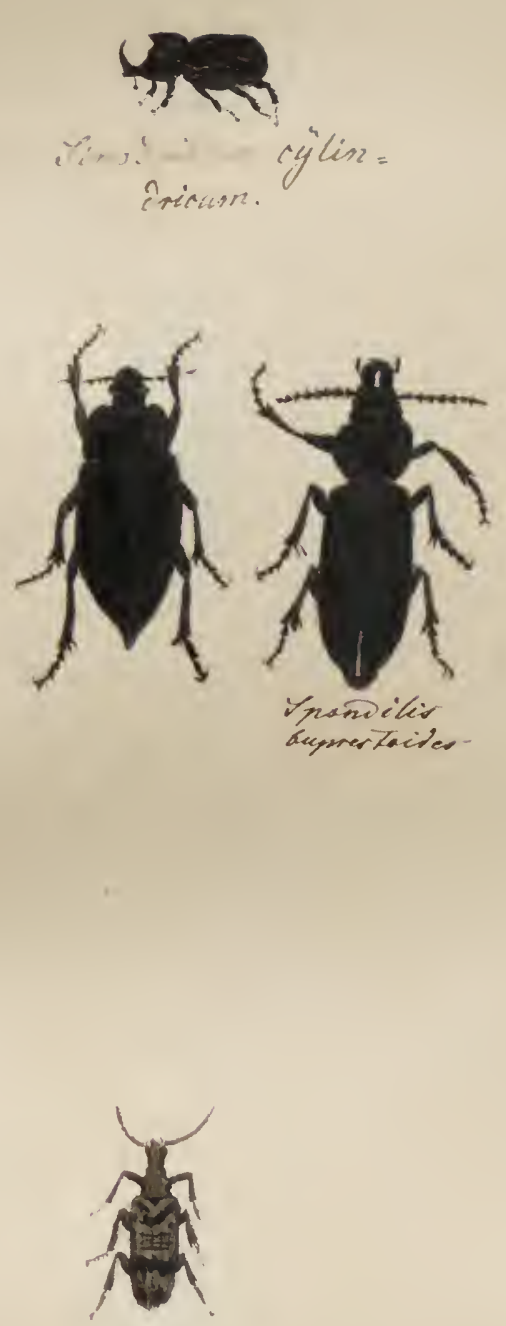

Phaquem

inaugator.
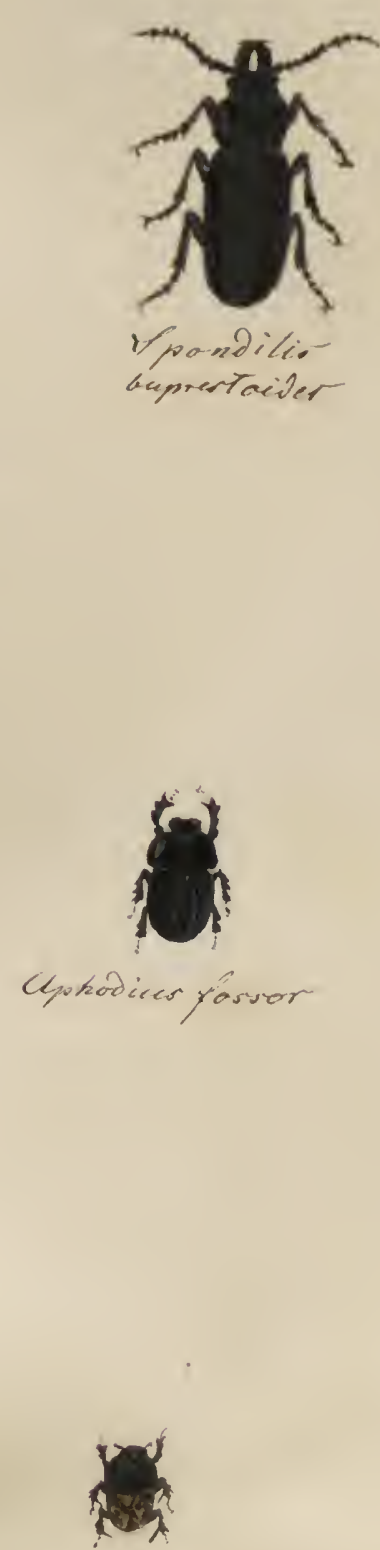

Cipsrics nuthicomis 

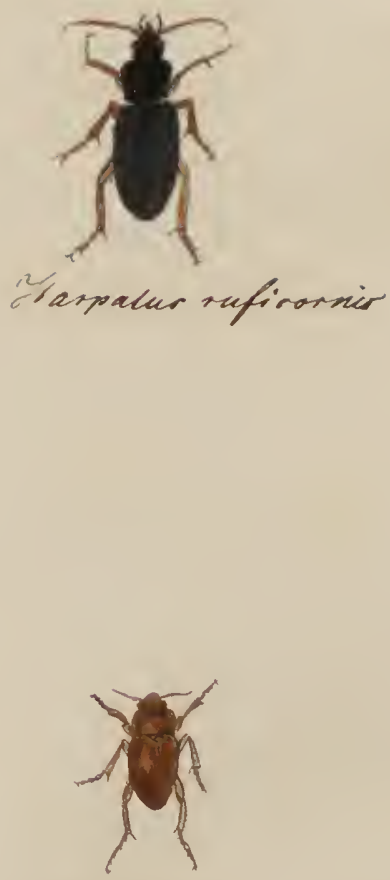

H. fulaus.

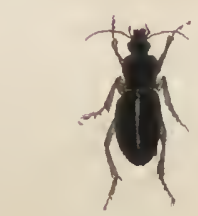

2f. nigrita

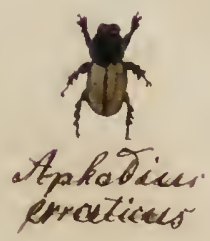

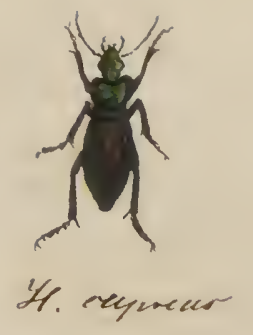
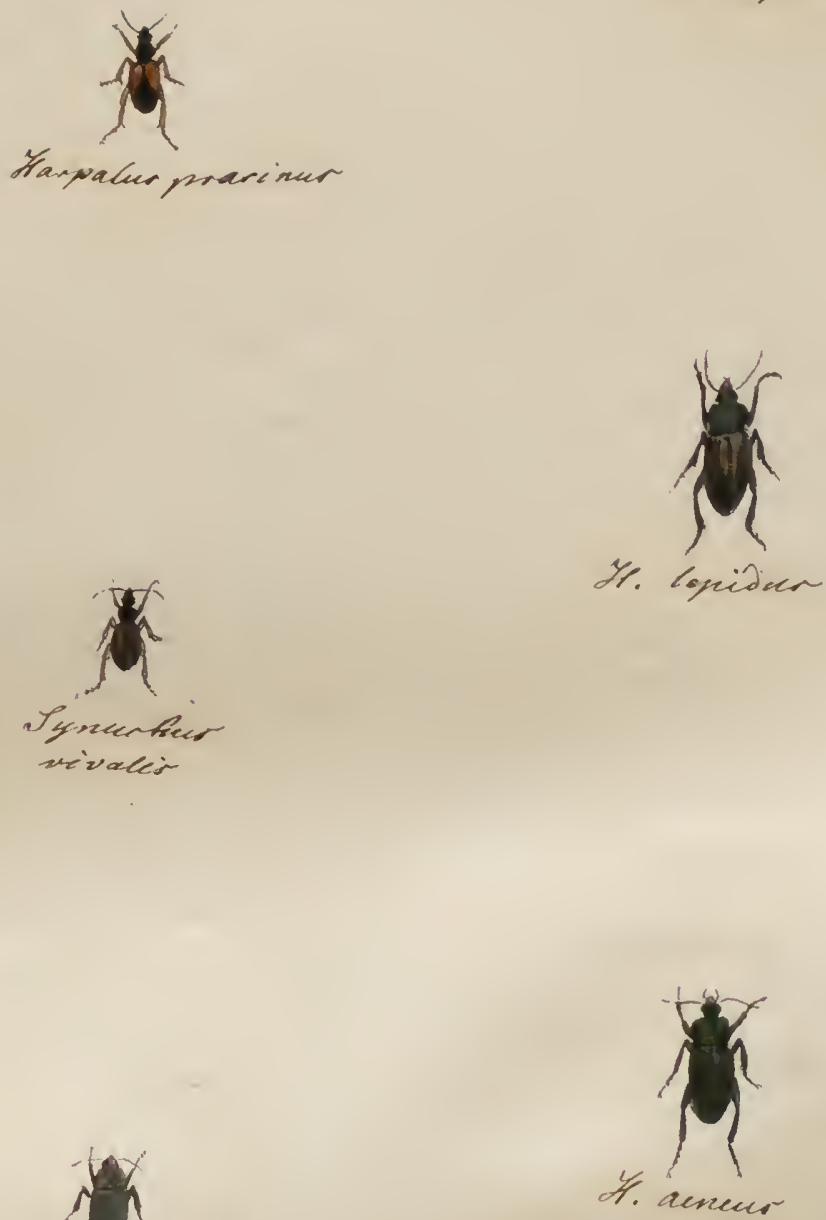

Y. acnear
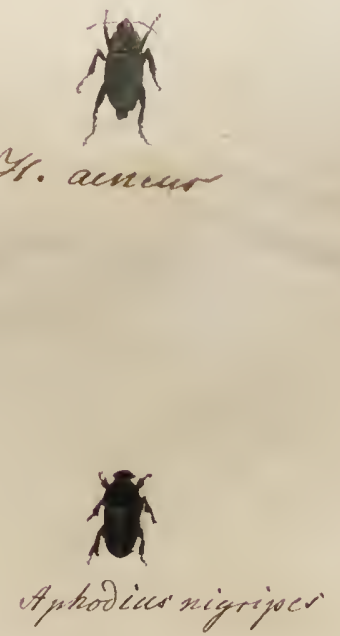

tyakodiur fimetanins 


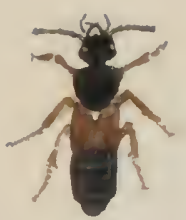

Staphigitinuer exy thopt terur

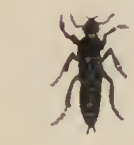

If. Laminatur

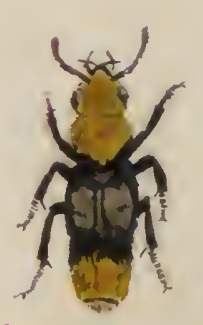

Ttaphïlinuor
firtus?

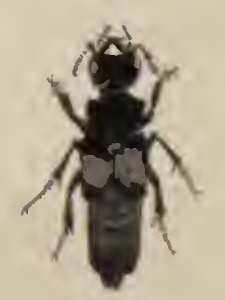

Yr. maxillosur?

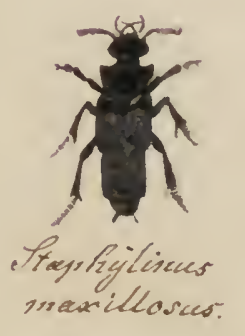

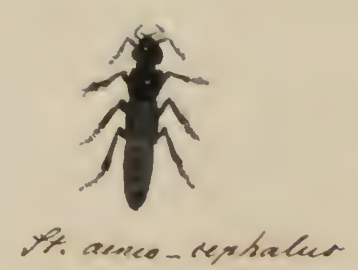

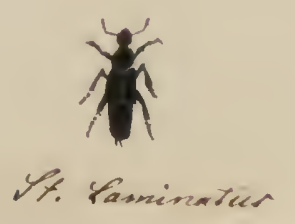

तर

IF. ater rorariues

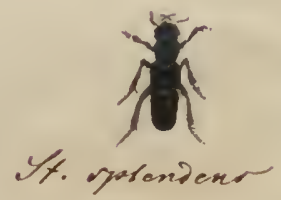




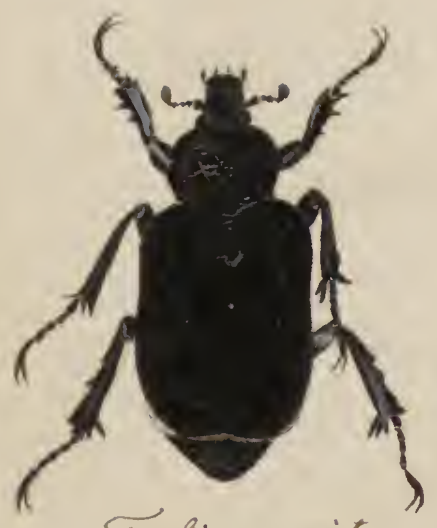

Srichics eremita.
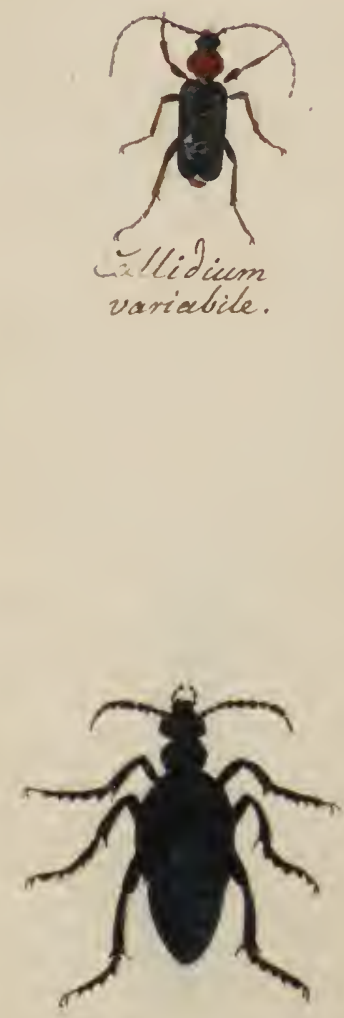
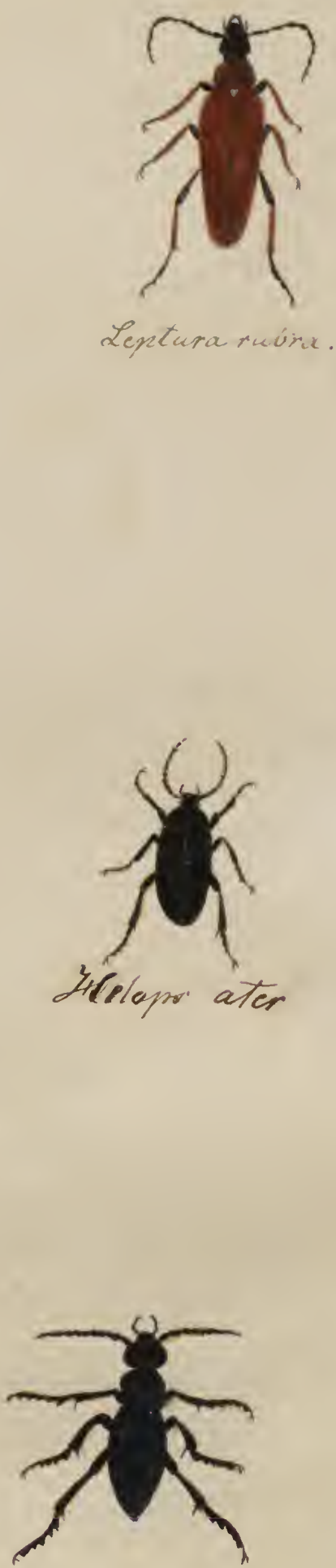

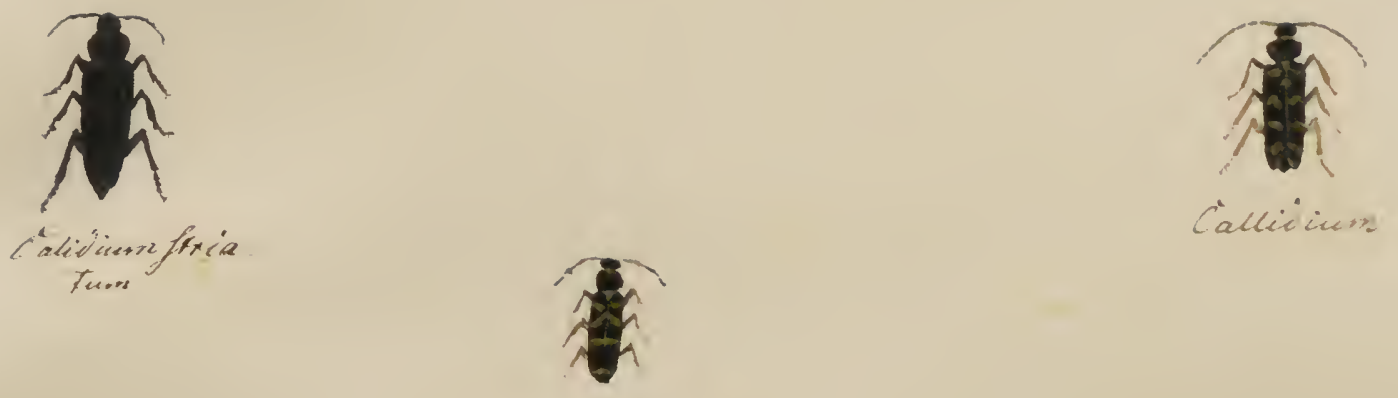

$$
\text { callidium arietio }
$$

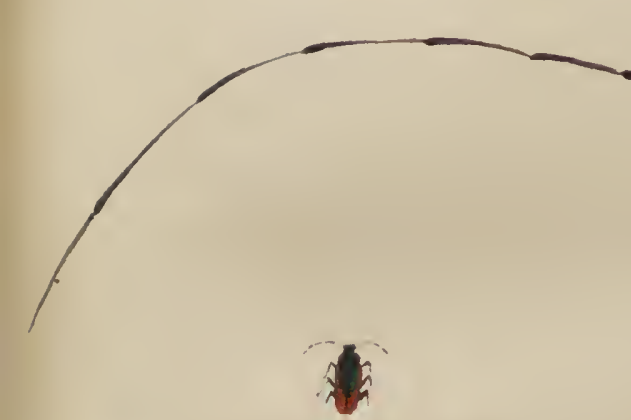

malarhice or new

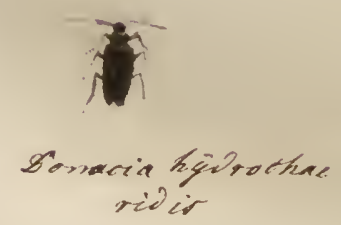

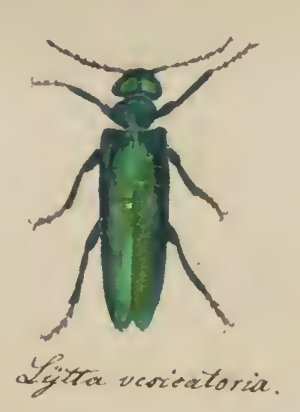

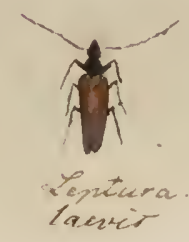

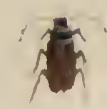



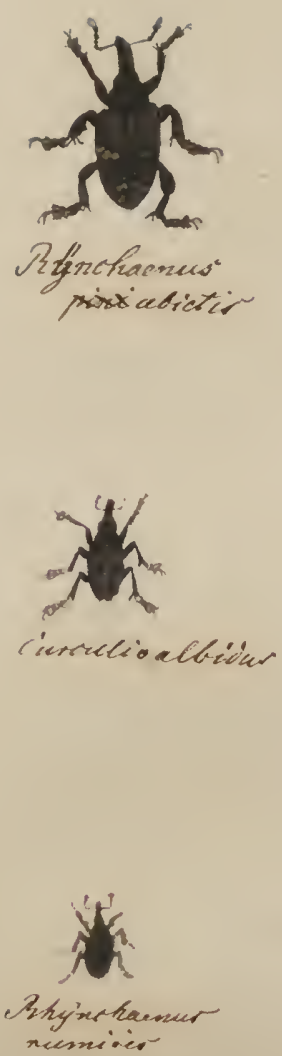

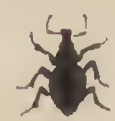

$+$

Anion a enewar

रू

Ciuraliopingré

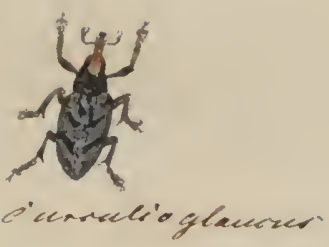

政

Byinhaesuer

equesfer.

准

Akyinstaenus

nelyigone

零

remrulic avatur

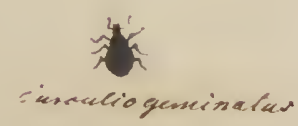

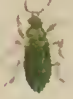

cierrelio nyigr

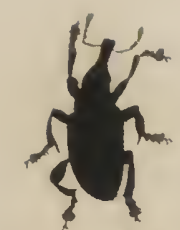

Migreatasuses

trangere

(

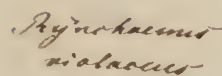

${ }^{4}$

effeion acrem.

$\int^{2}$

currelio gensinatus

1

Nh

cumplis recuctatur 

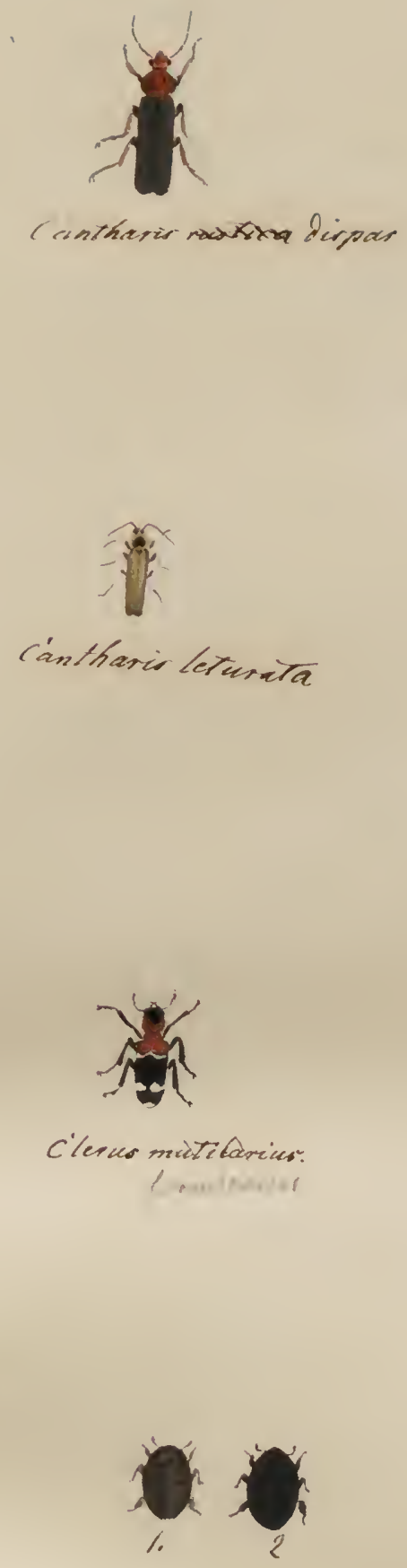

1. Byorris pilula

?. - ater:
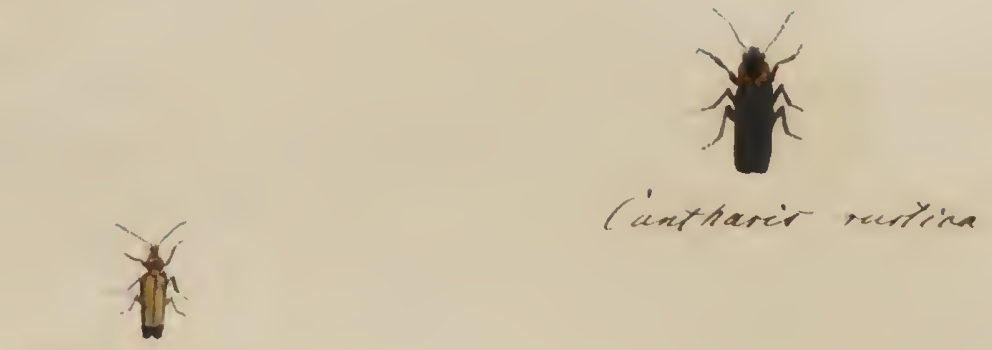

Cüntharì melenura
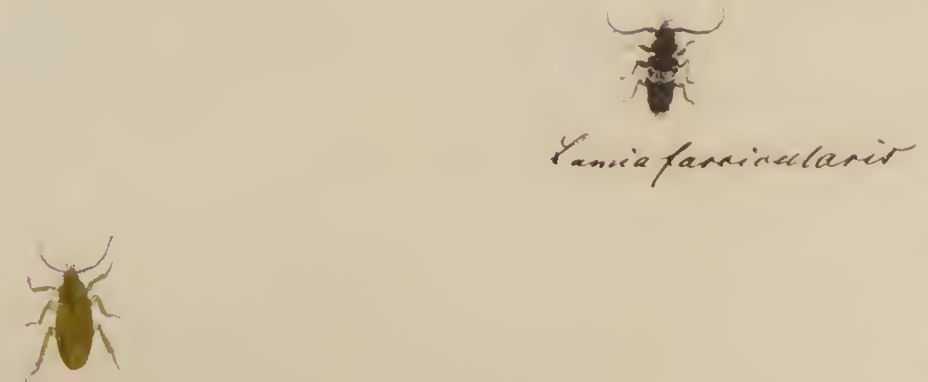

Cirtela ulphurca.
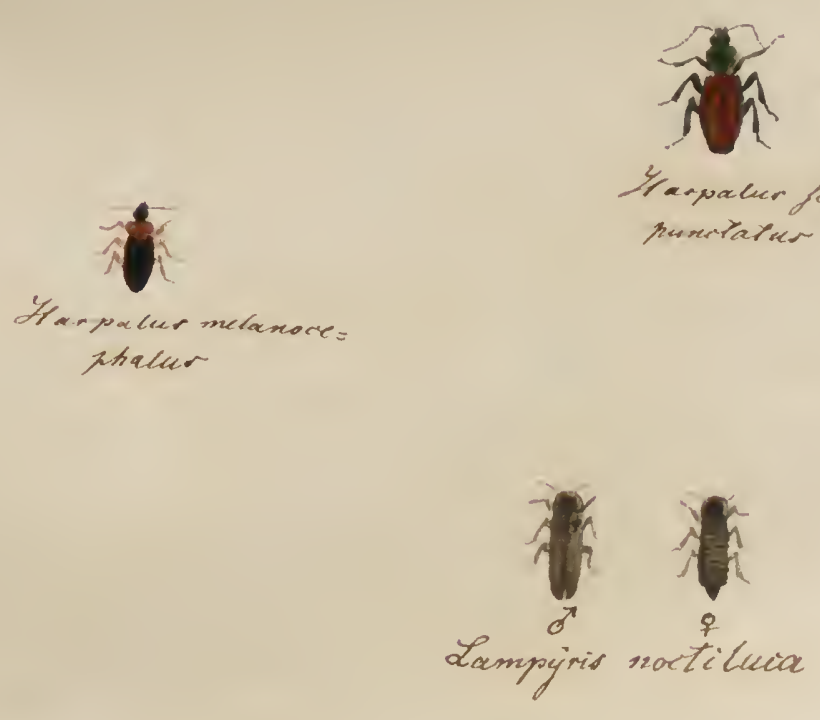
15

iemsinelear
humeralior

Corsindla of

$\therefore$ ininentequvingues

Yipherioium

rivisulta bi
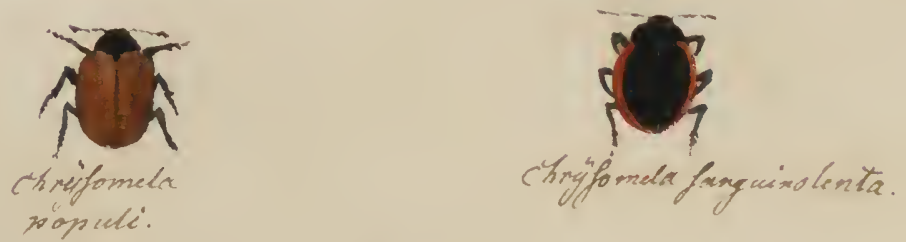

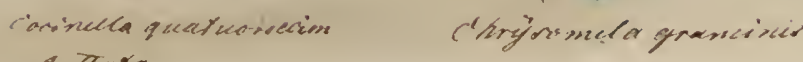

Wris area futsaya.

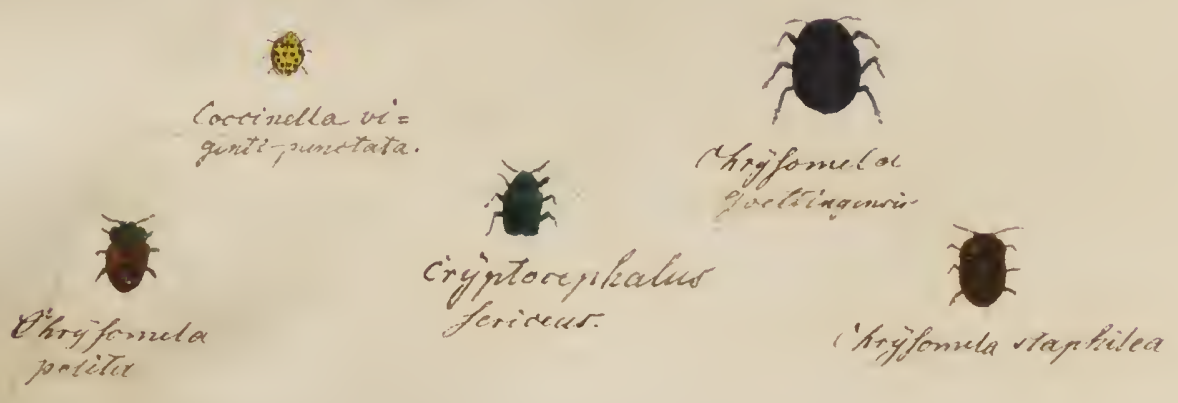





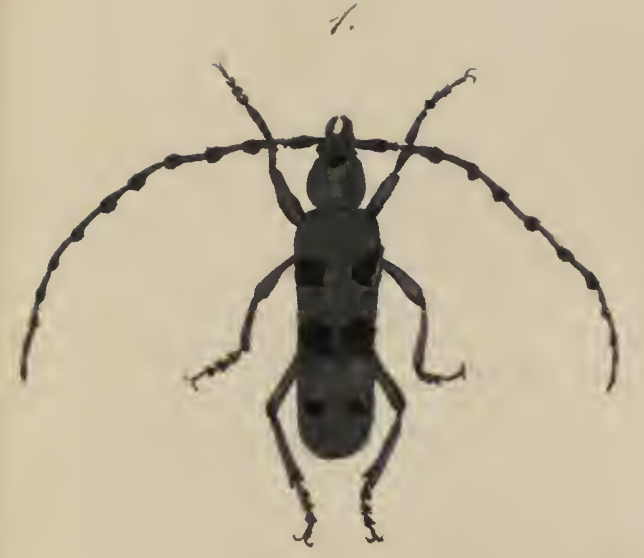

2

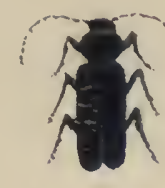

incicium riclaceum.
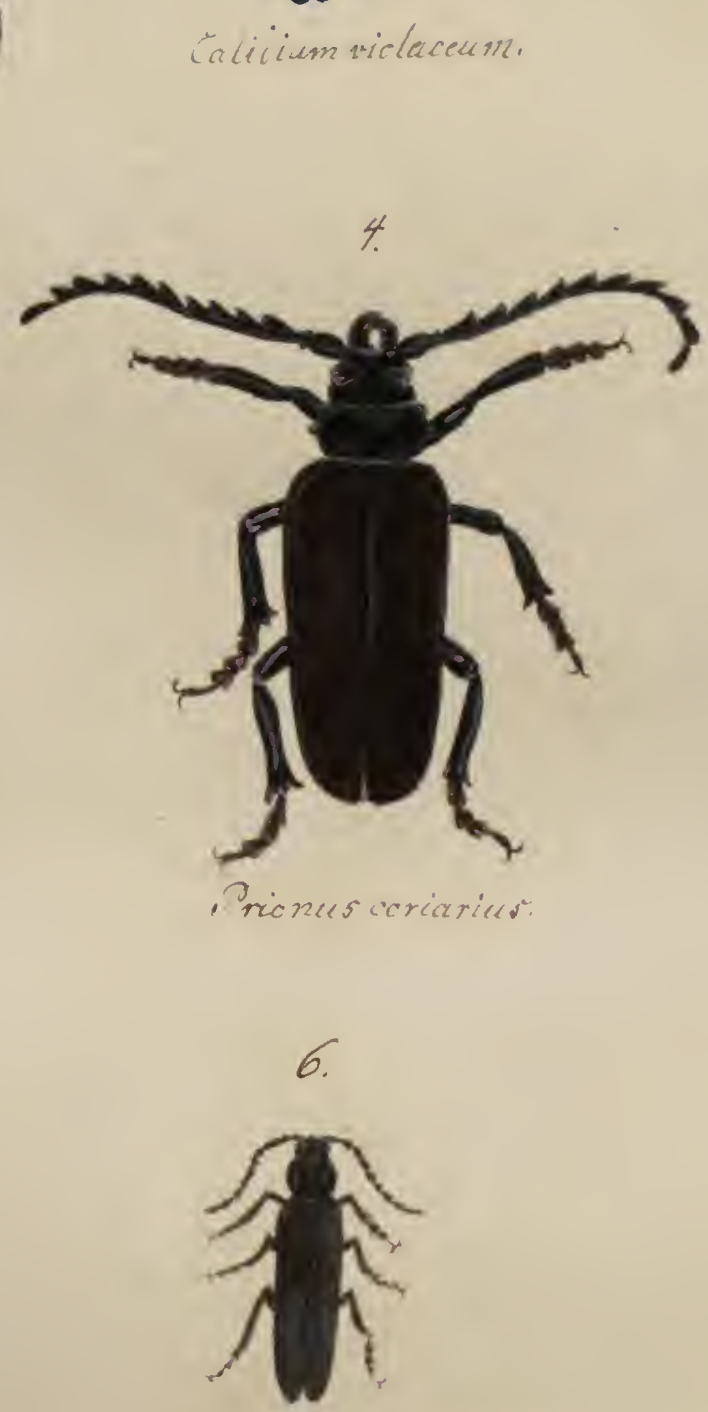

Càlliéium rectiows
3.
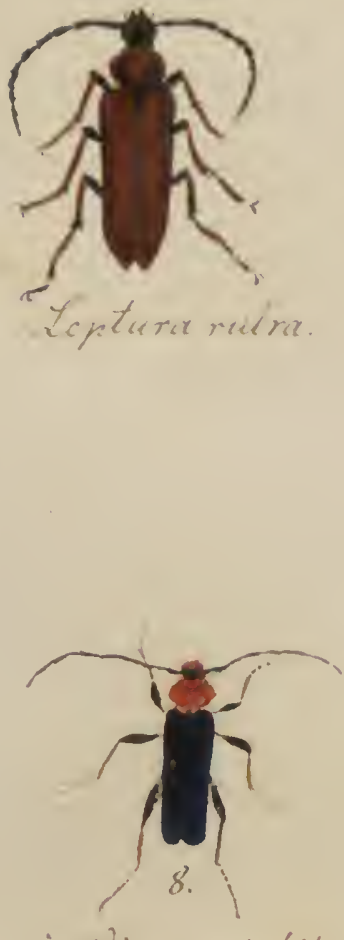

iallivium variabile

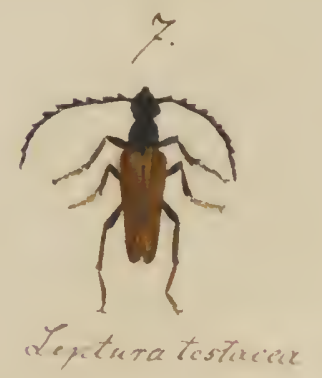

1. Cerambigr alpinus. 


\section{vinign nuslawdidg}

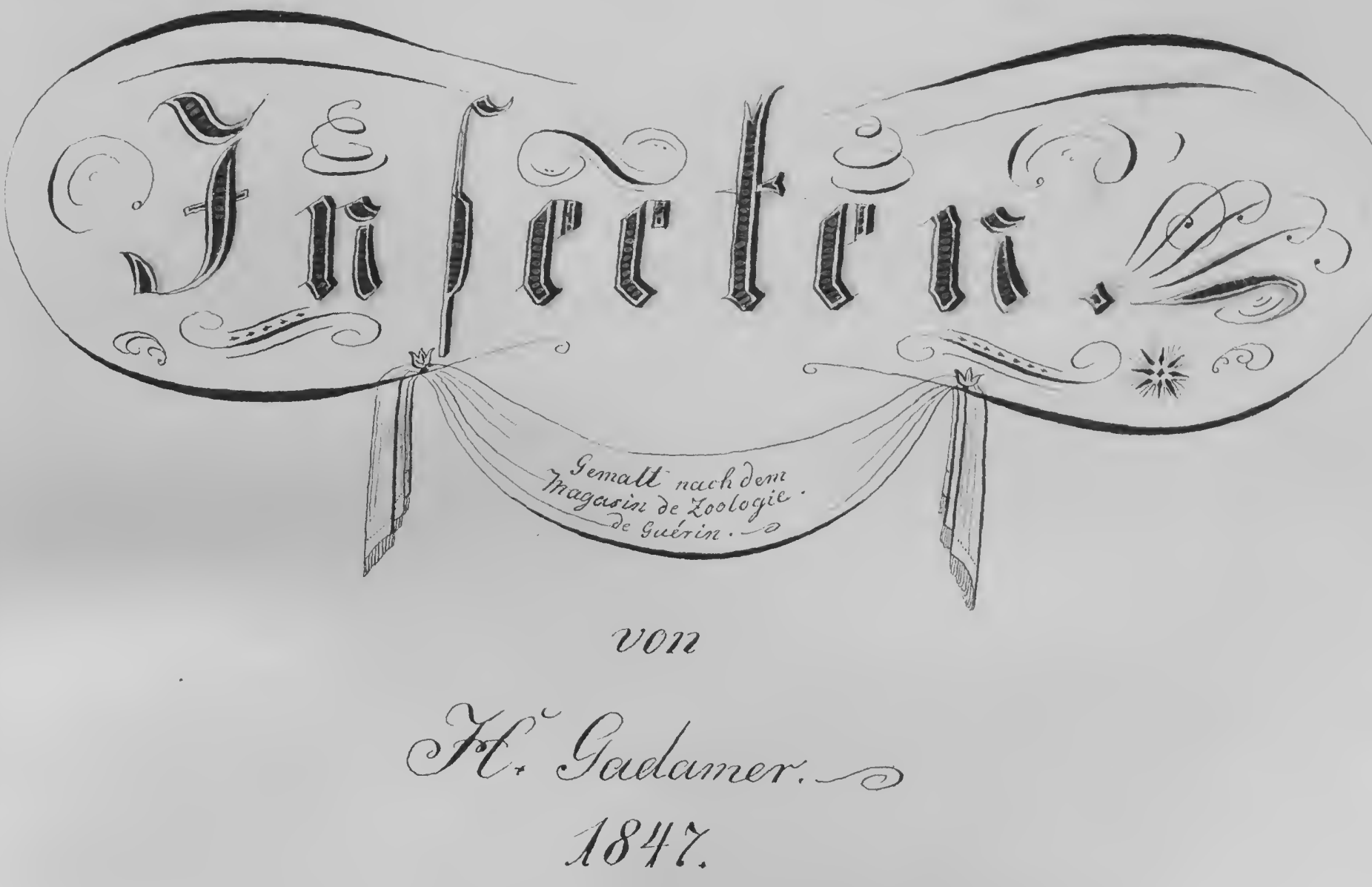




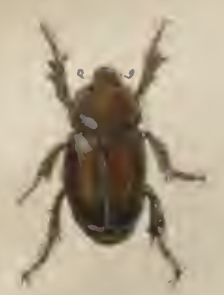

18.
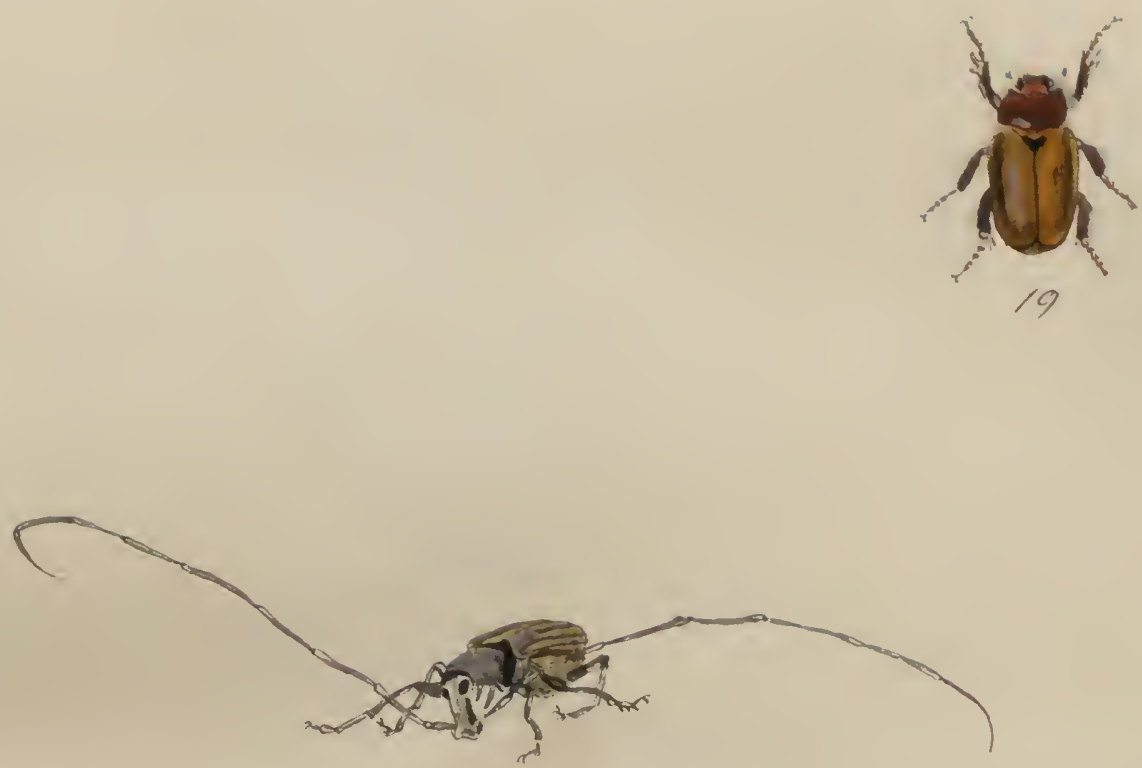

为

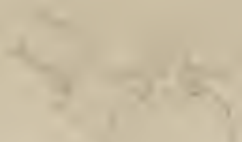

5

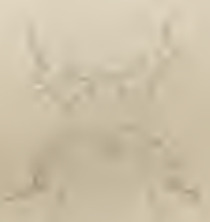

22.
21.

73.

\section{,}

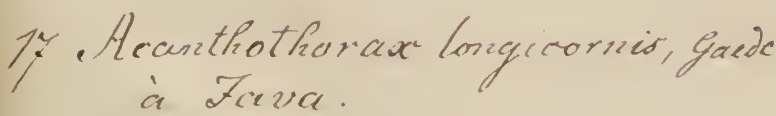

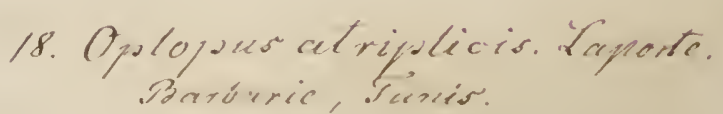

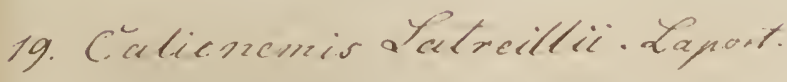
If alic.

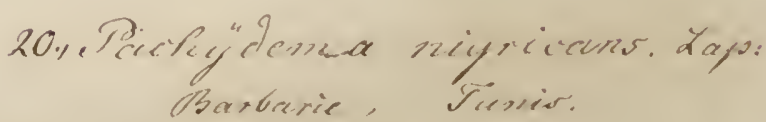

21. Huelotontha blioiri ì Serfic.

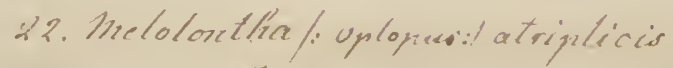
Teris.
23. Inetotonthe Foubtionii

de Bresilie. 
19.
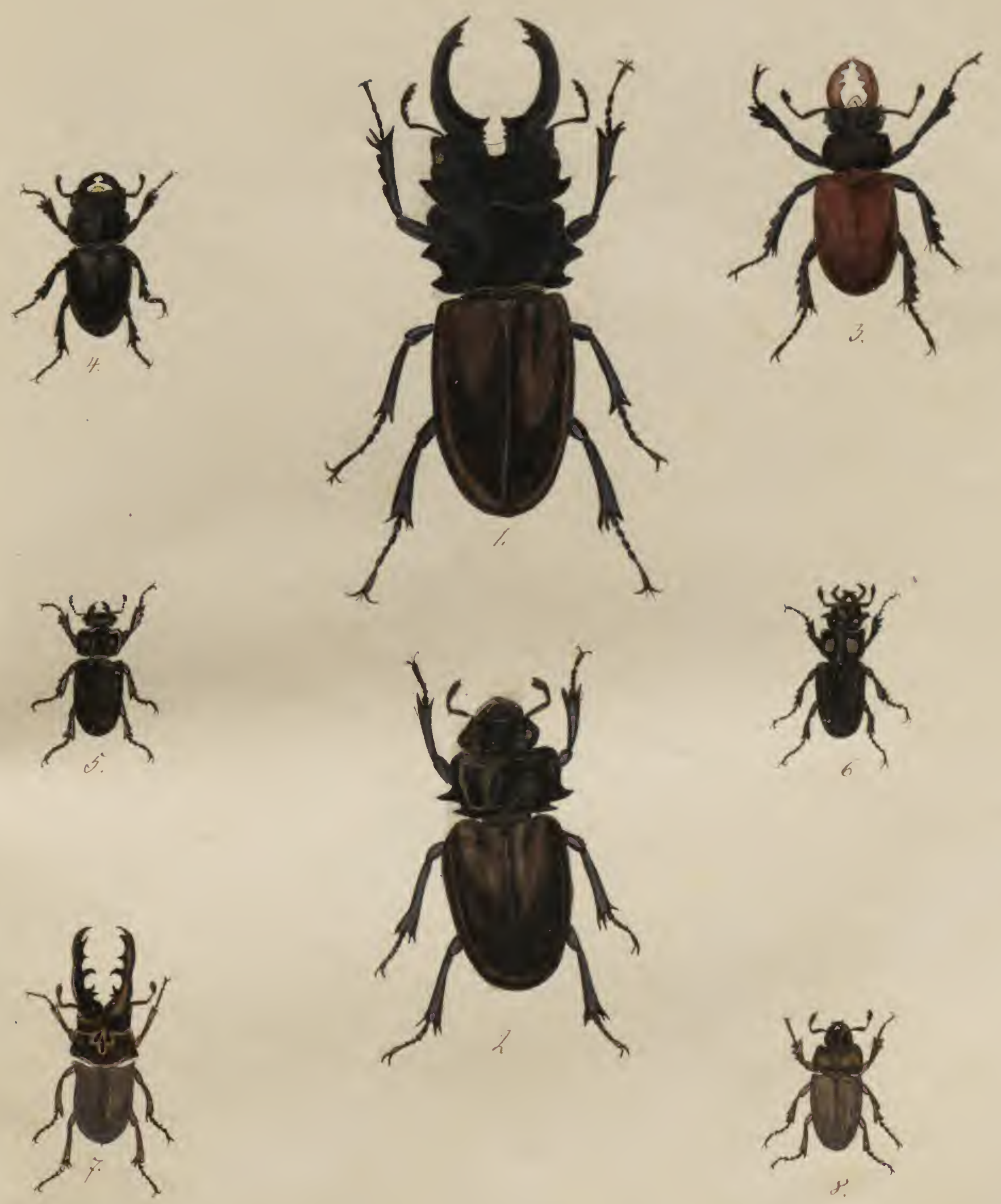

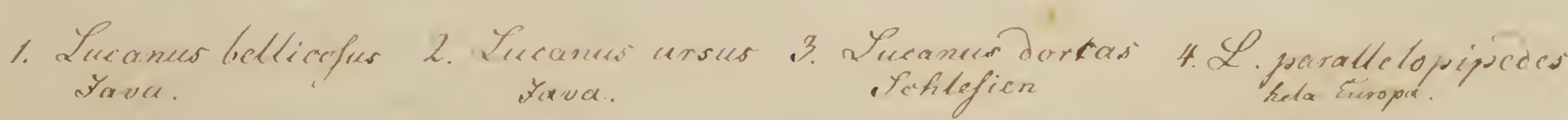

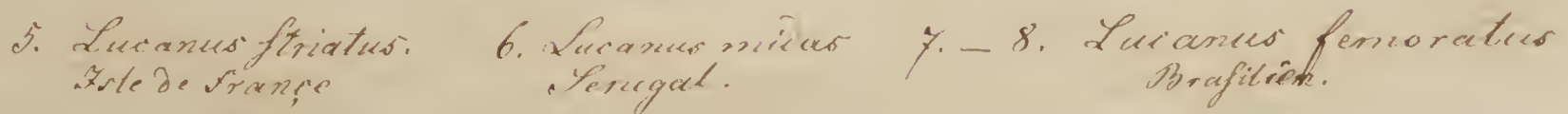



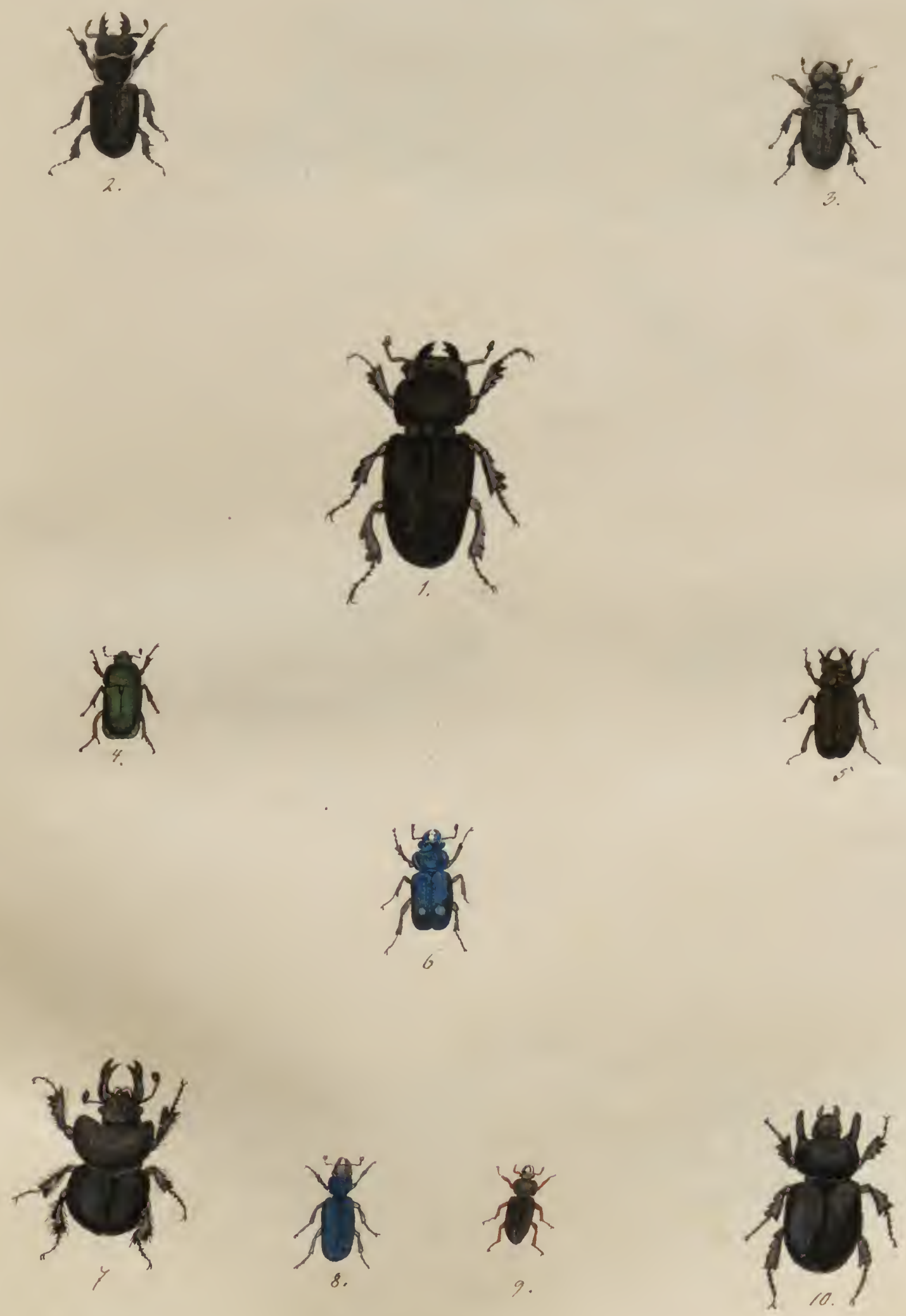

$$
\begin{aligned}
& \begin{array}{l}
\text { Lucanues capra. } \\
\text { ifidra kuropa }
\end{array}
\end{aligned}
$$

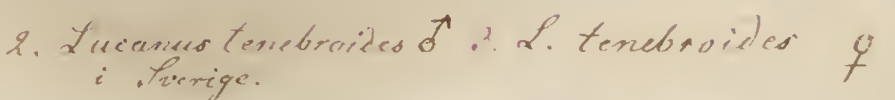

$$
\begin{aligned}
& \text { 4. Lueanes rafipes } \\
& \begin{array}{l}
\text { 5., Turanias balbi: } \\
\text { nom "lemvitia. }
\end{array}
\end{aligned}
$$

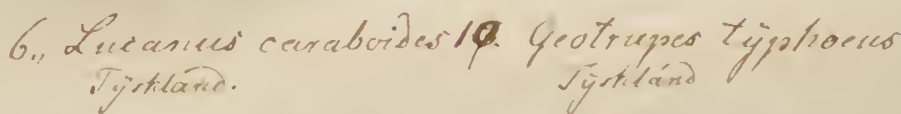

$$
\begin{aligned}
& \text { 4. Trogufits enerulea }
\end{aligned}
$$

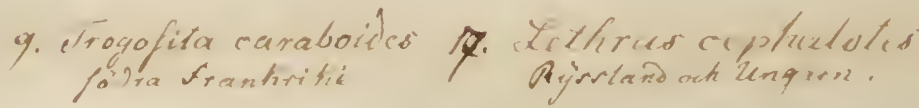



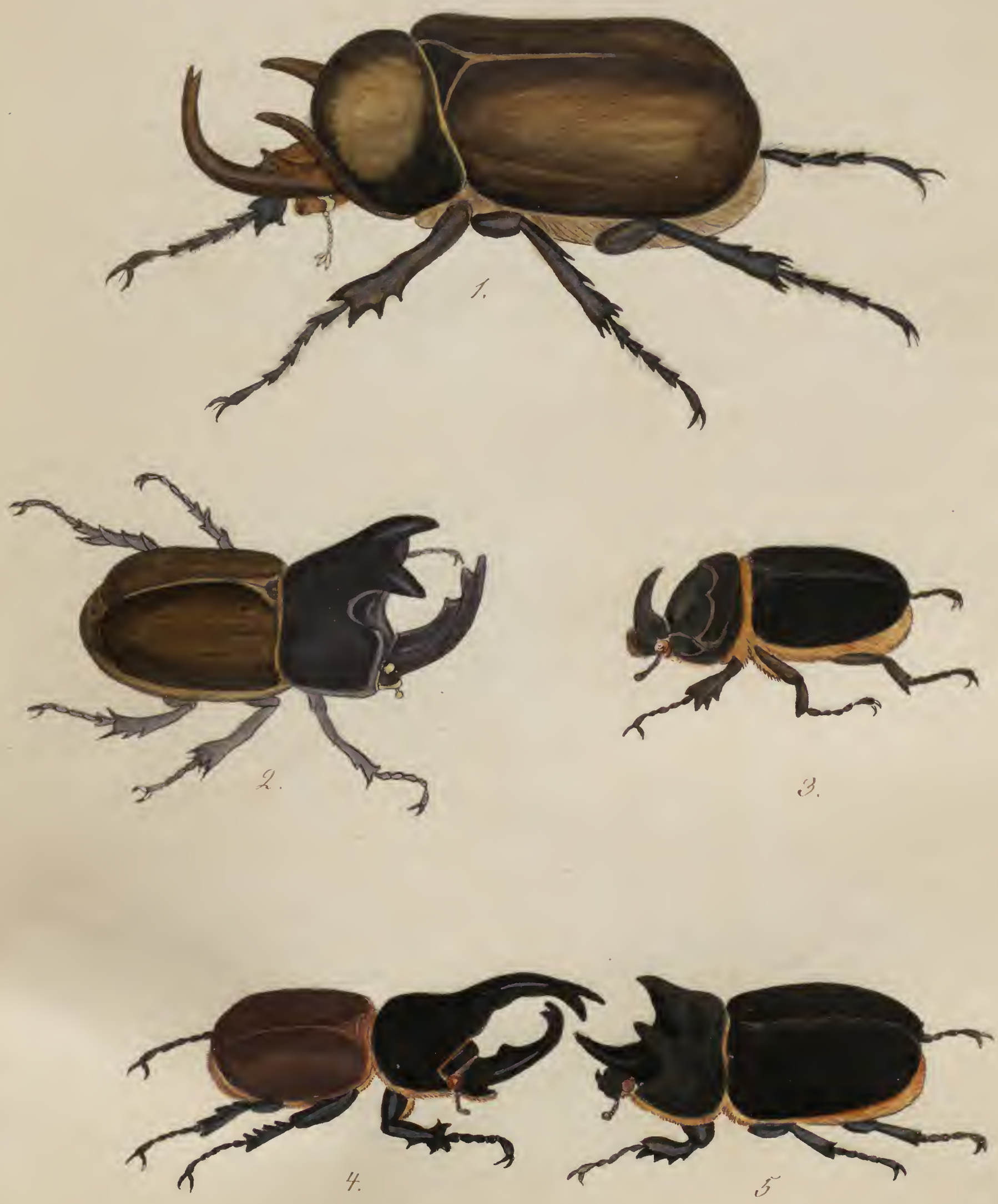

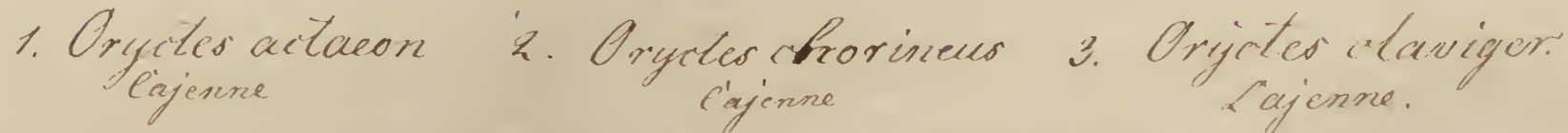
C'ajenne a ajonne. 4. Orjittes gideon S. Oryetes alucus.
china o. Sava 

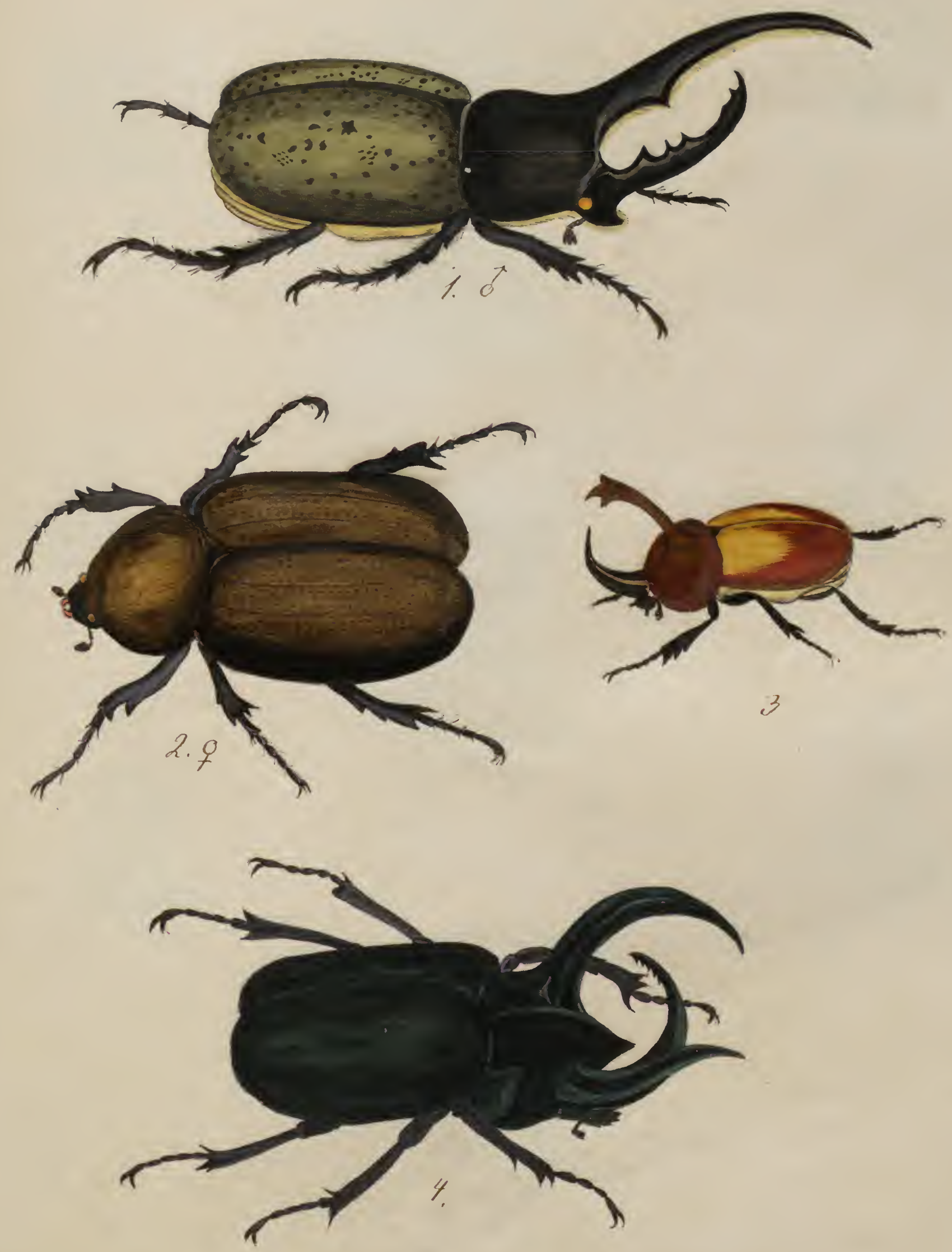

1. ach 2 Cryctes fiercules. 3. Oryictes rhinoceres
Antillerna on Bzravilien.

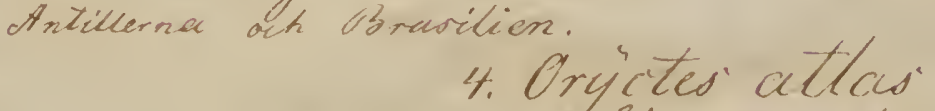
Disra - Comeritía. 

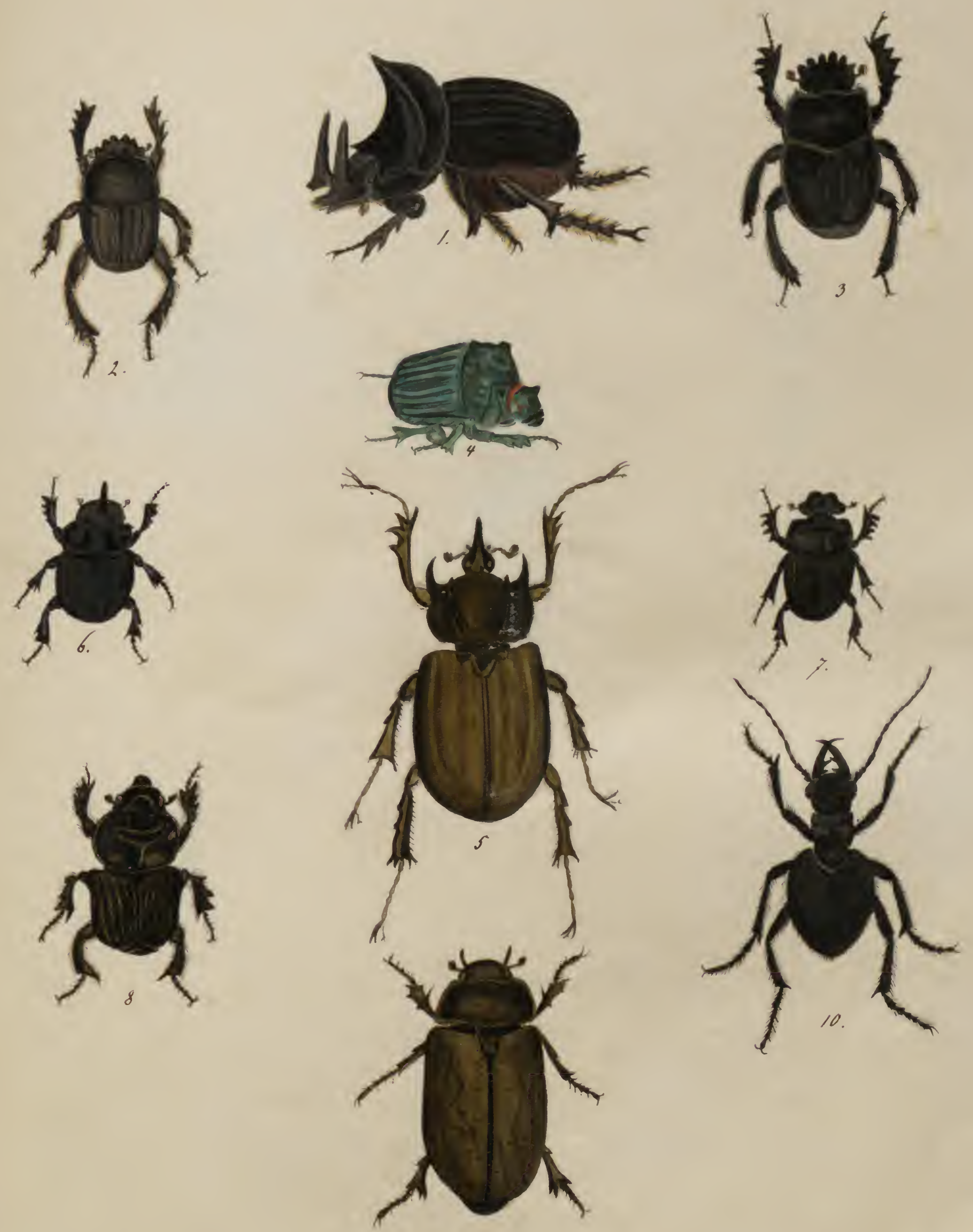

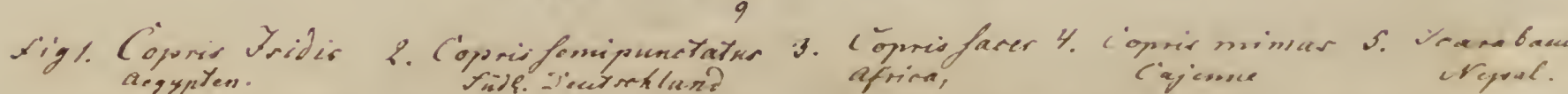

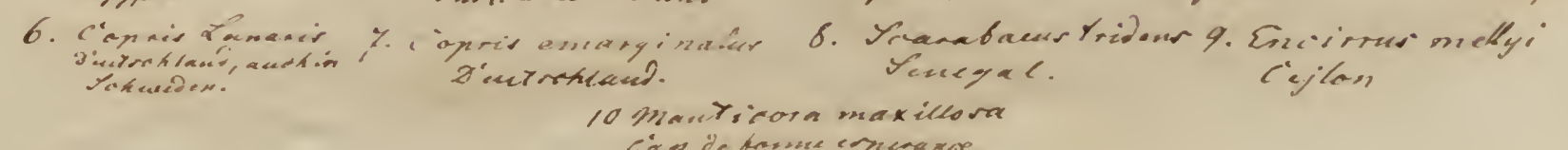



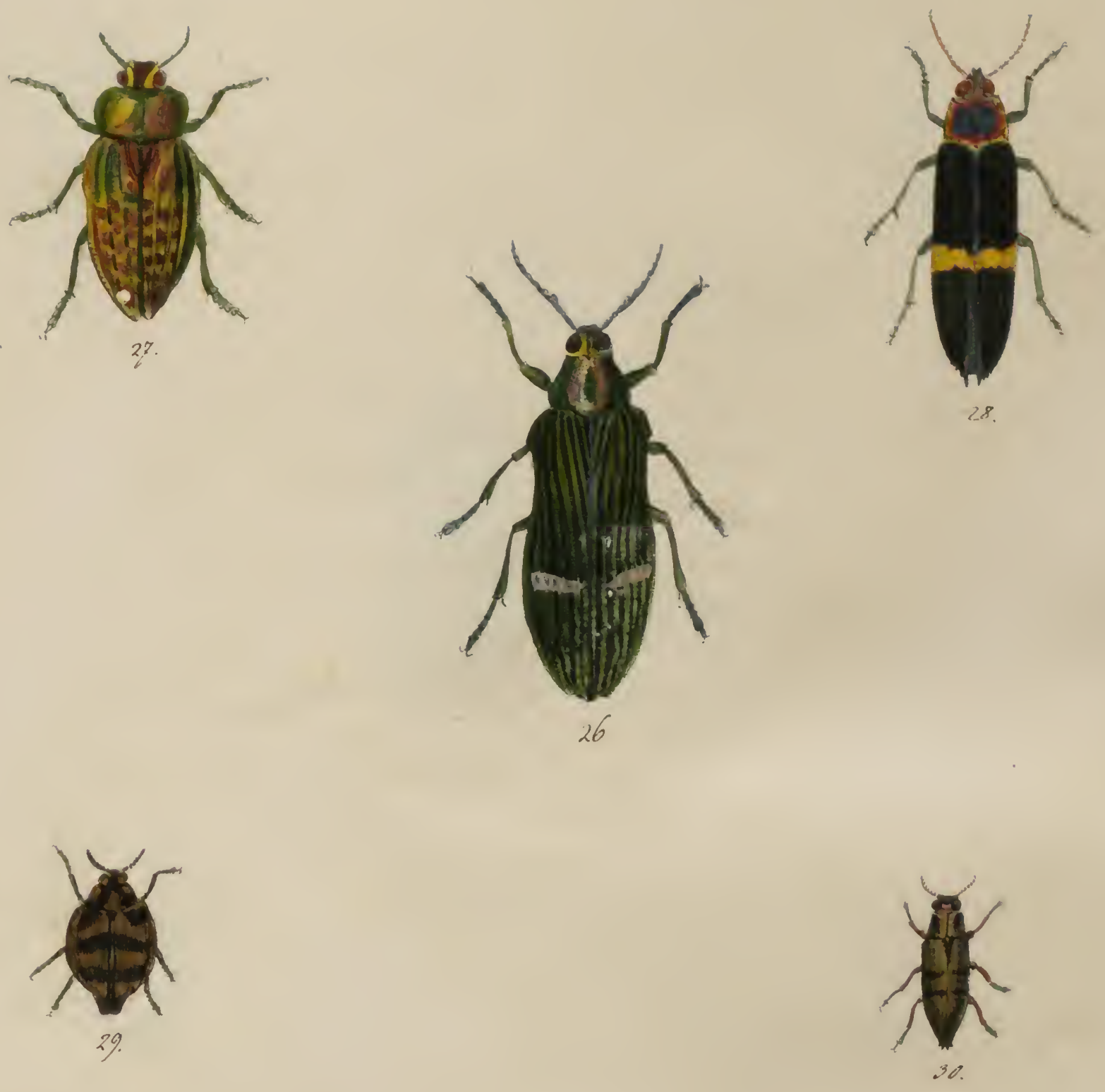

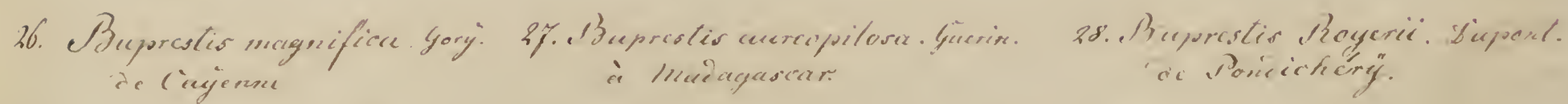

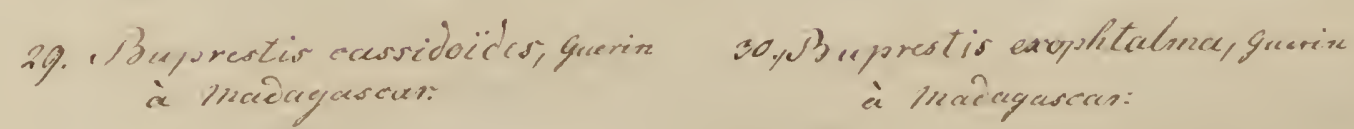




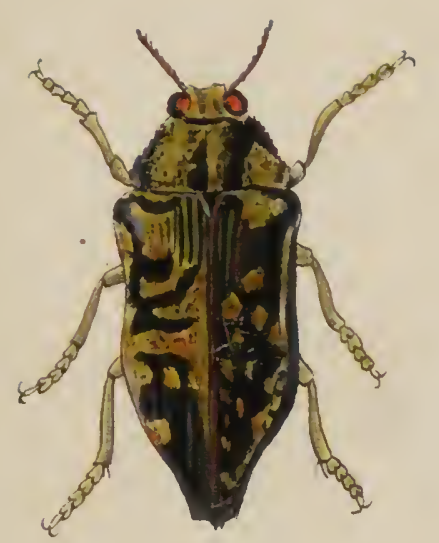

22
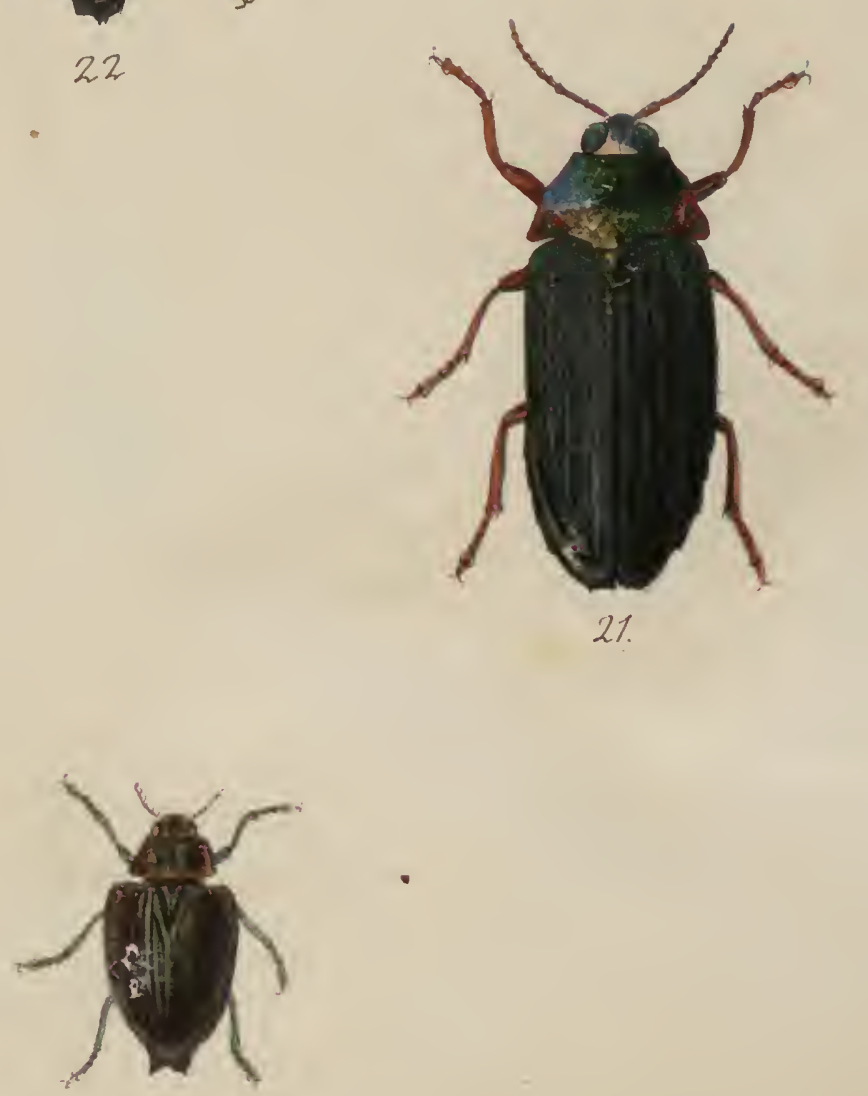

24.

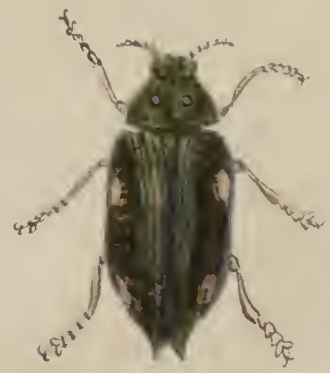

23.

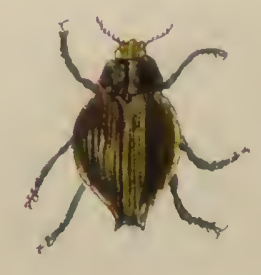

25

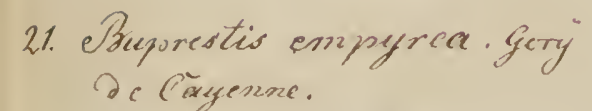

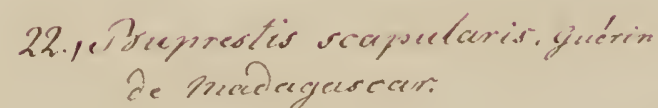

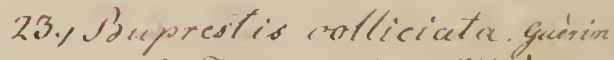

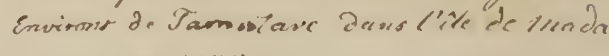
geseces:
24. Buprotis complameta guérior
à Samertave.

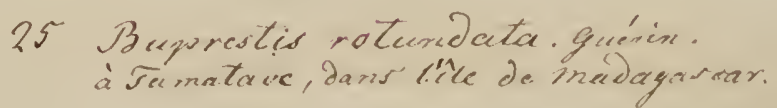



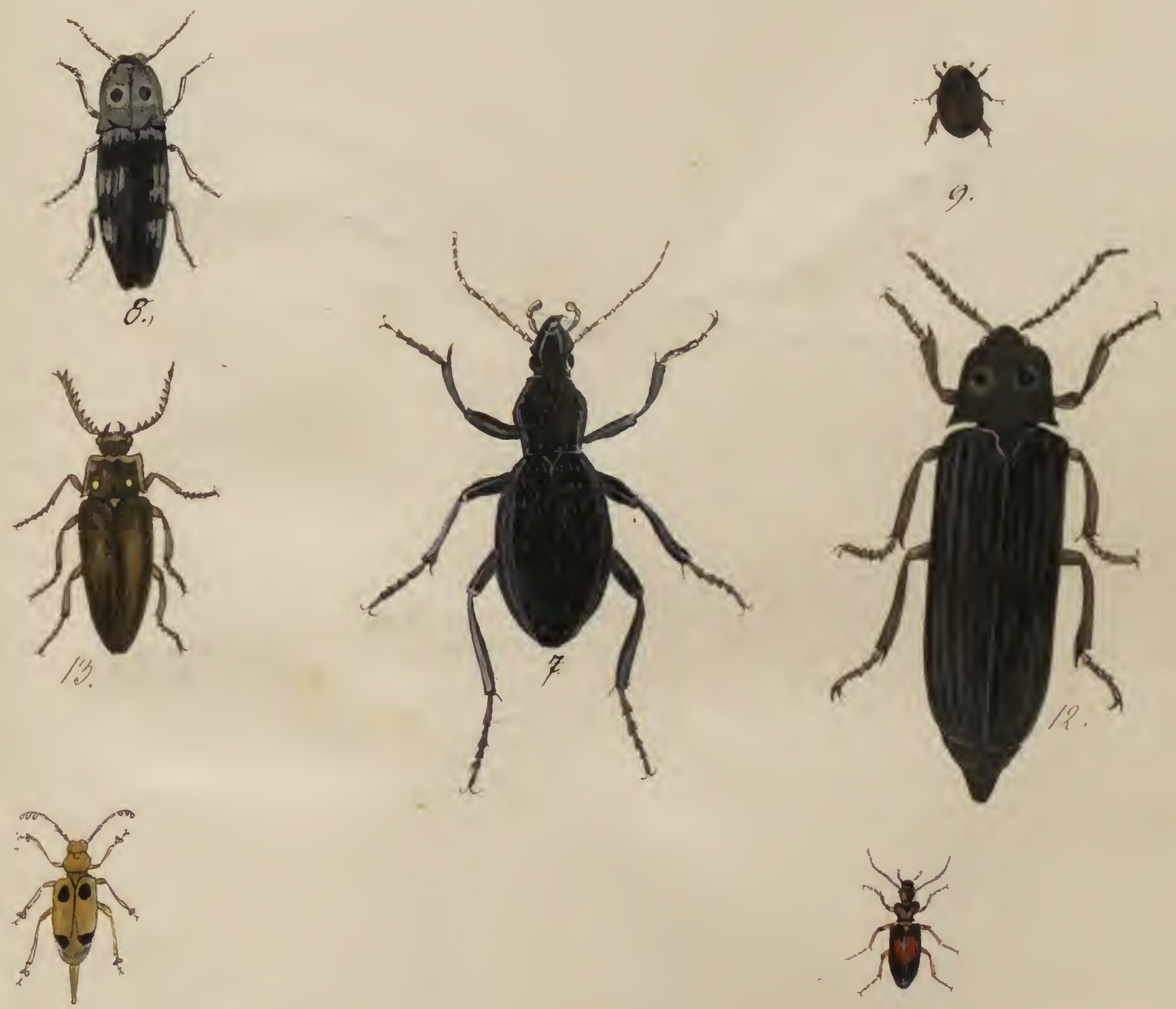

10.

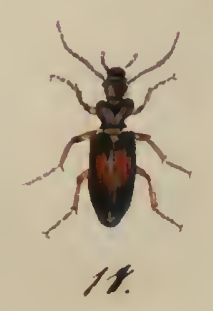

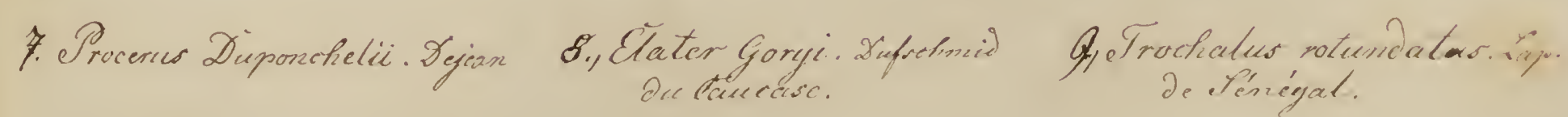

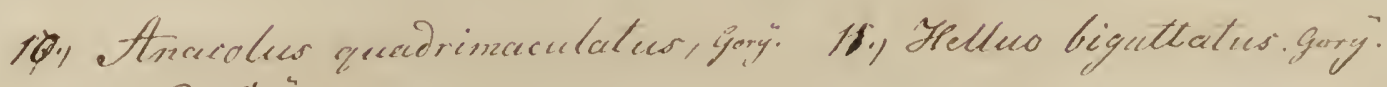

$$
\begin{aligned}
& \text { de Caýernue. } \\
& \begin{array}{l}
\text { 12. Elater qigars } \\
\text { or Seruegal. }
\end{array} \\
& \text { 13. Clater noctilueves } \\
& \text { deo Znoes arridentu. }
\end{aligned}
$$




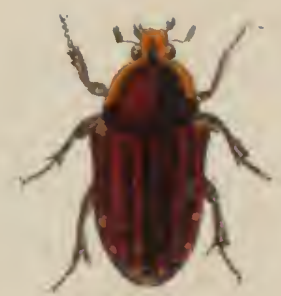

13.

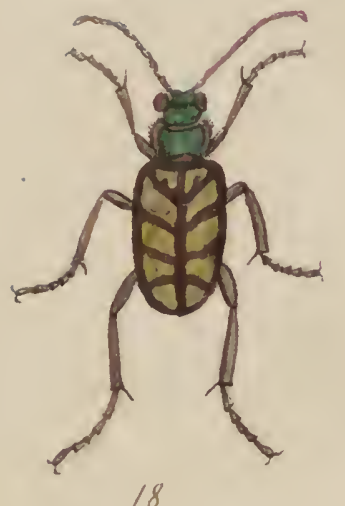

18
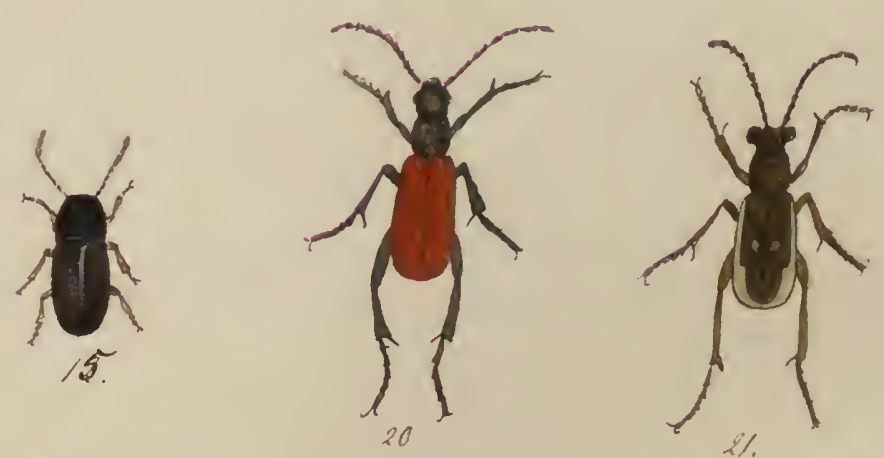
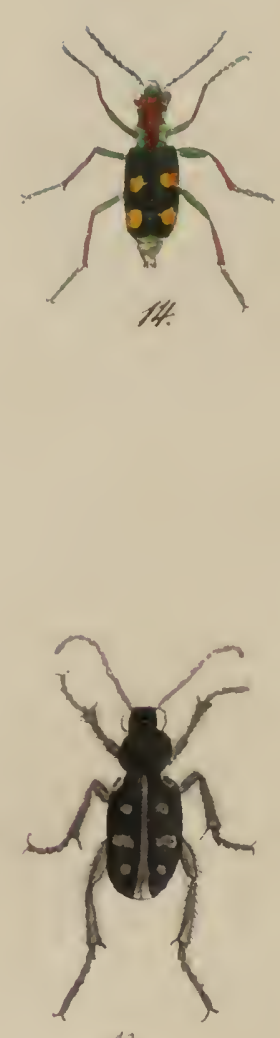

11

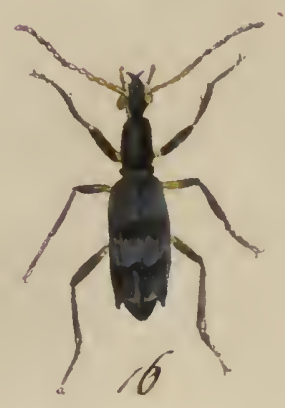

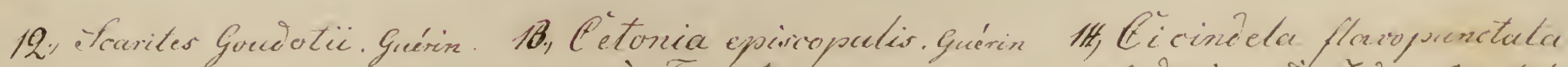
¿s Tanrialowe.

-Anowion. Disetruas-Cricnlades.

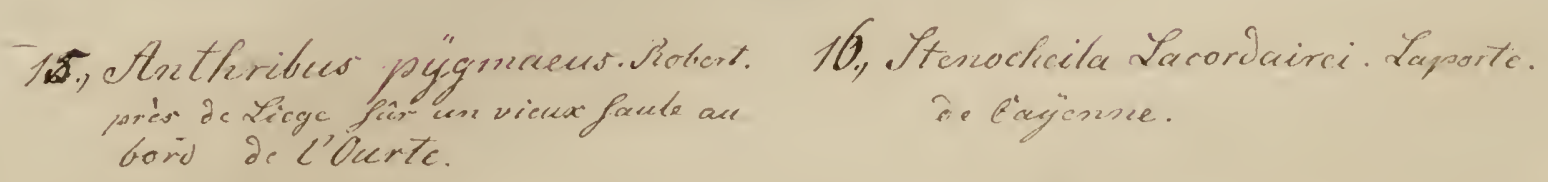

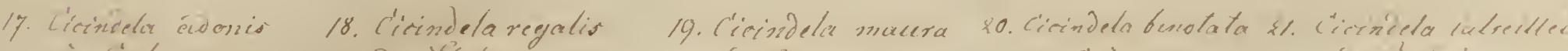




\section{$\frac{1}{4}$}

33
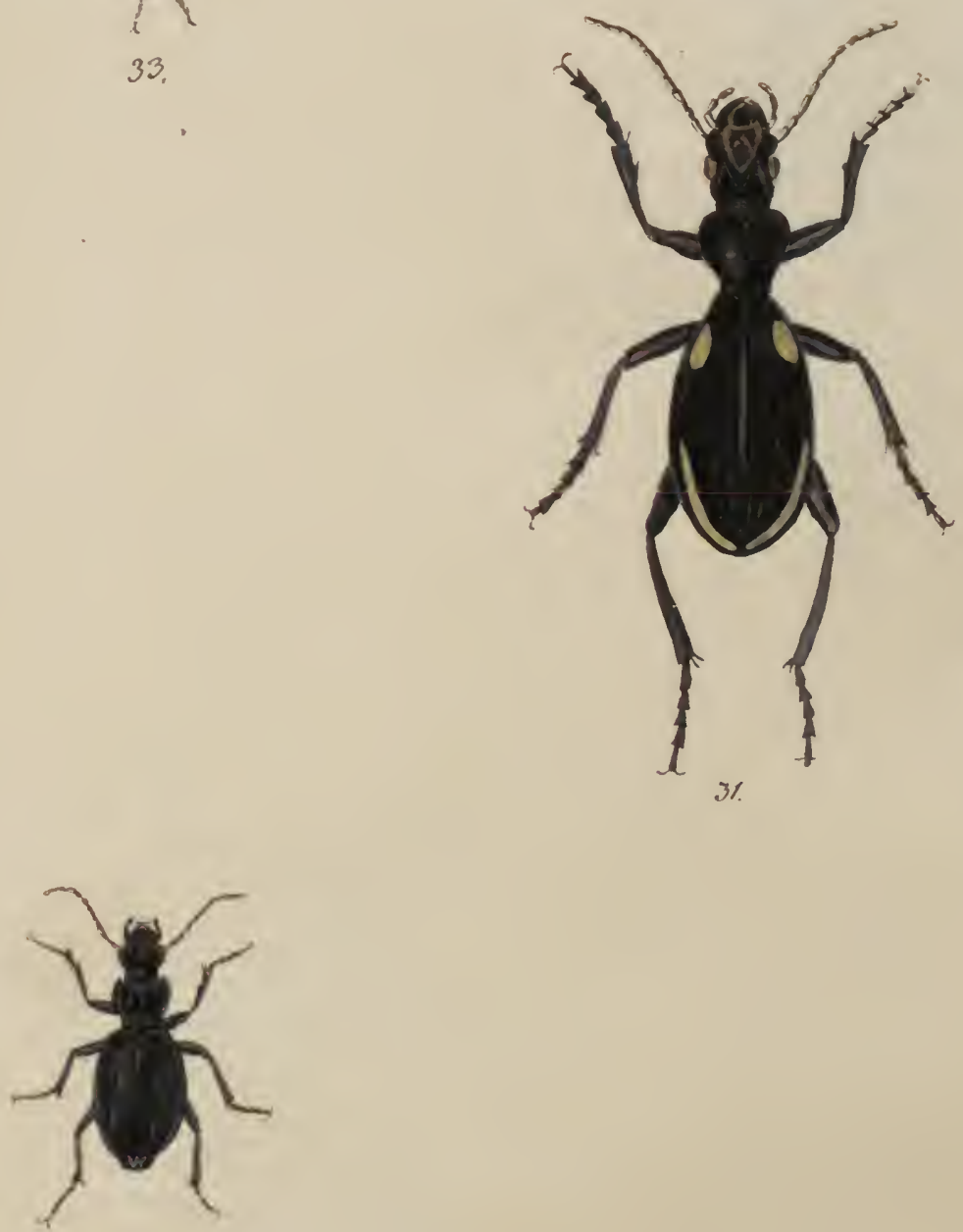

34.
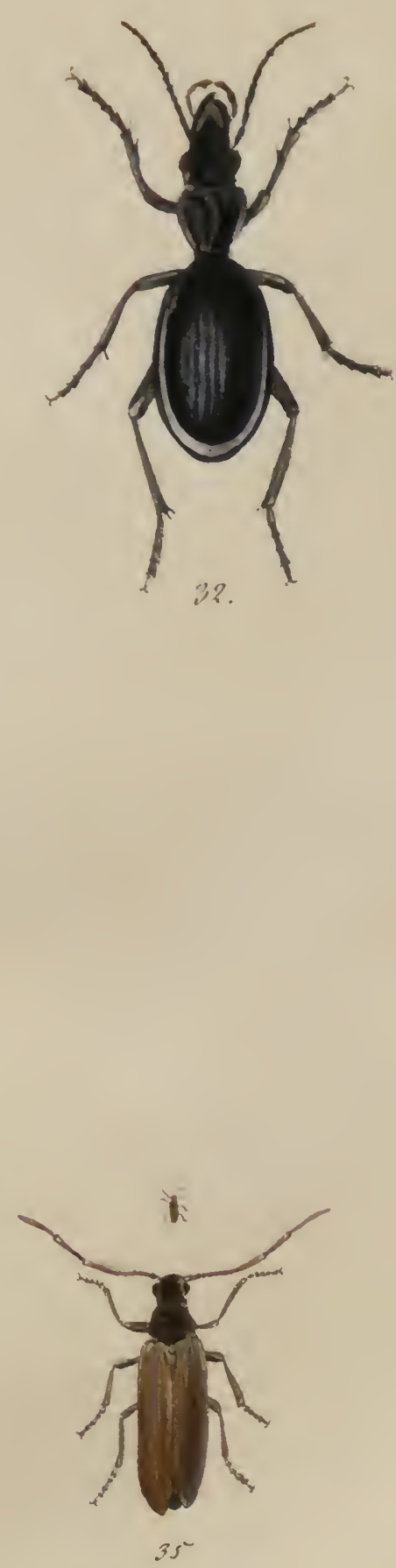

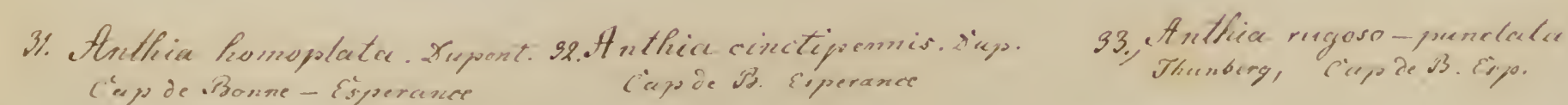

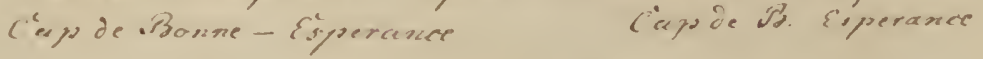

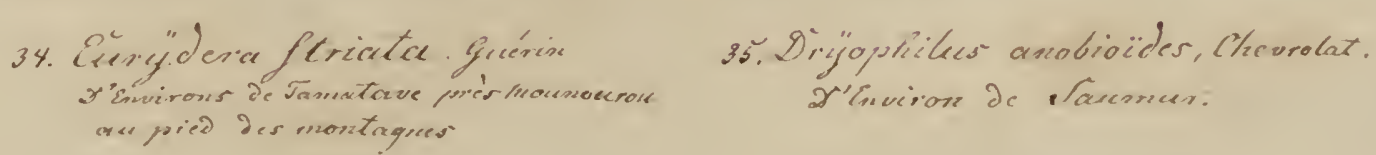



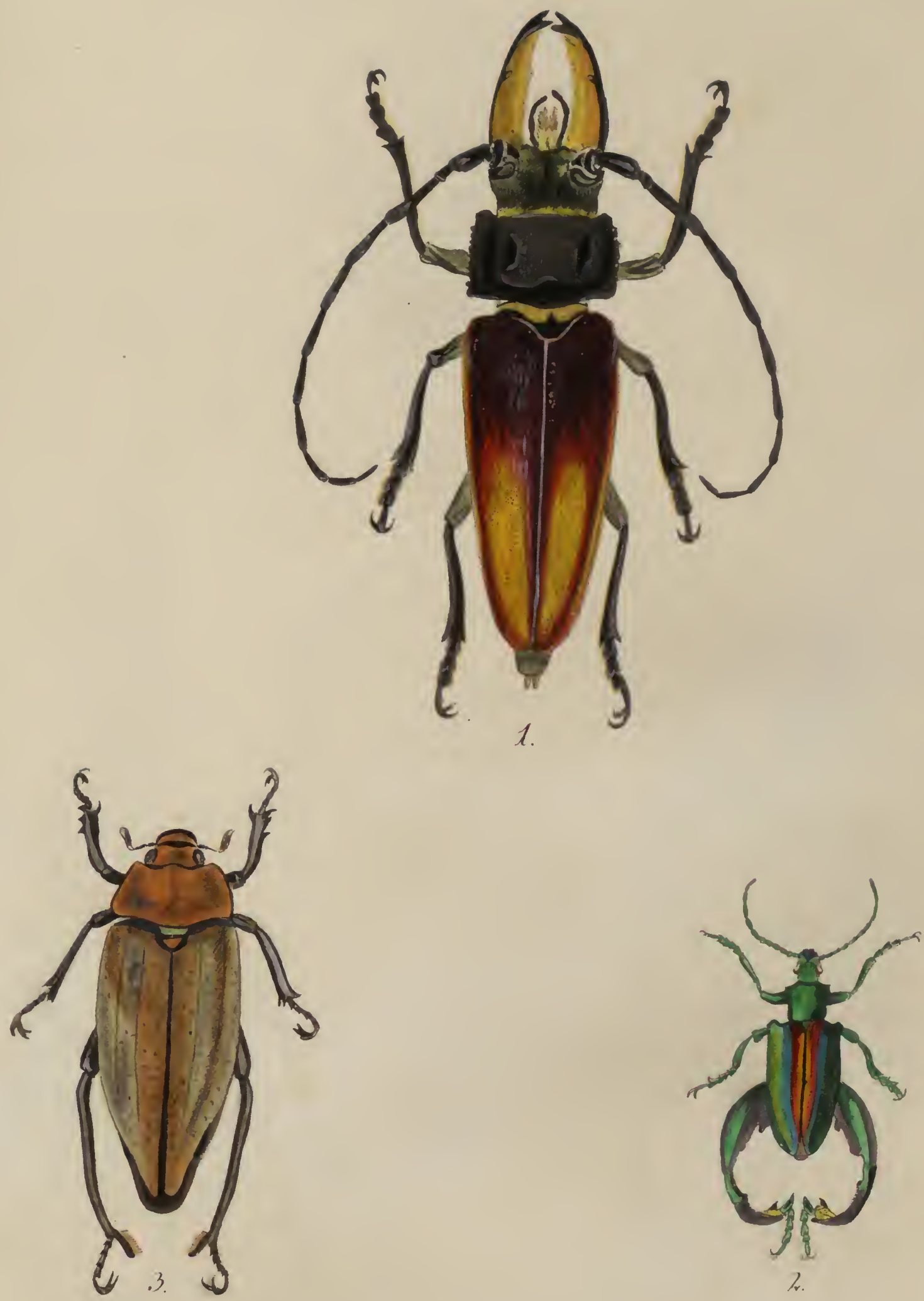

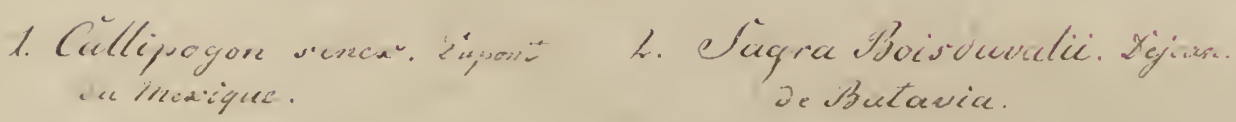

3. Fiderosternus buporcoloides. 


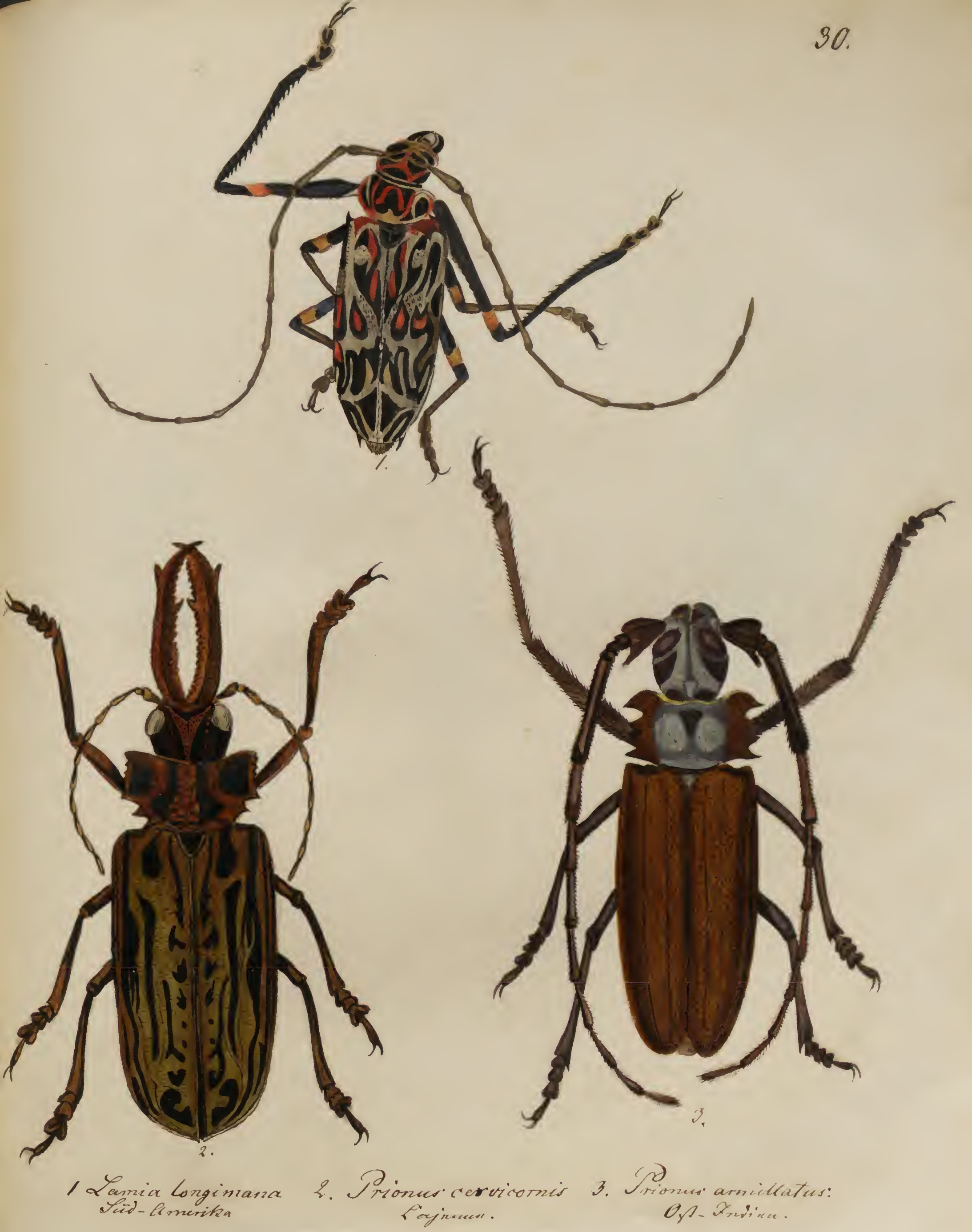




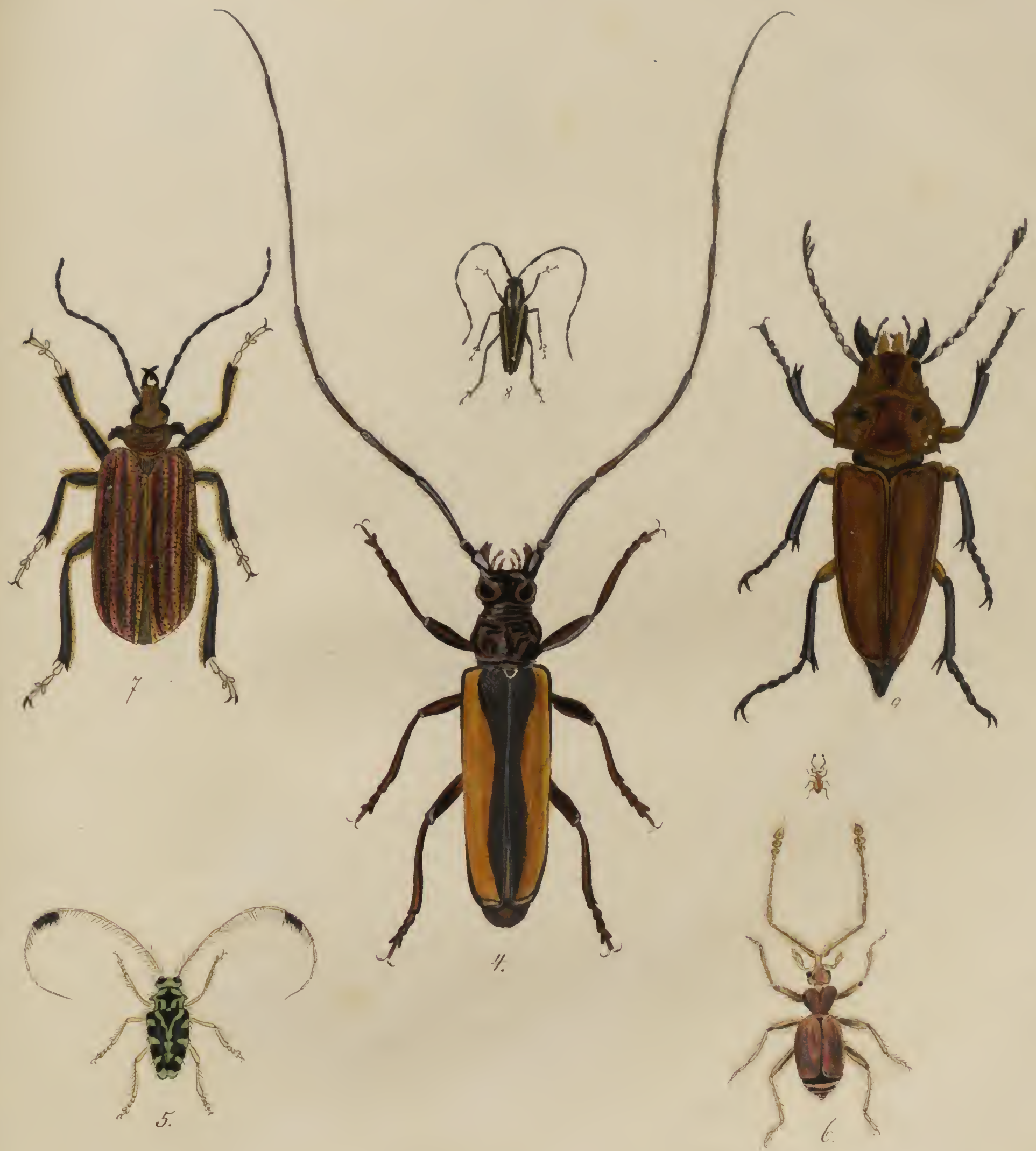

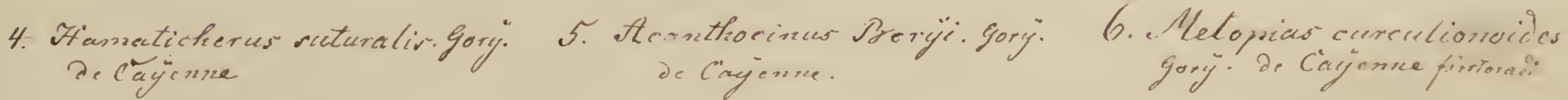

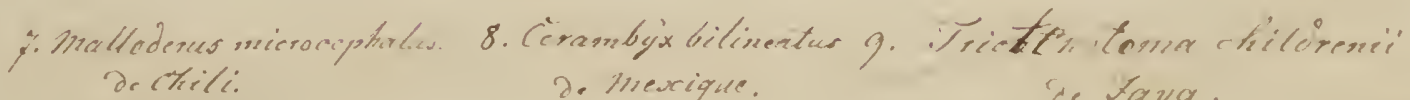



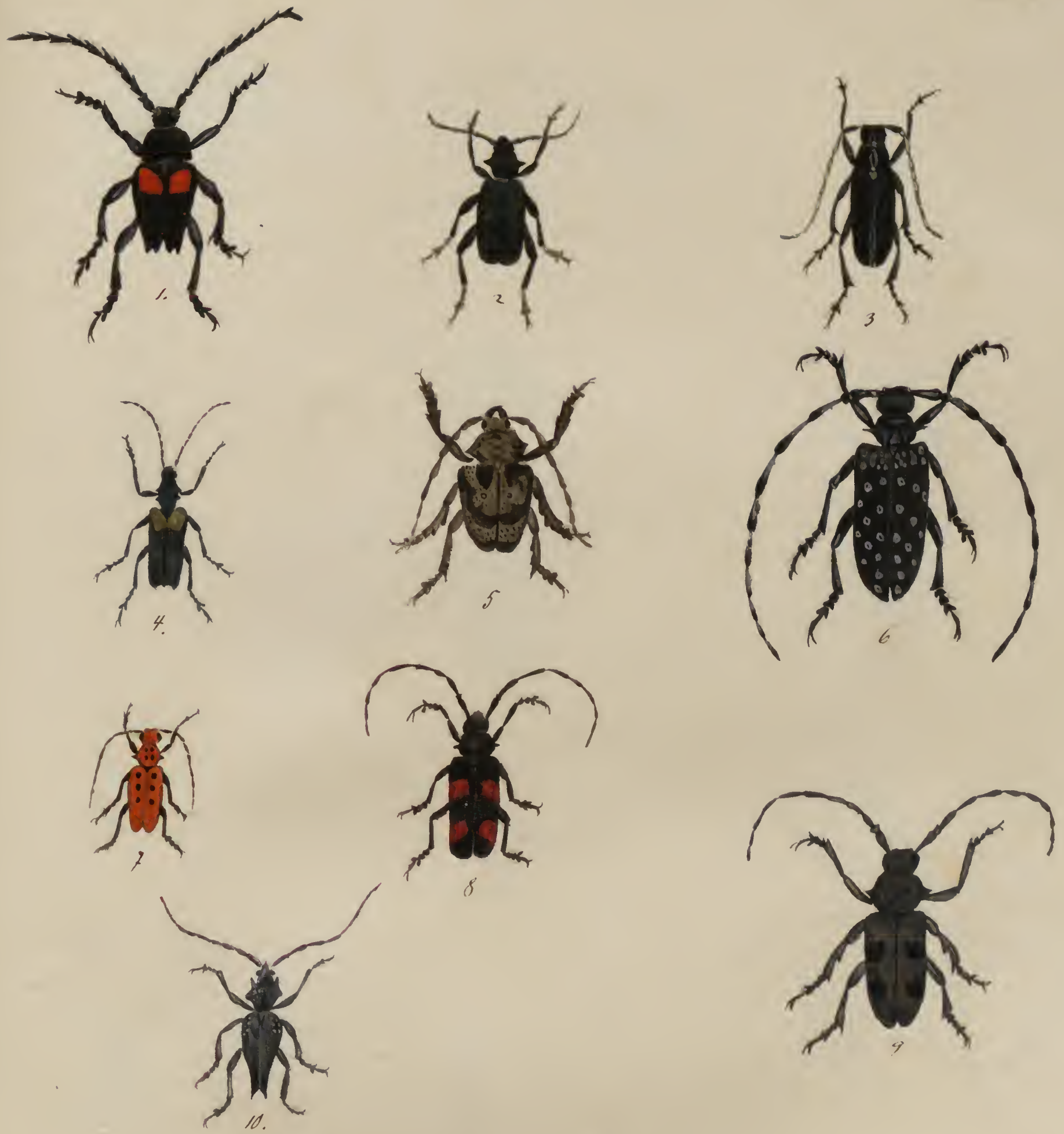

1. Callidisen unifaspiatusn
Ciajesne

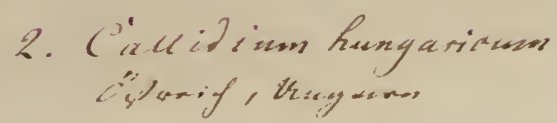

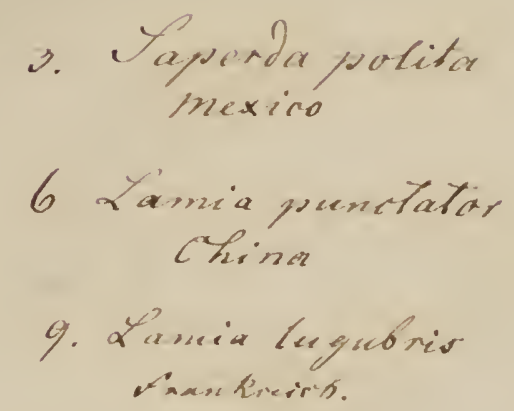

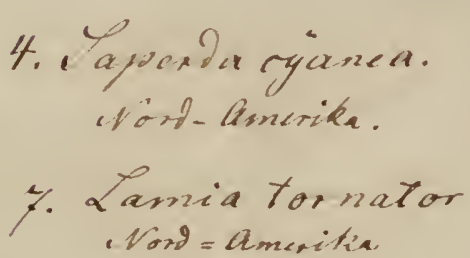

5. Lamia feorpoio.
Obuation

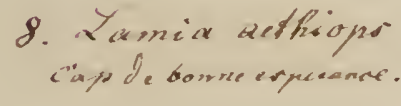

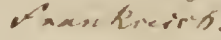

10 Cerocgidon horrerir
iven- Hellaro. 

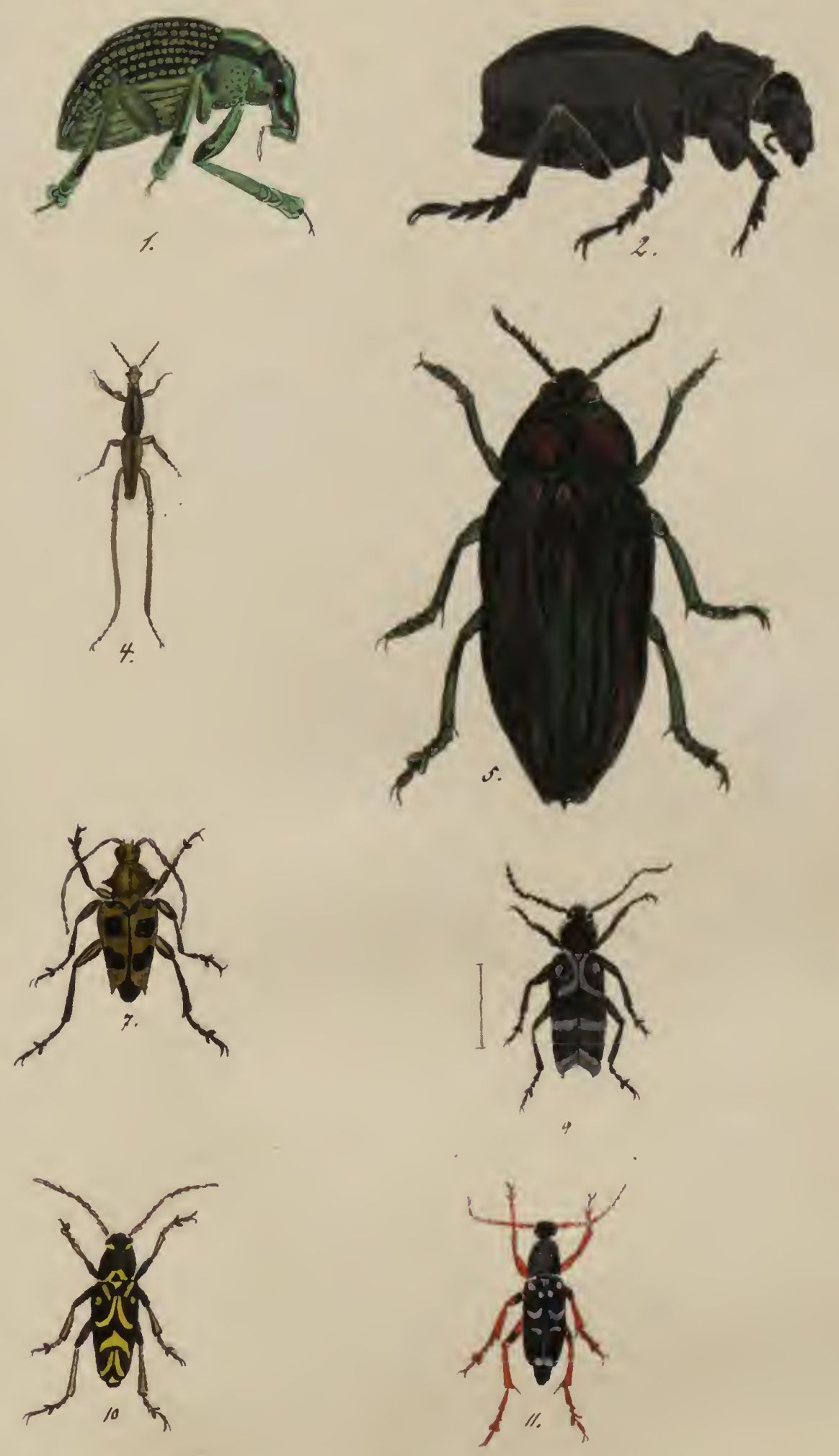

1. Entymus imporialis
1. OBnaritie

$$
\begin{aligned}
& \text { 2. Brustriciersus apterus } \\
& \text { Affrique. }
\end{aligned}
$$

4. Caloiromus Ineltyi
Cost Int.

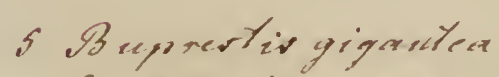

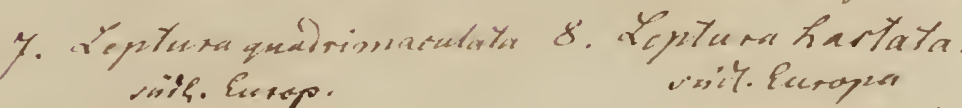

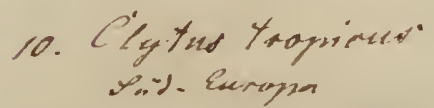

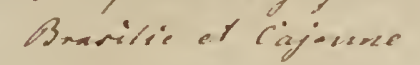
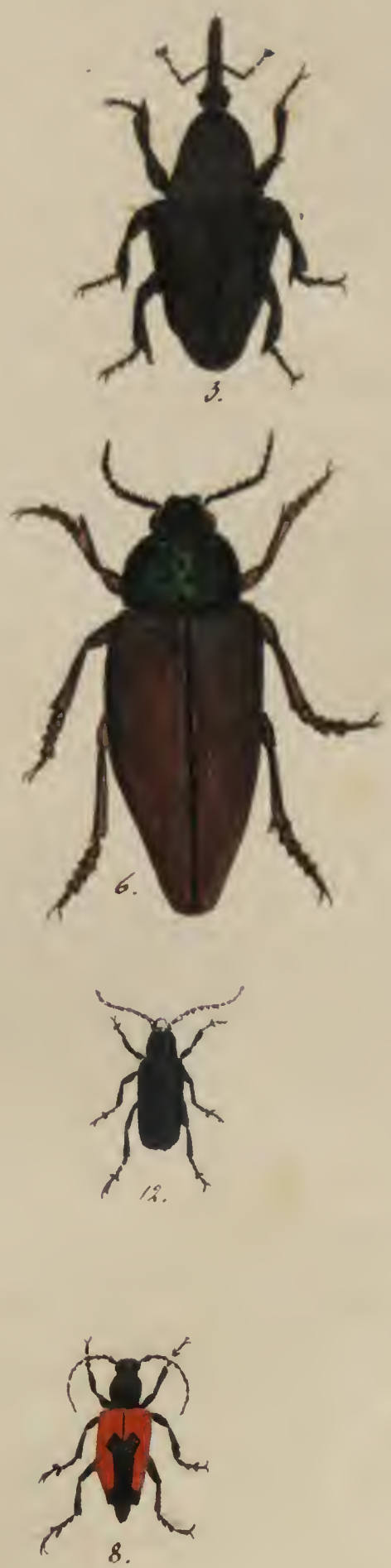

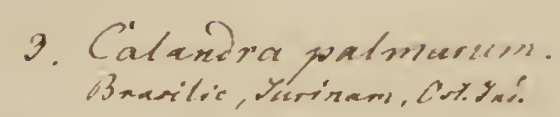

6. Mouprestis chayour

9. Calligiund pbebejusp

11. Cigyzesfenipumeitatess
Cifne..y. 


\title{
ORTHOPTERA
}

\author{
et
}

\section{HEHIPT IRA}

\section{SCANICA.}

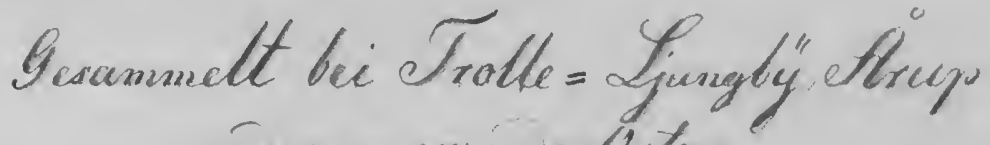

rúse asugrengencever brtere

scush ier Nutur

gennalt von $1 \mathrm{H}$. Sundeaner.

$18 \frac{47}{48}$

Enthâlt auch

ceuroptera. 

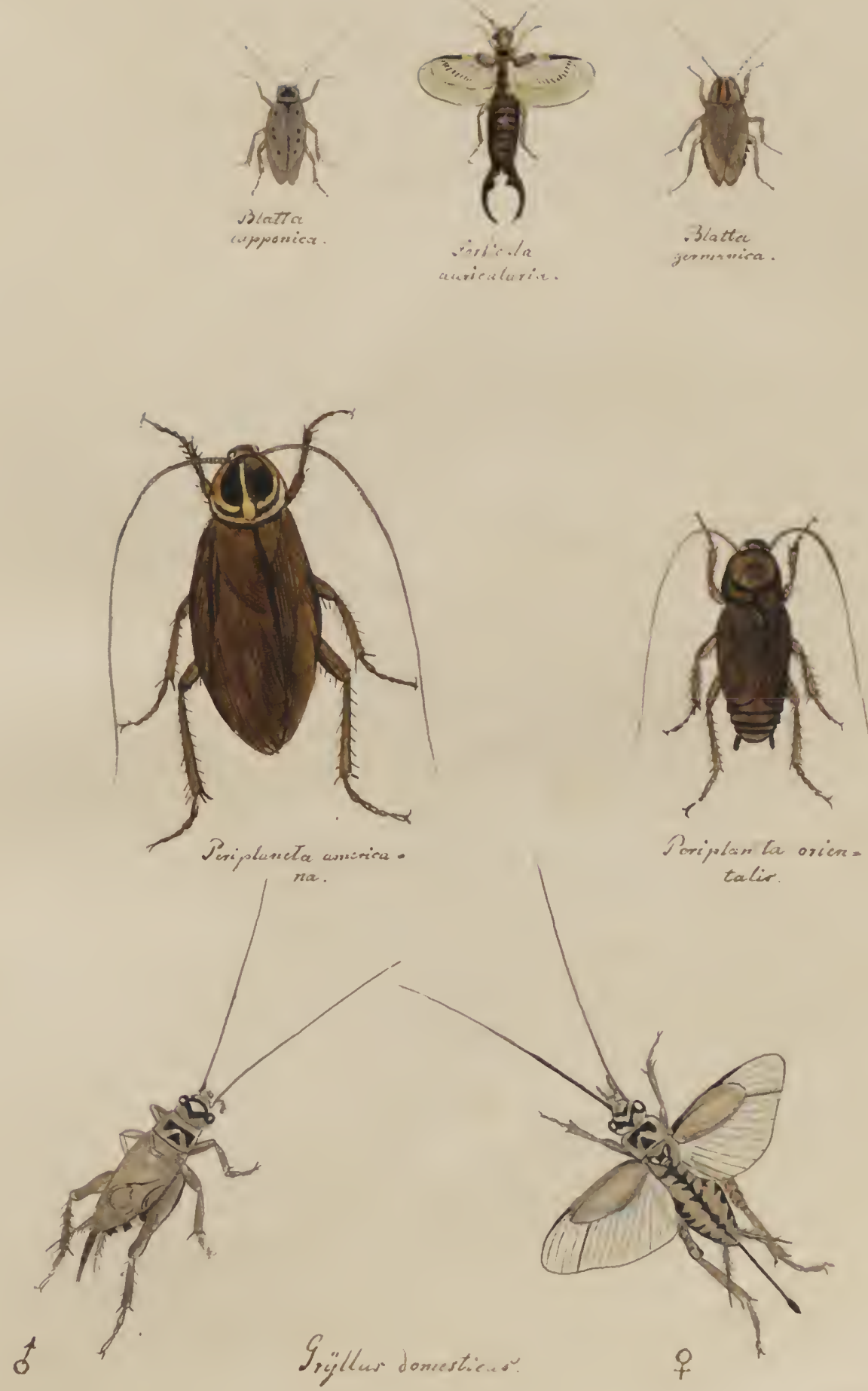

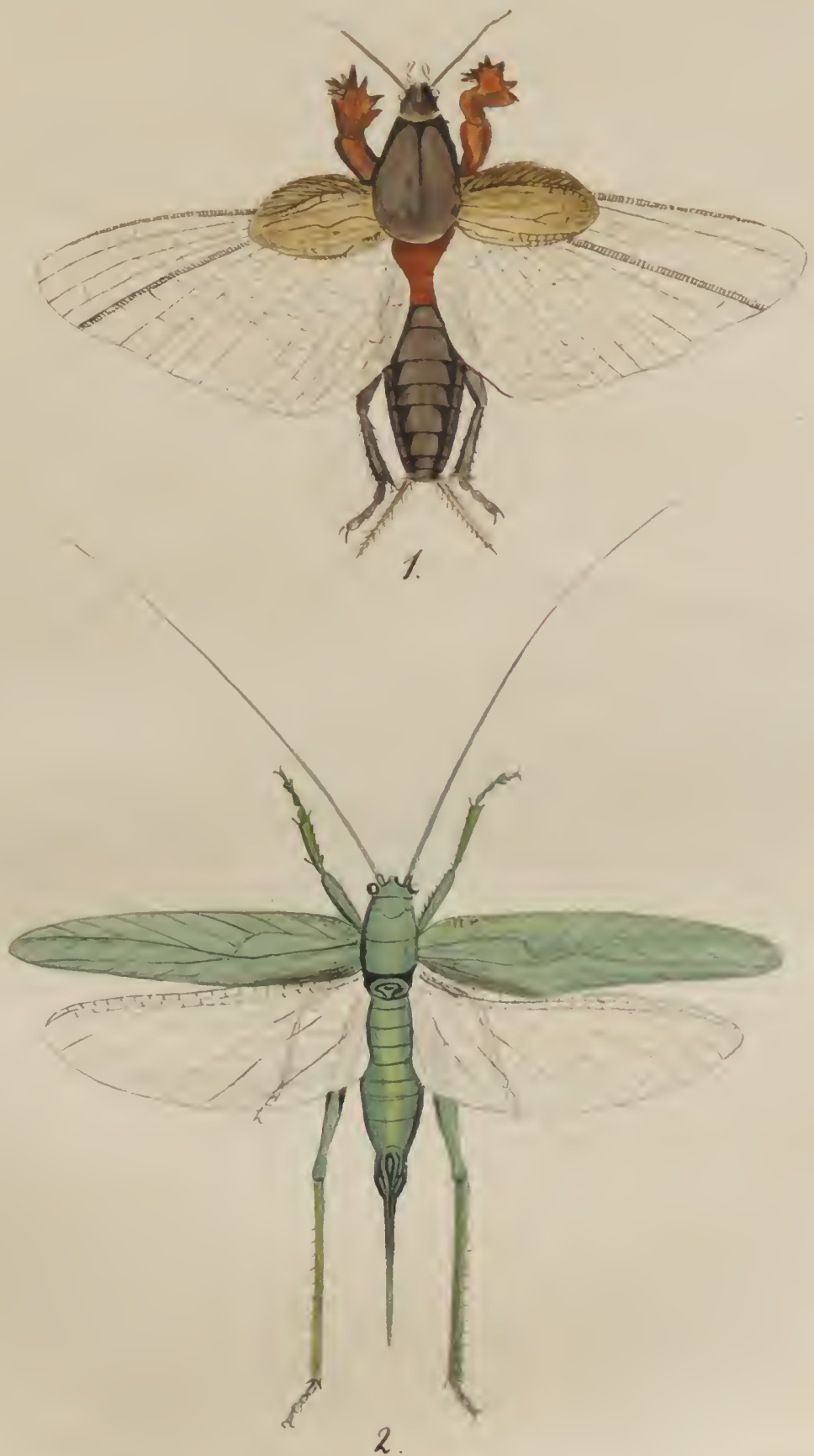

1. Gryllatai, vonlyaris

2. Locustue virivivion. 

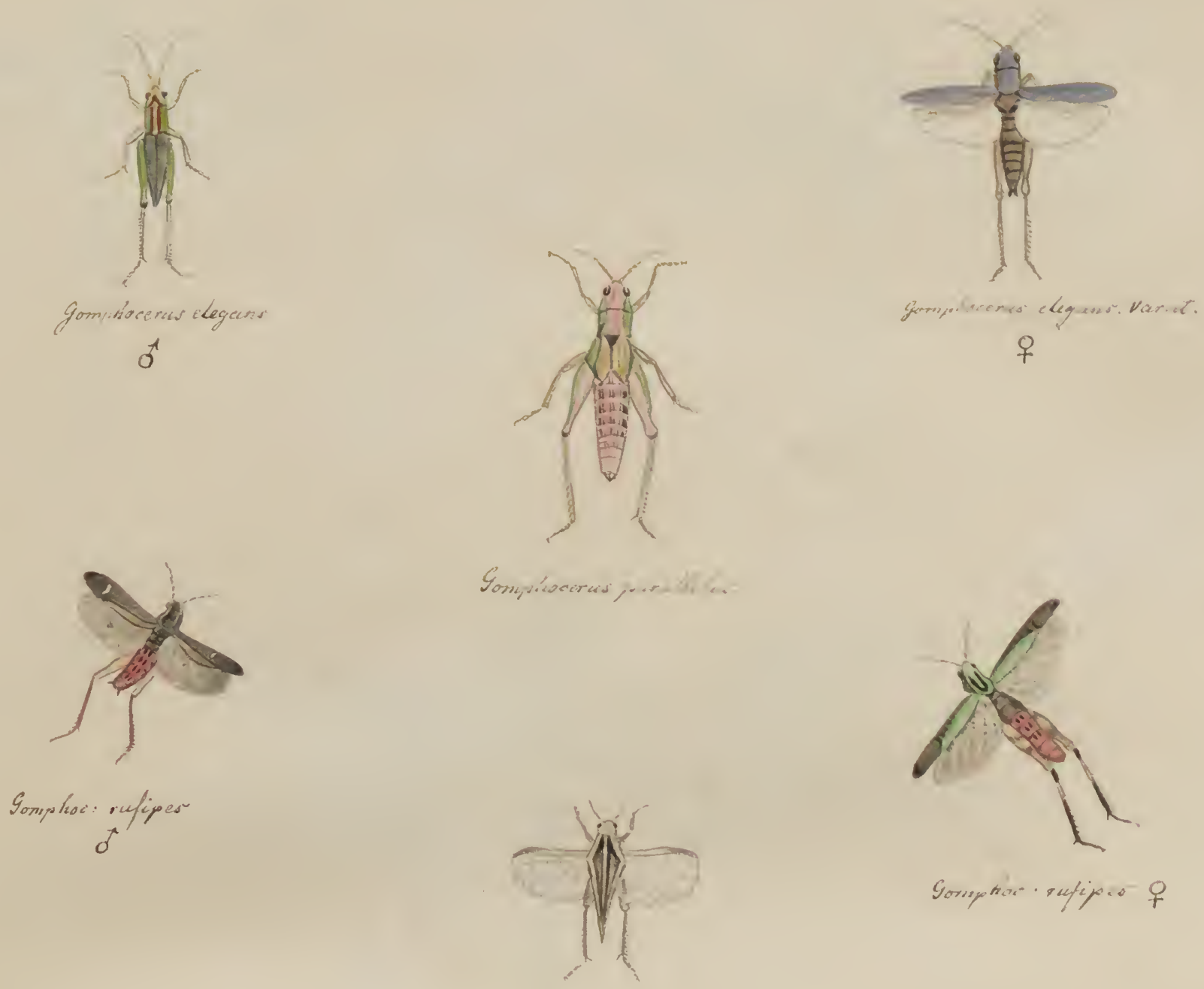

Gorspption.sufip.s 우

Tetrice fubulata 

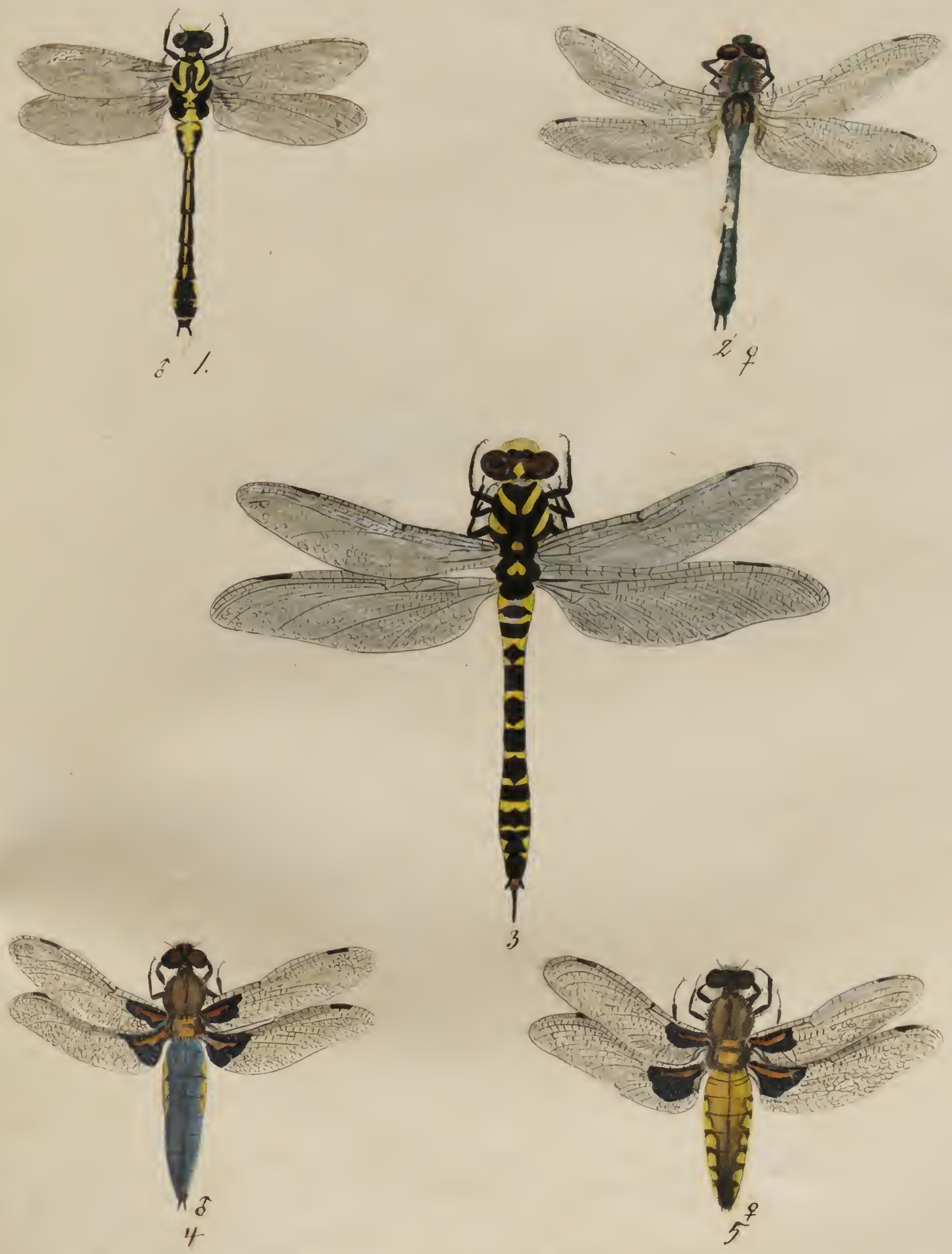

1-2. Libellula forcipuata dot $q$. 3.

$$
4-5, \text { Libellula Depresser of ex } q
$$






$$
\frac{E T^{2}}{x^{2}}
$$


IIPIOPTE =<smiles>C=CC1CCCCC1C(C)C</smiles> 

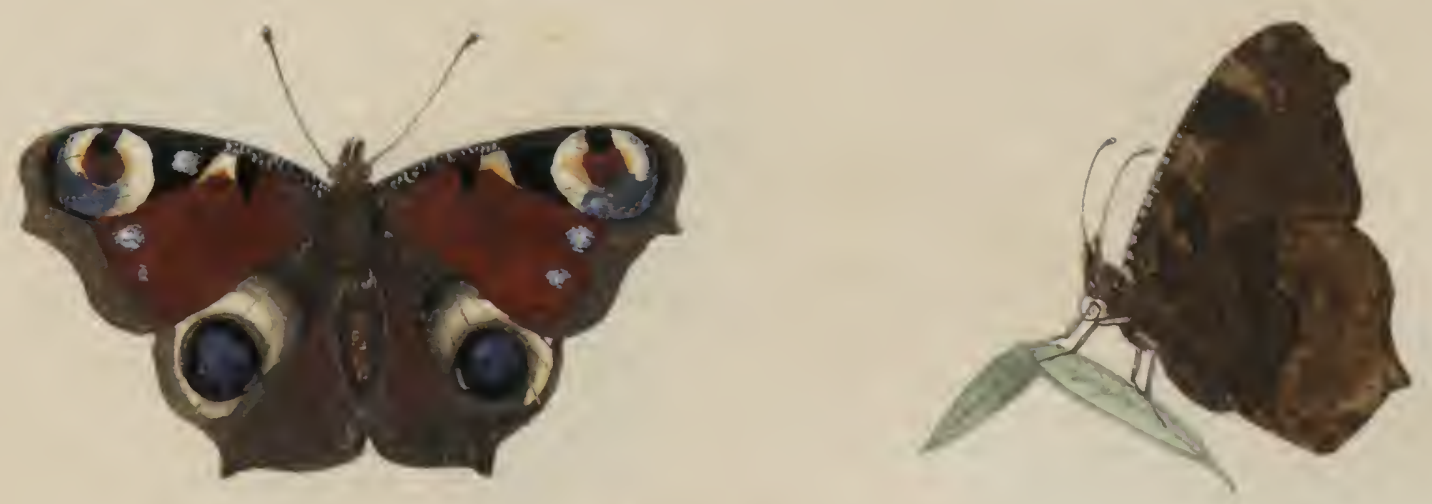

etyleis eto.
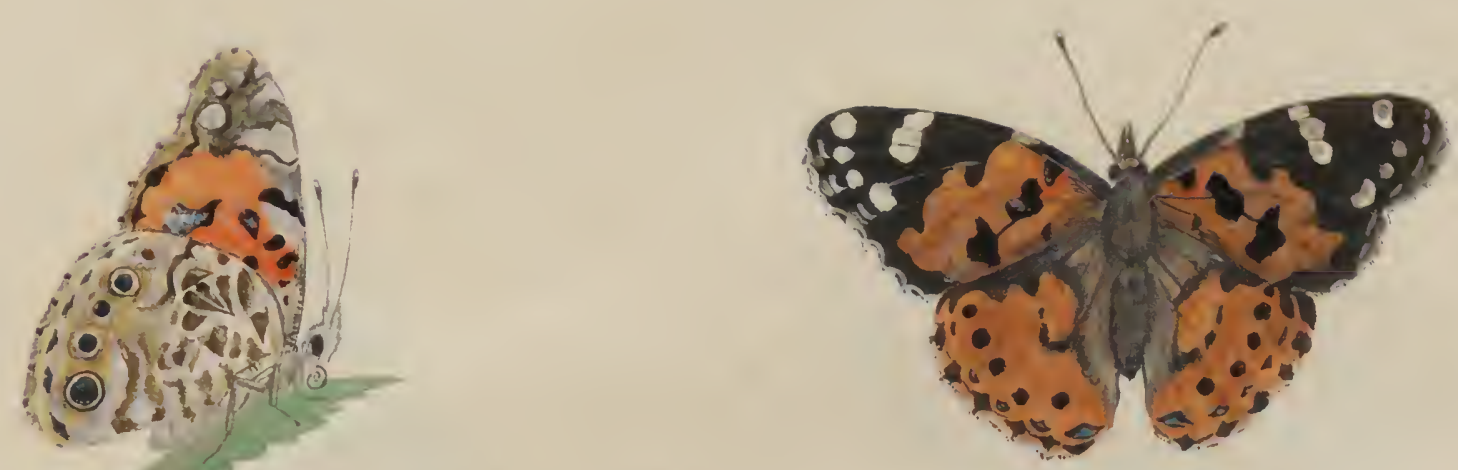

Agla is Caroui.

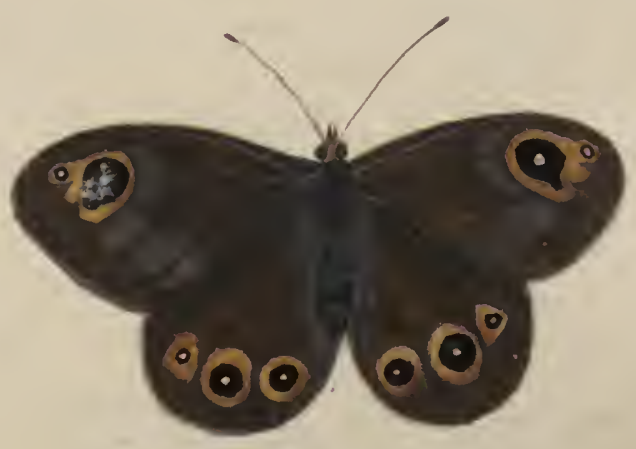

Érebue Heara.
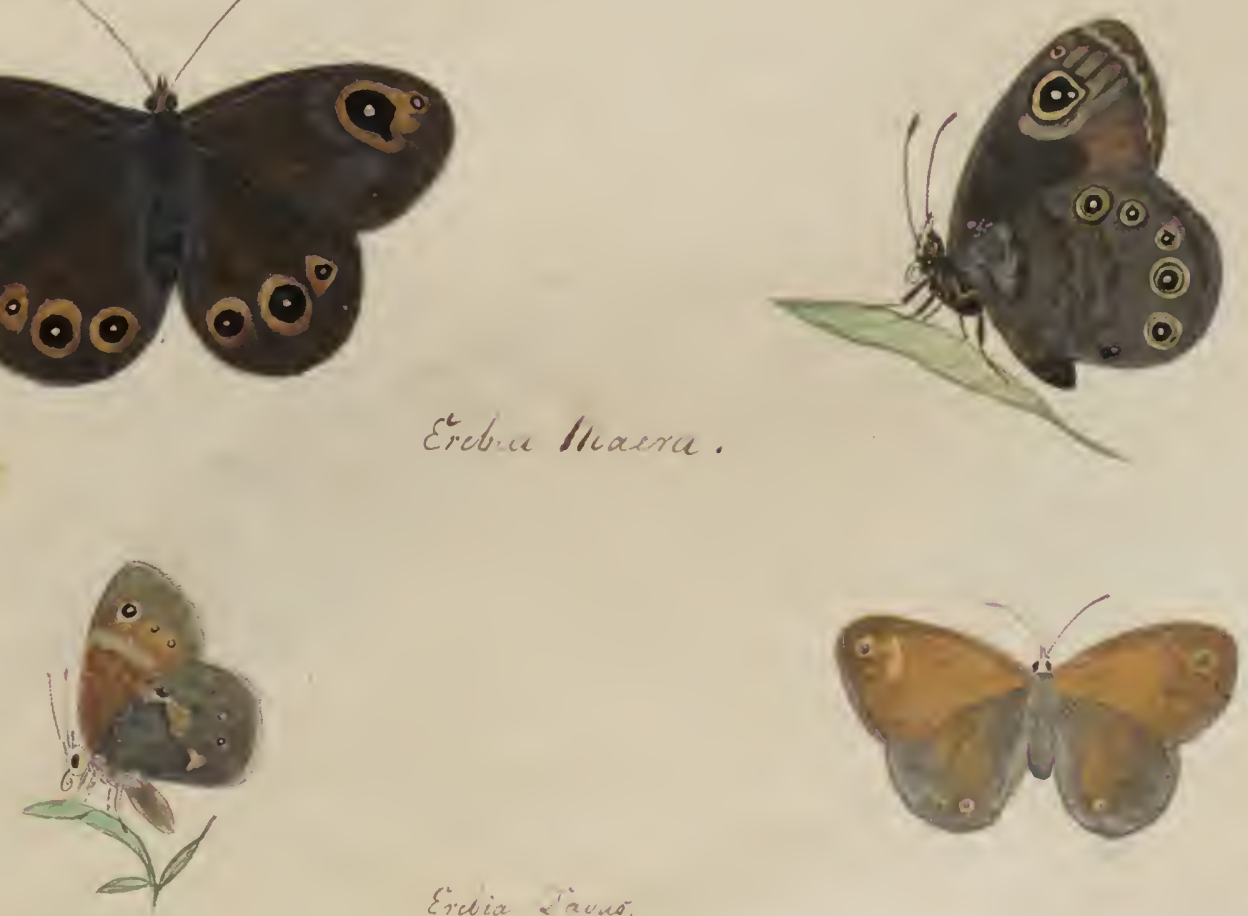

Ervia Tauro. 

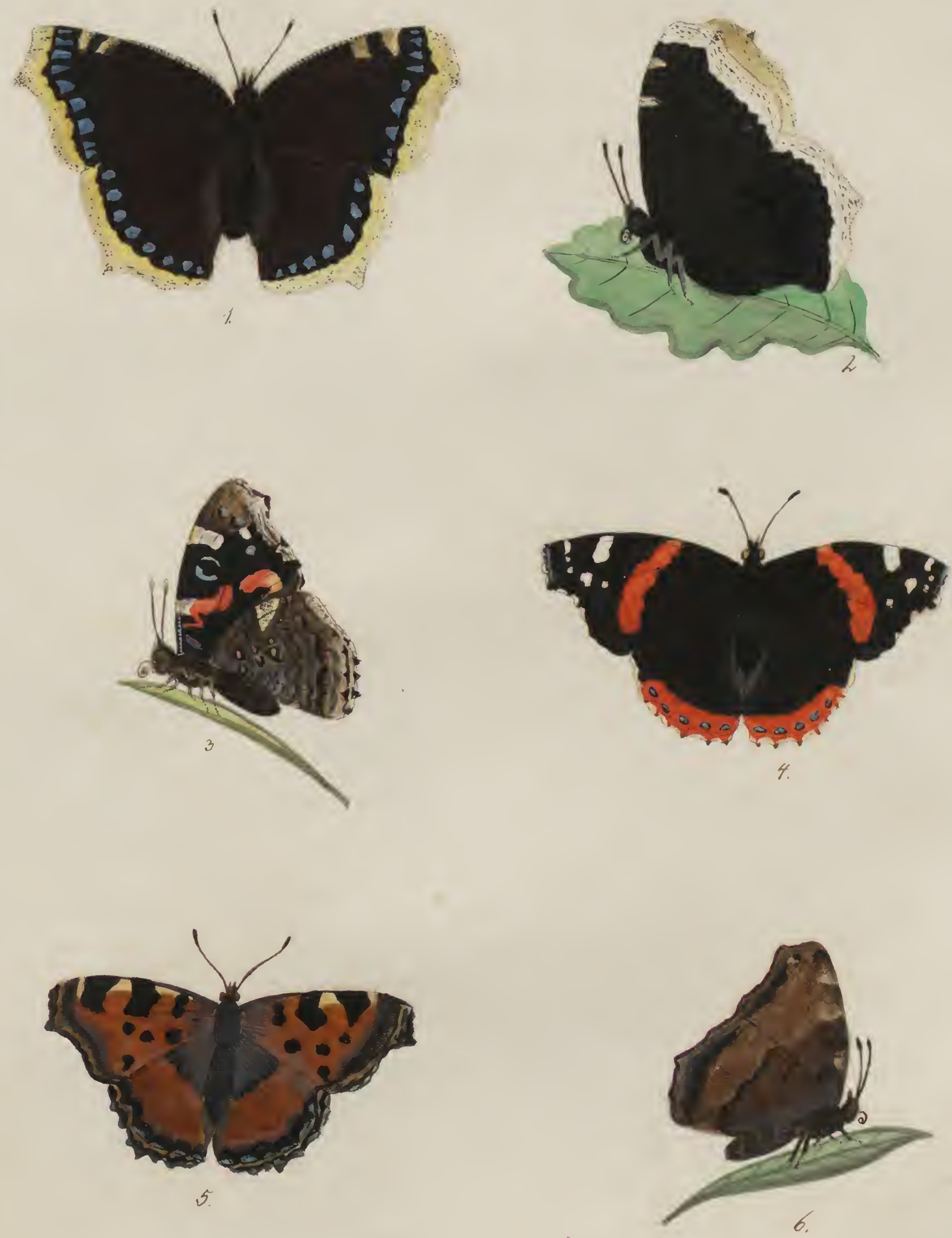

$1-1$ Sapuivio Atretiop....

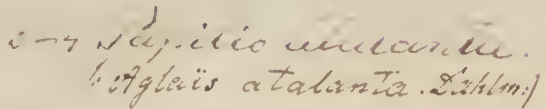



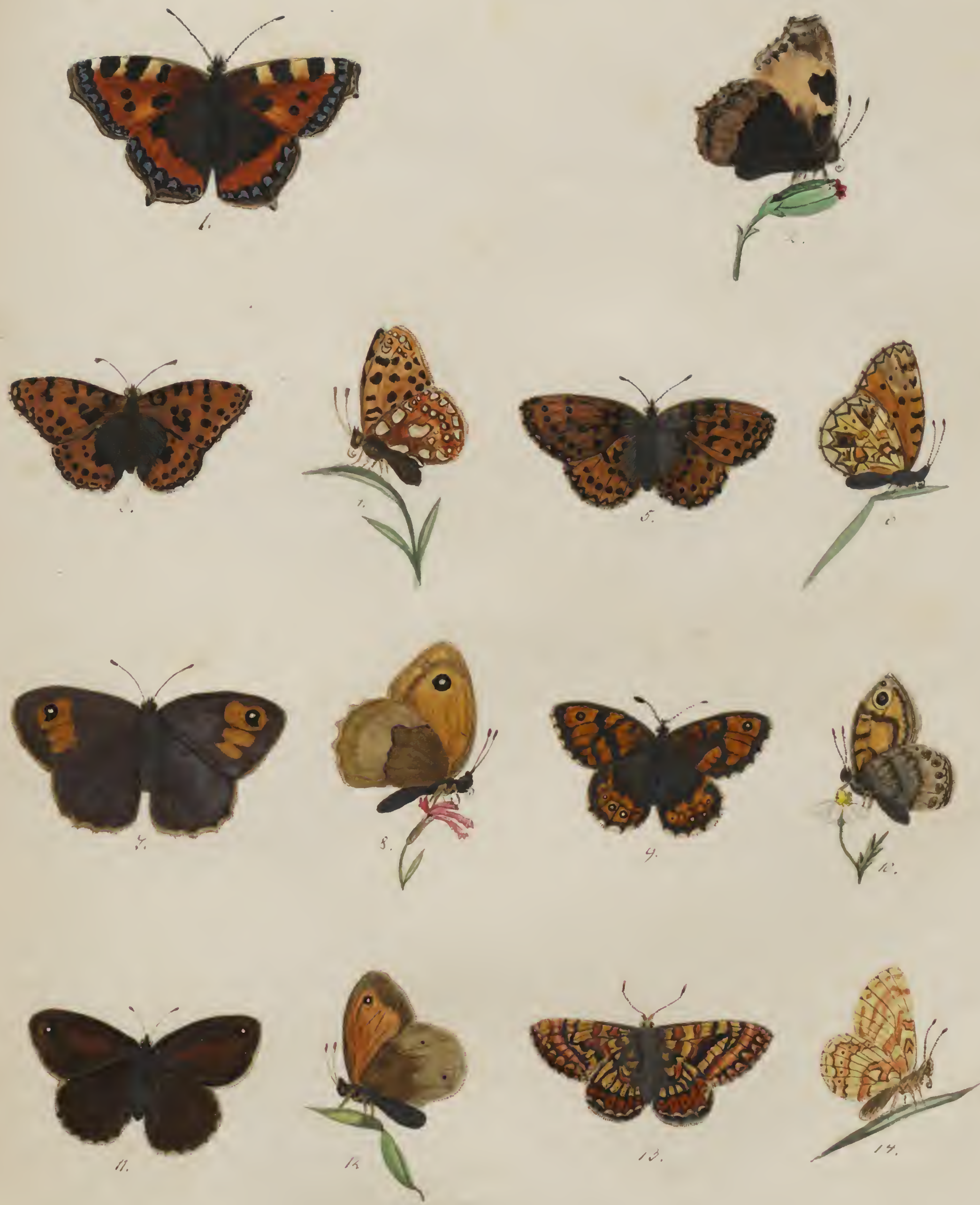

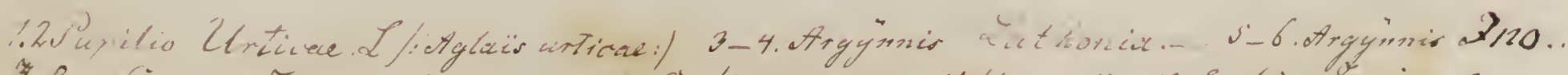

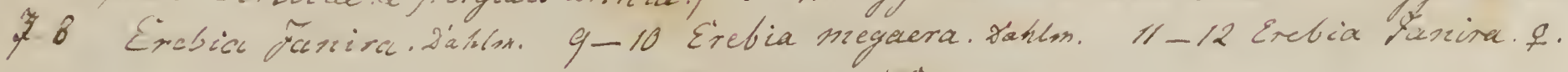
13-14. Hetitarea dilia.r. 

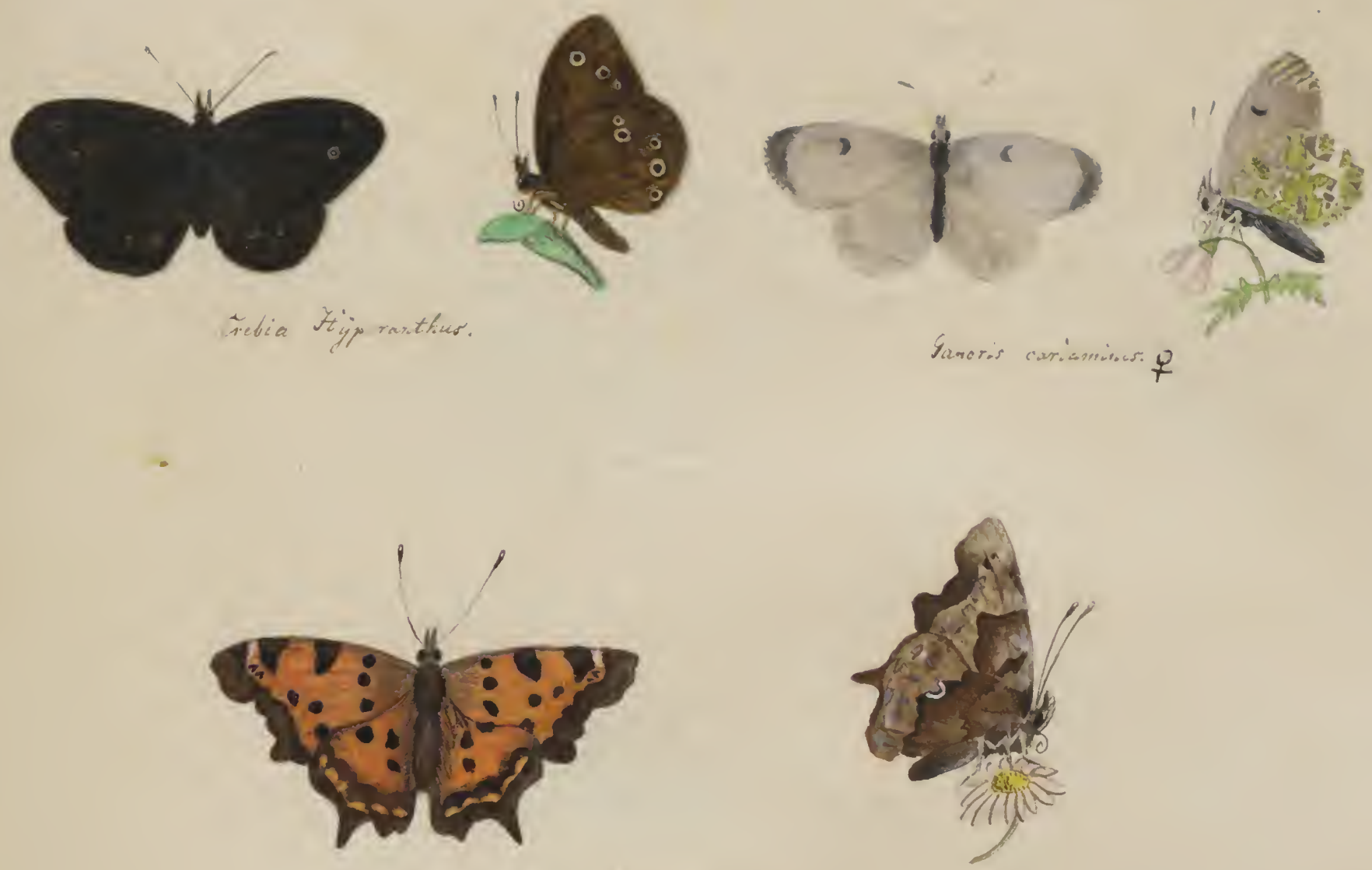

Agless $C^{c}$ albun

i
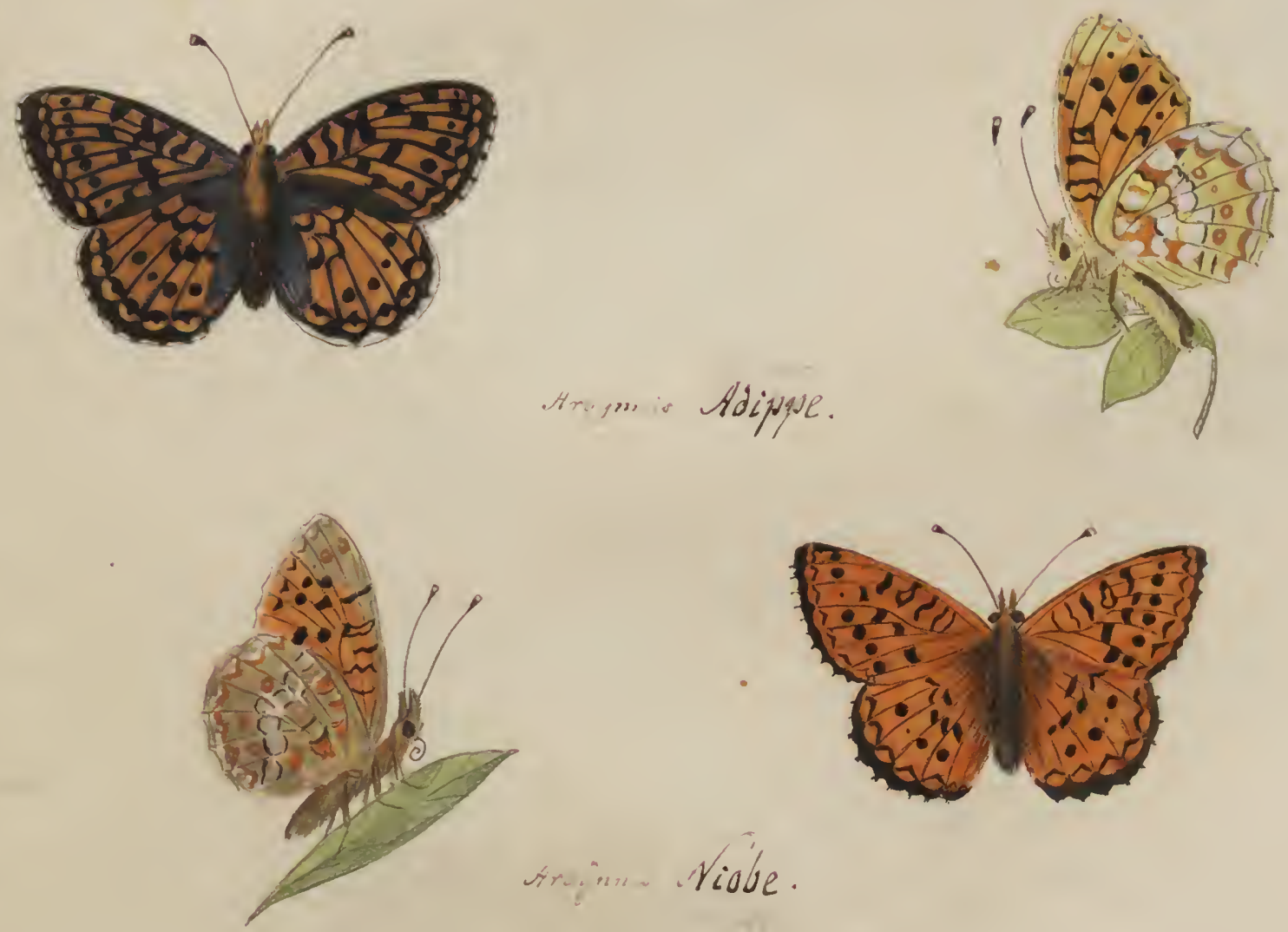

Hr.., in is Mdipgse.

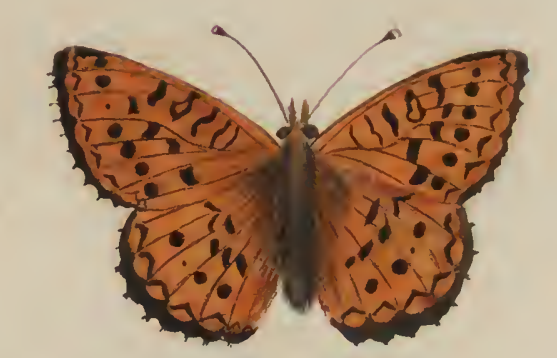

sir.t. Viobe. 

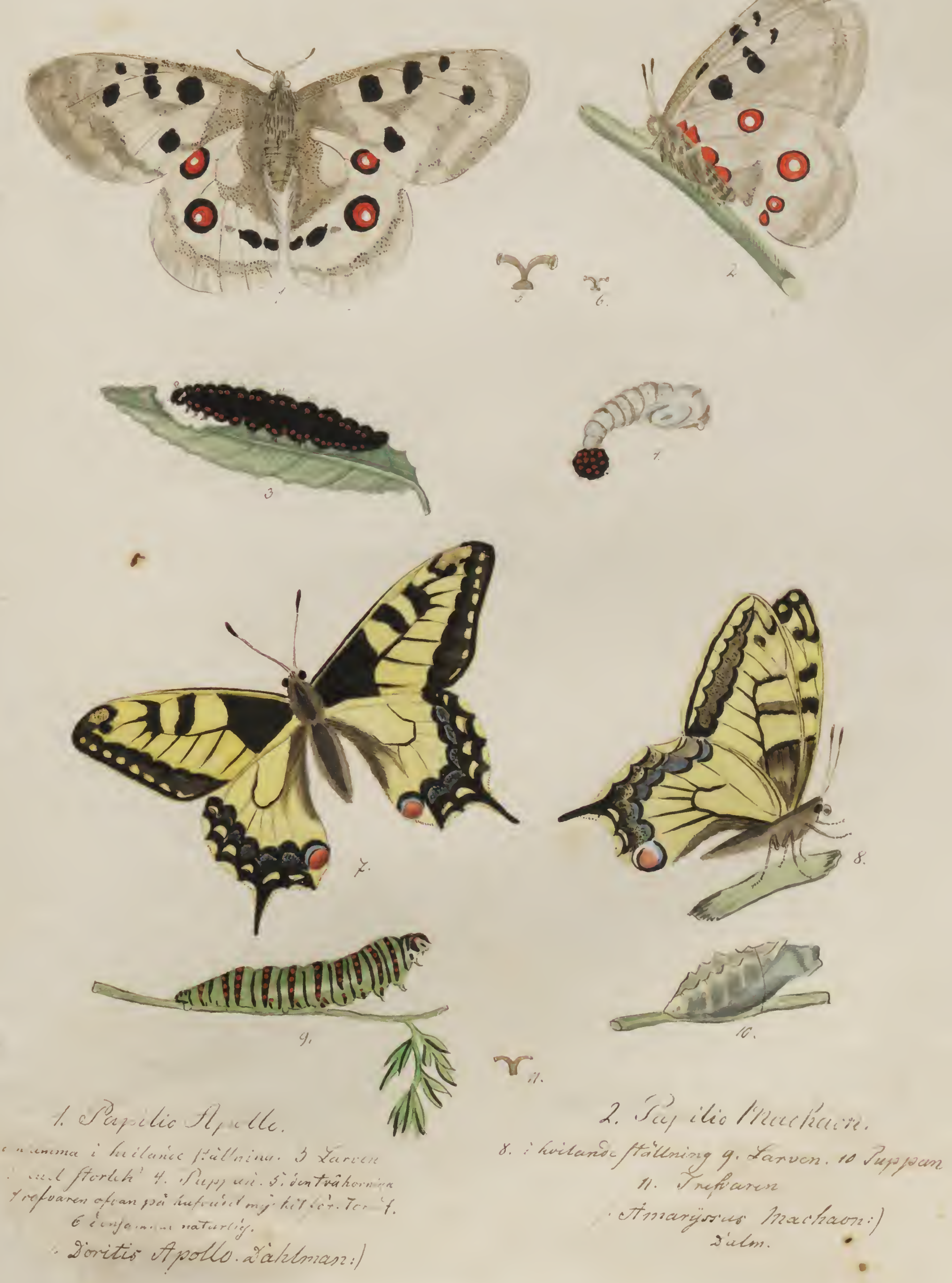

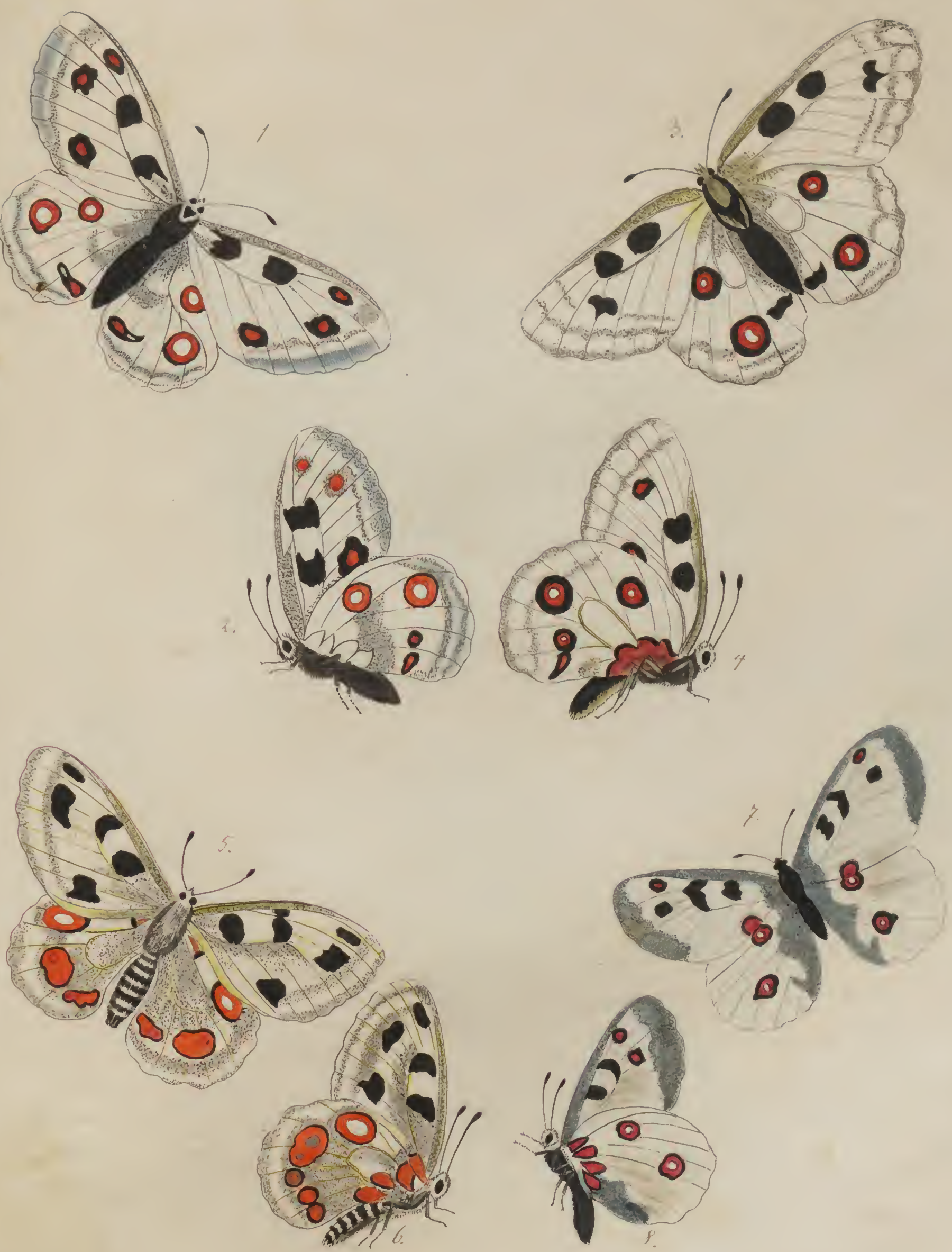

1-b. Tar Rüpotera Apoolle.
Vixidiatear.

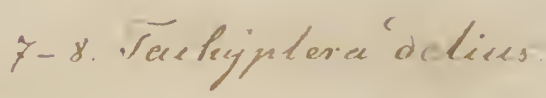




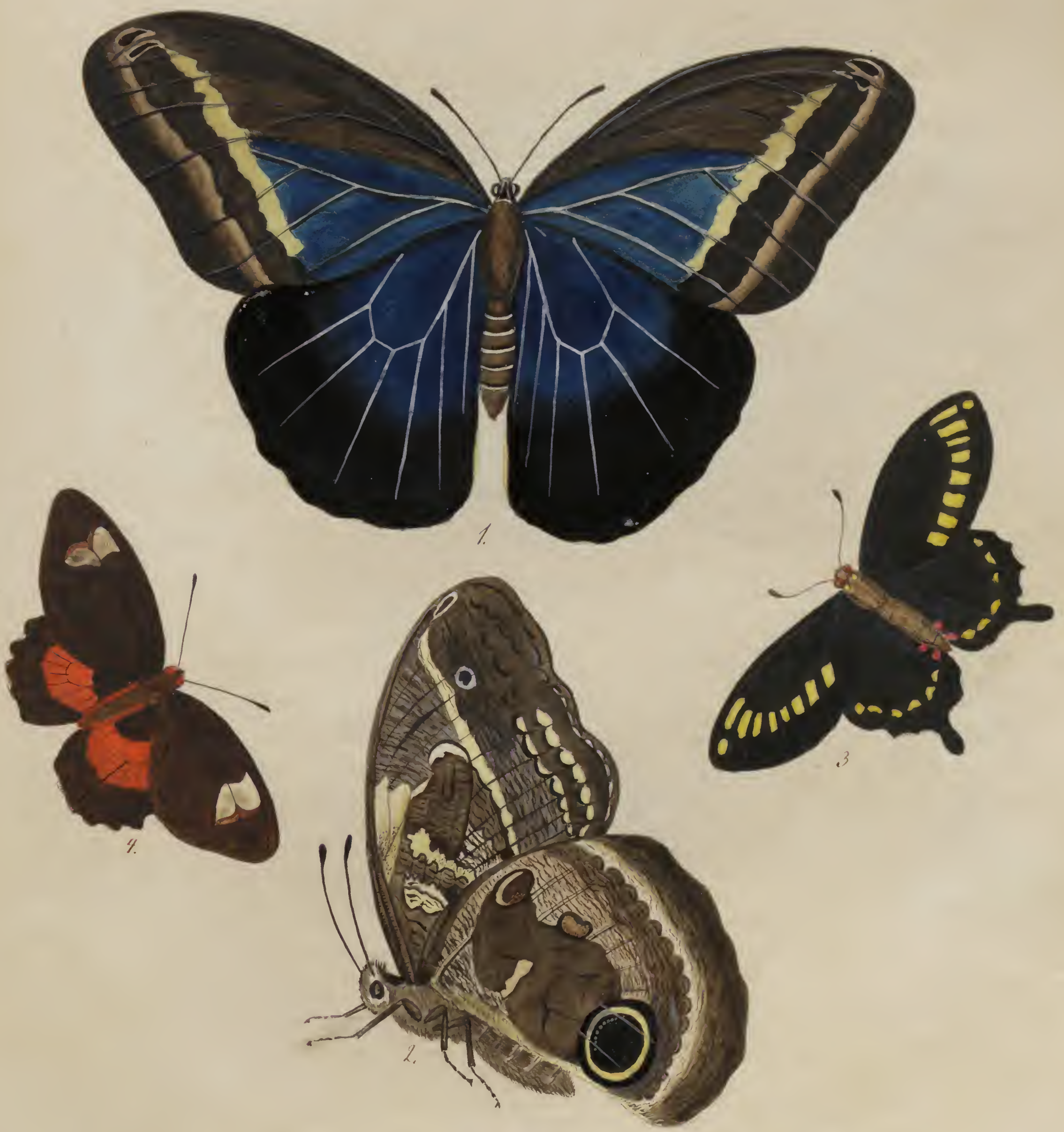

1. ims Lo. Aëronauta curilochus. 3. Aeronauta peteides minst Surinam. win' Ost" Jndien \%. Dachipatasa arcas nüb' Boravilien. 


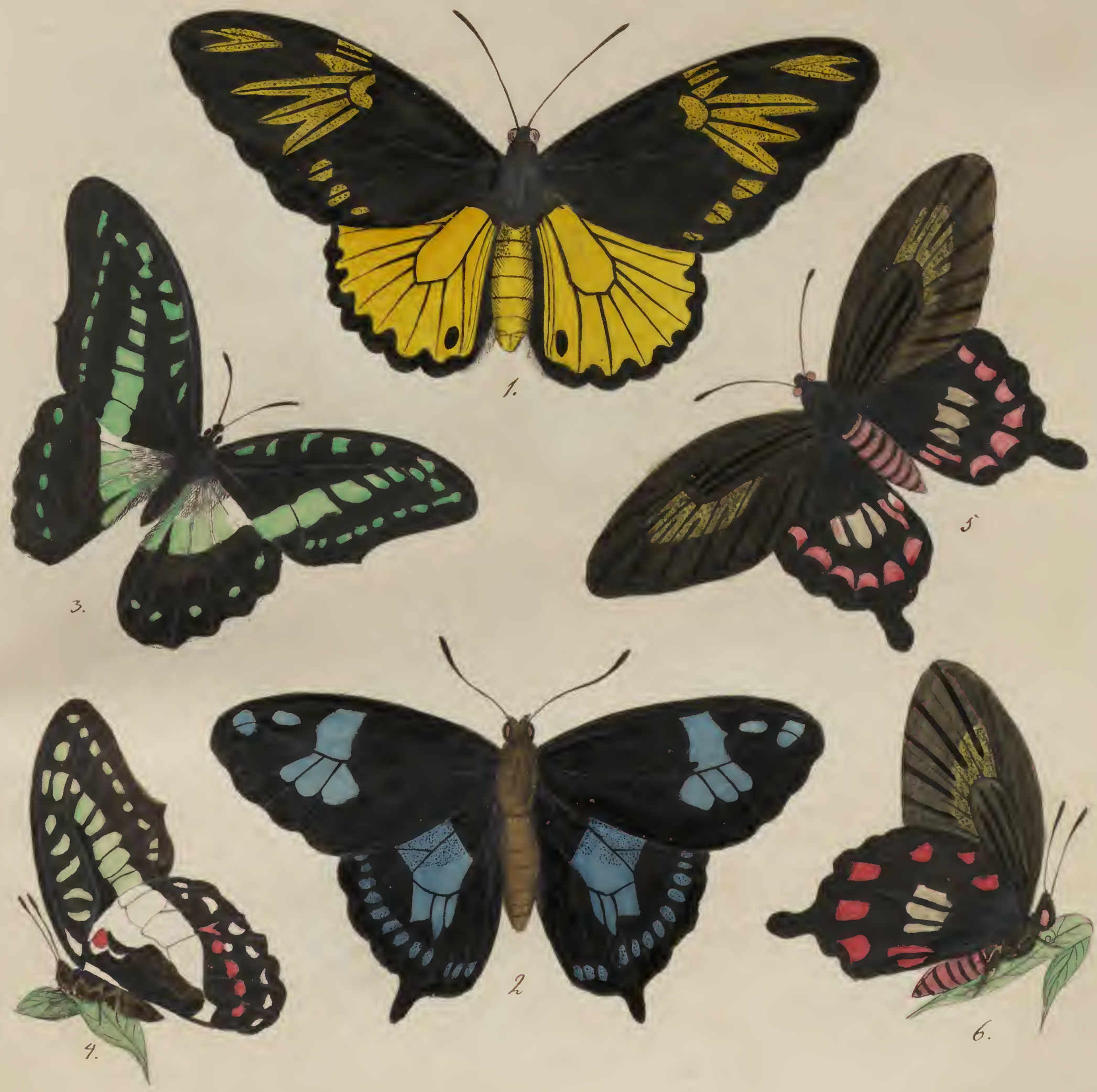

1. Hërnauta anpstrisus 2. Aïrsauta phorbanta. - Fideuneritín. 3.4. Air nauta eurypy"lus mant Sarra. s-6. Ac̈rneuita diphiless. siir Arien. 


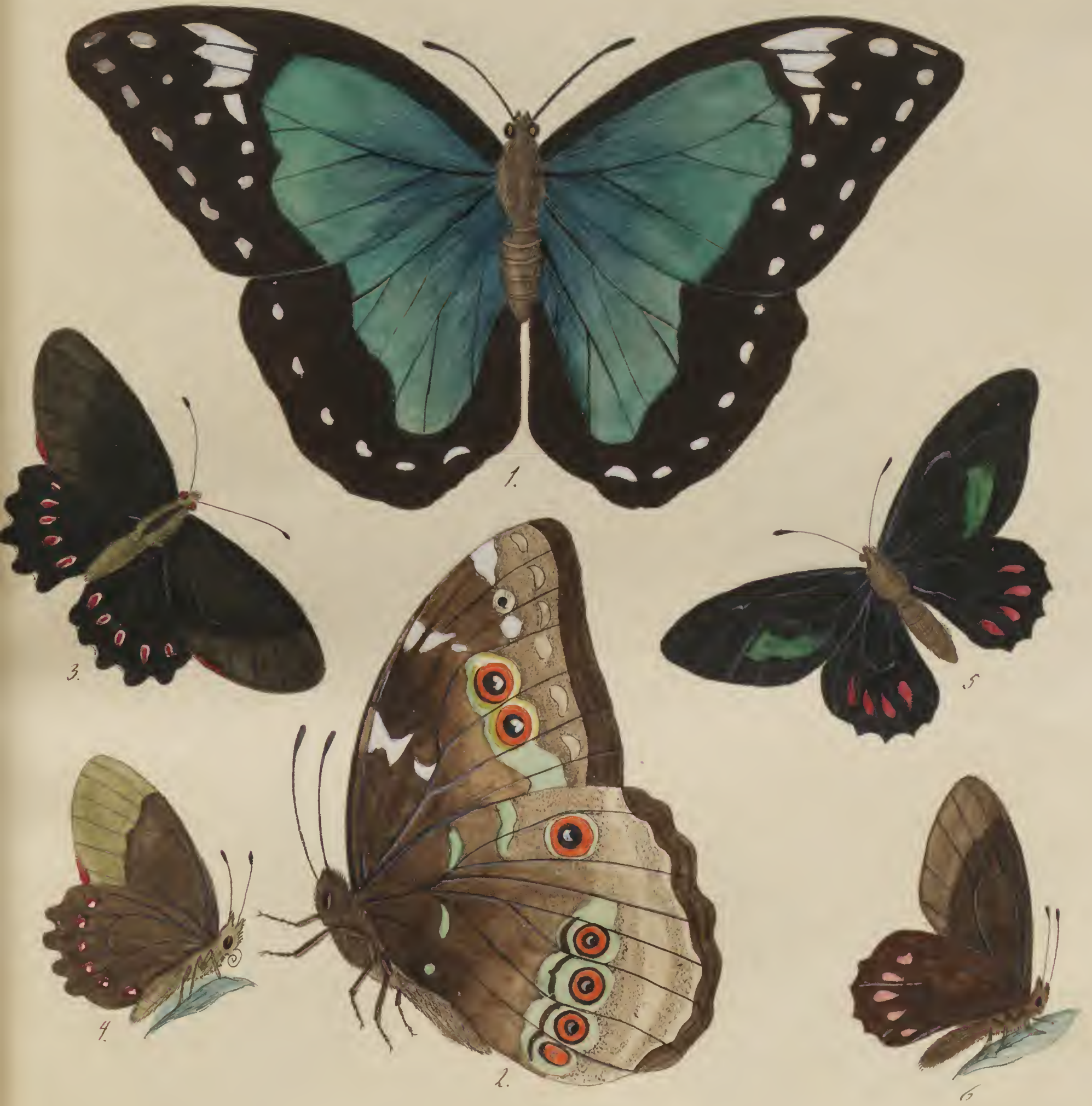

$$
\begin{aligned}
& \text { 1-2. Aërncuter nestor. }
\end{aligned}
$$

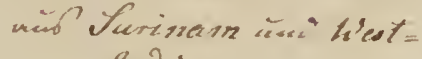

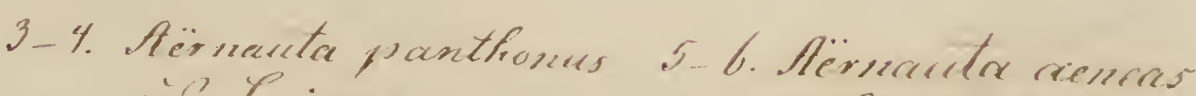

$$
\begin{aligned}
& \text { Indien } \\
& \text { airb Yurivient. }
\end{aligned}
$$

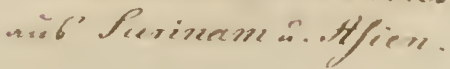




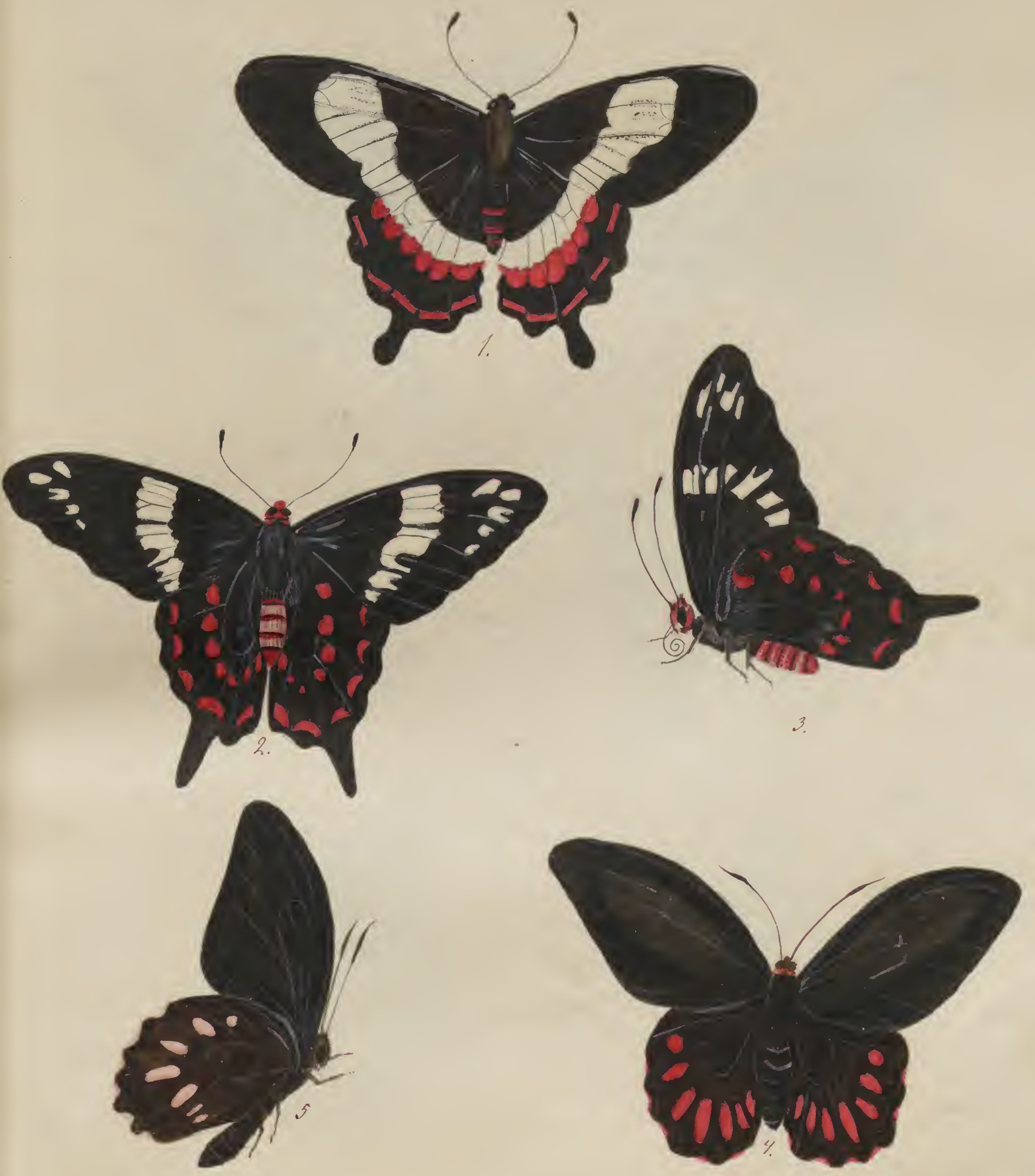

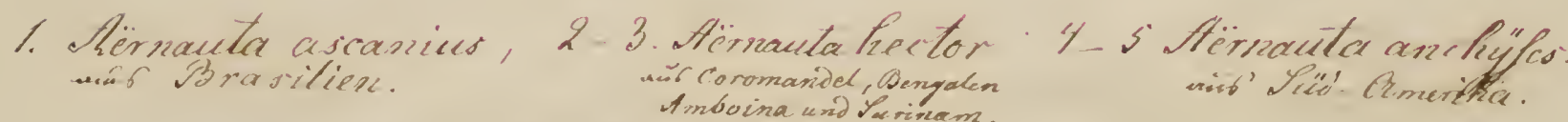



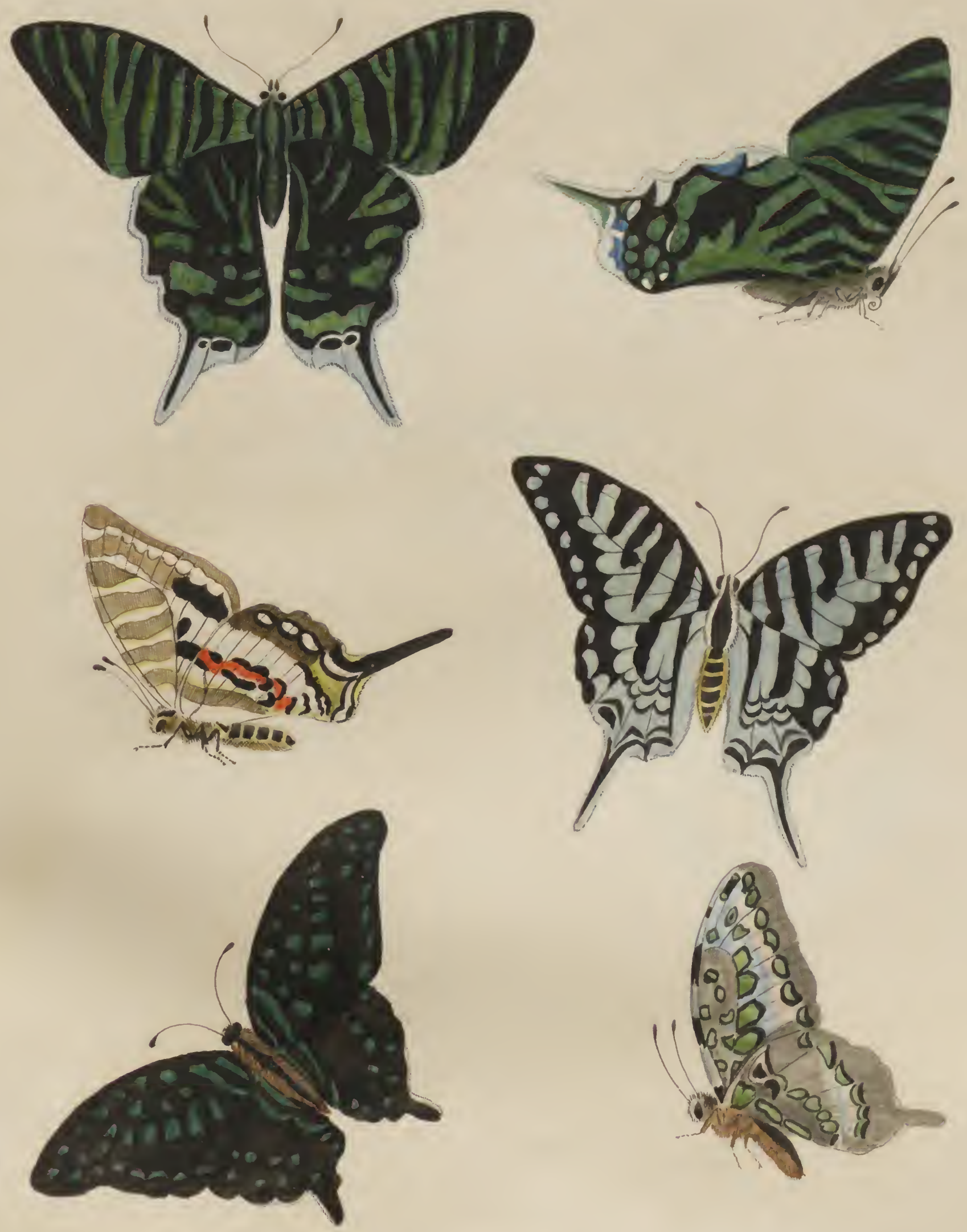

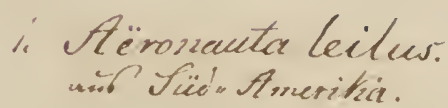

1. Aïronauta nominus. unio Amoritice.
3. Aërencuitur agamesunen. uséb. Asicus. 

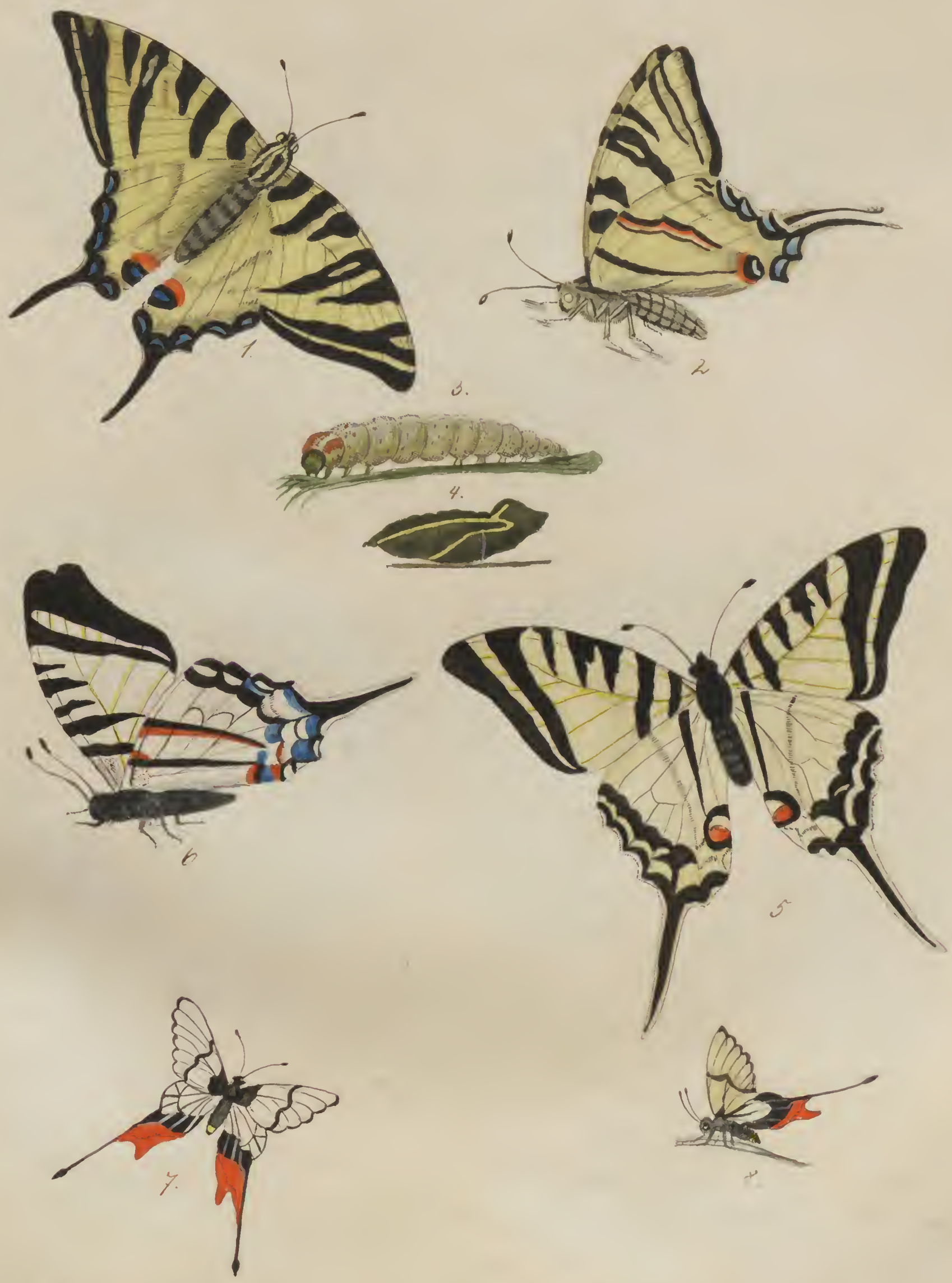

1. etëruinuetir podalivius.

Desiers varve.

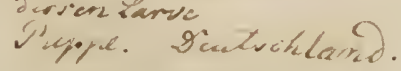

5-6 Aïronastex ponté silaws. won S Seree

y-8 Aïromaile thorineus mis ferinant. 
54.

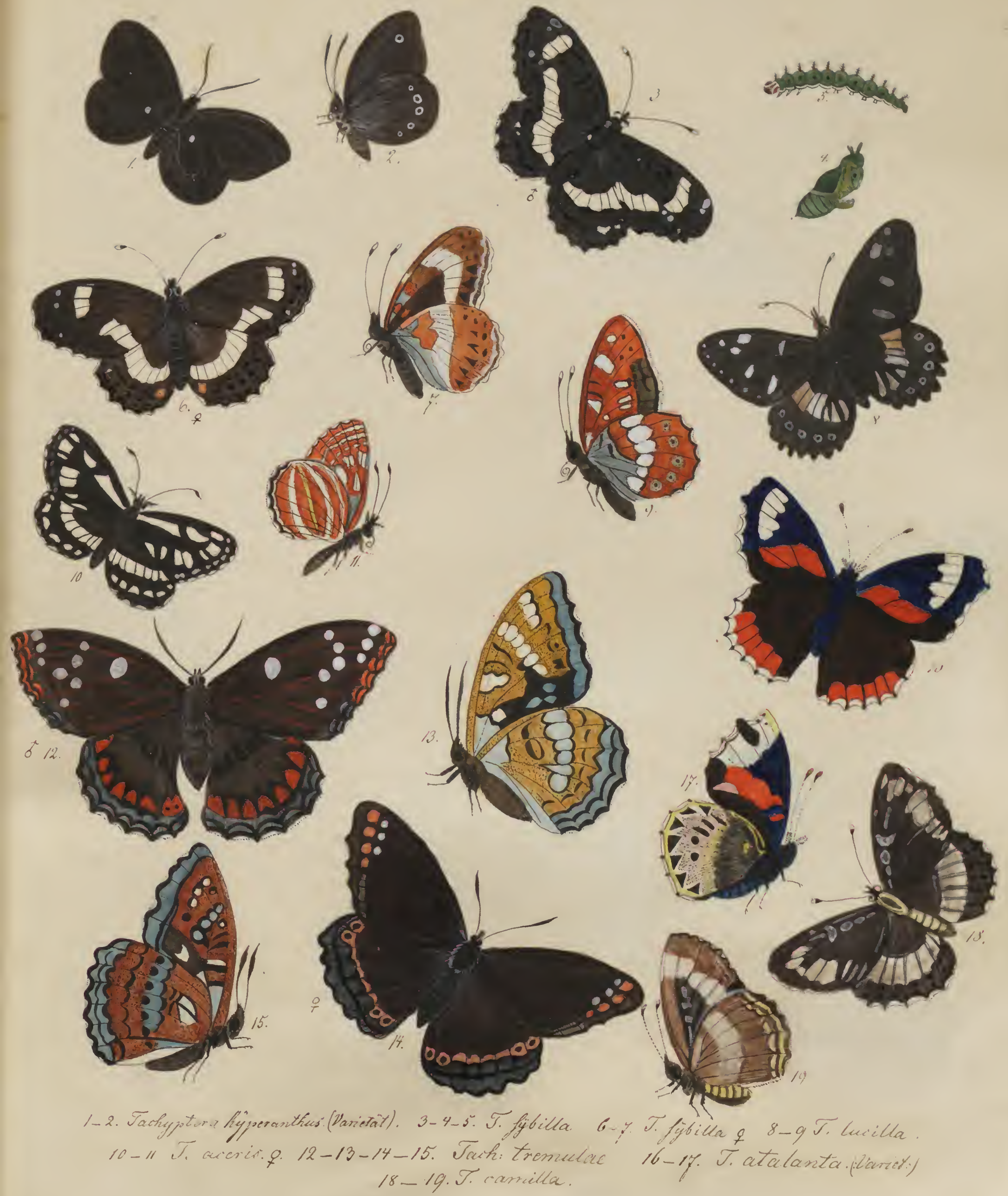


55.
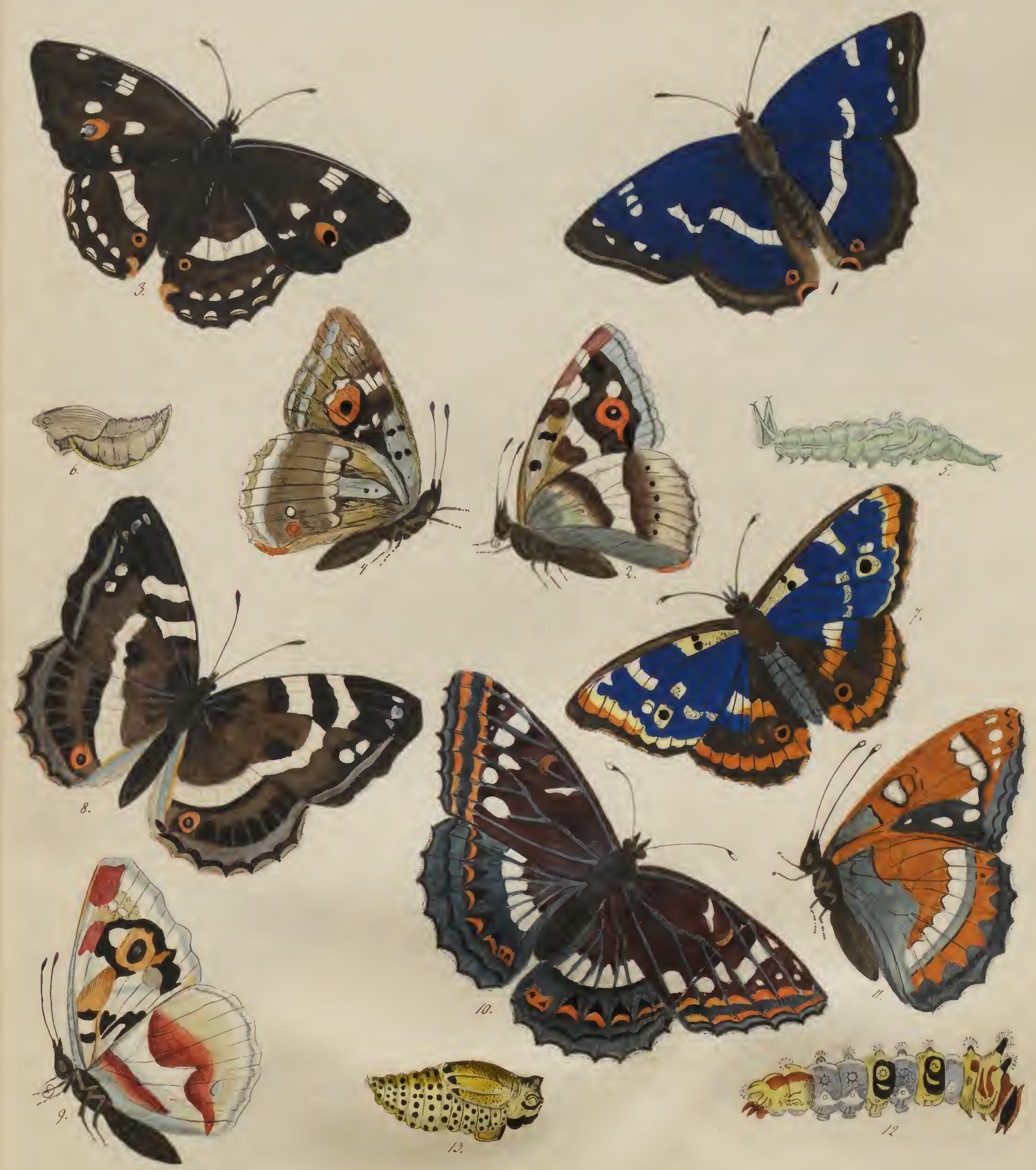

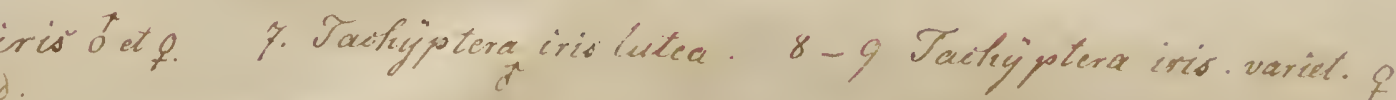




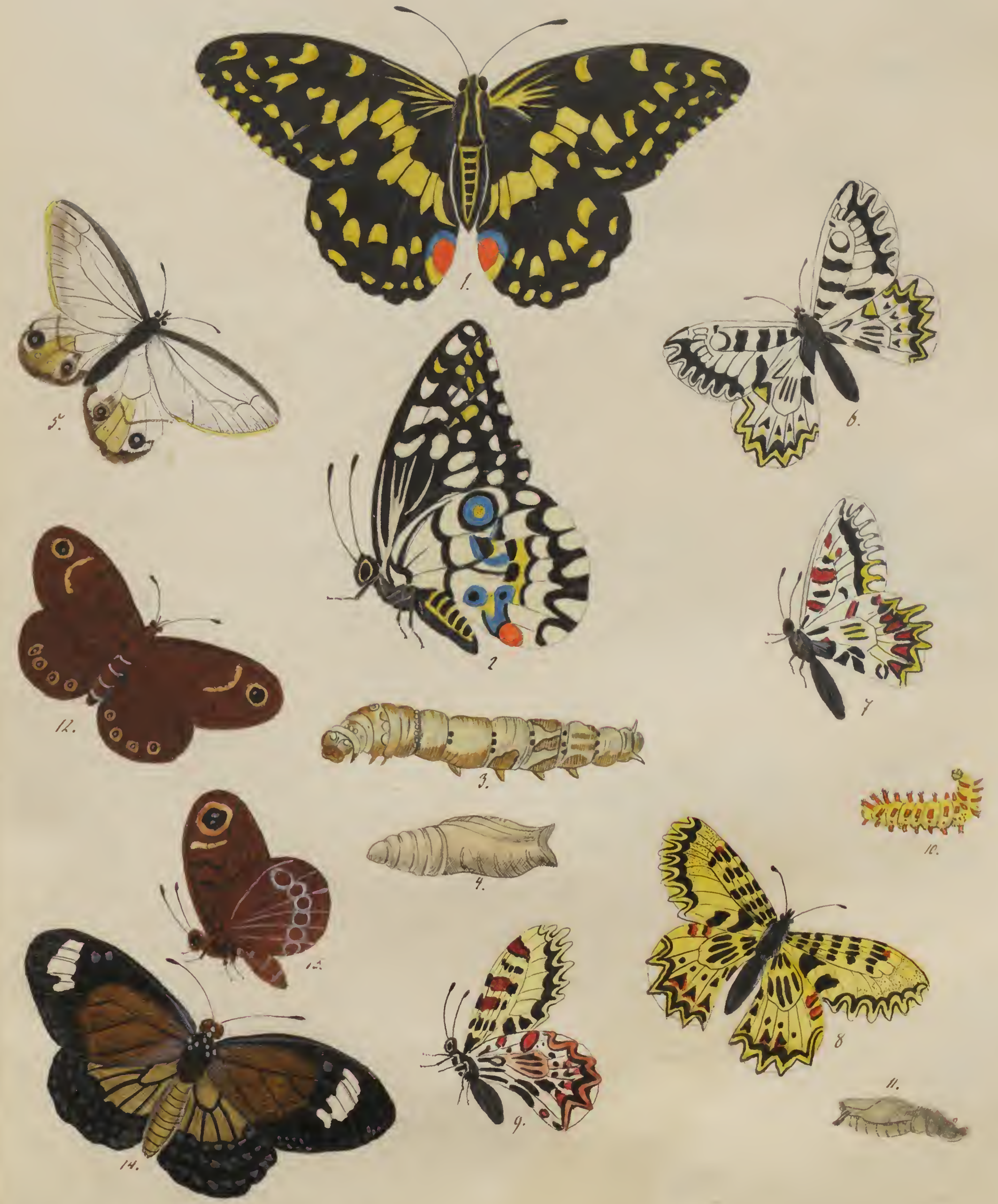

1.4. Fourajotera denwoleur.

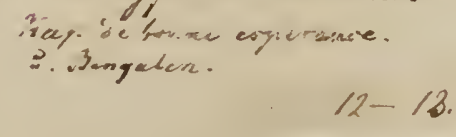
12- 13. Tactriptera Tytus. 14. Jack: plescipopus 

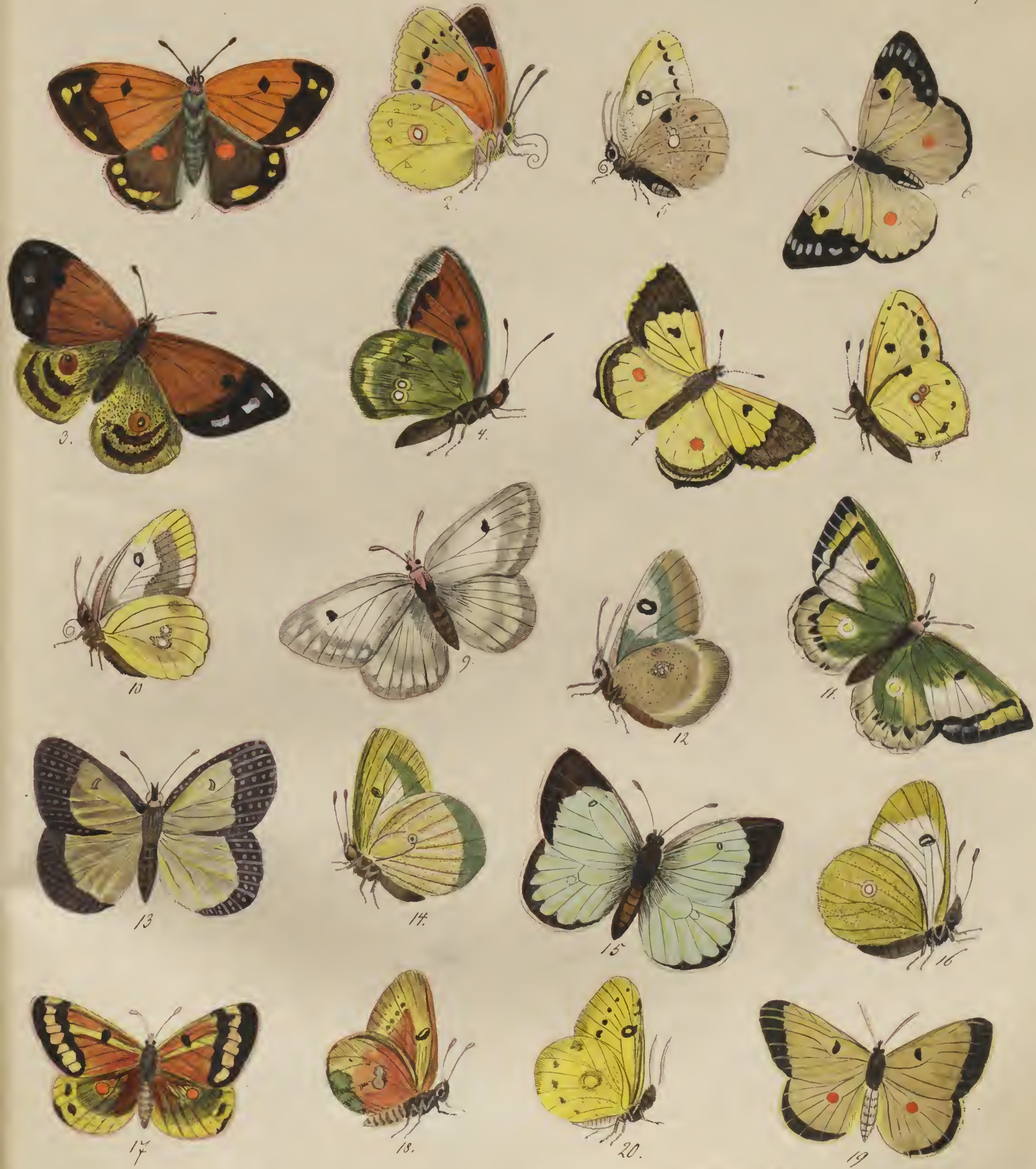

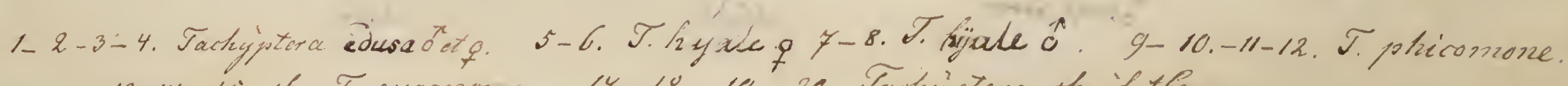

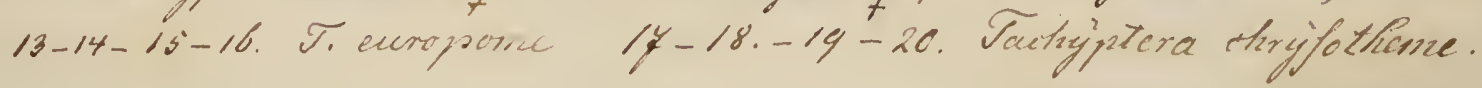



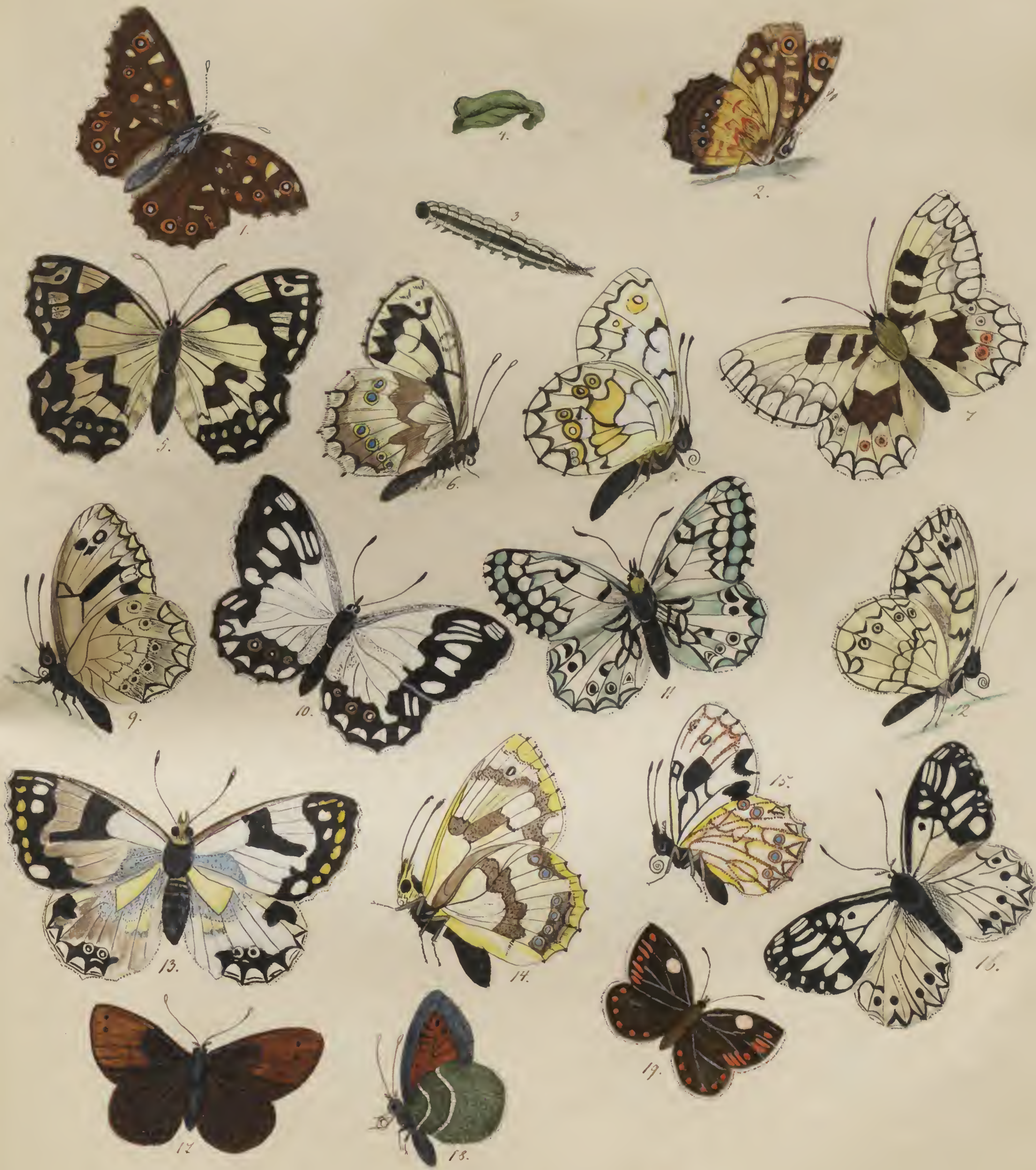

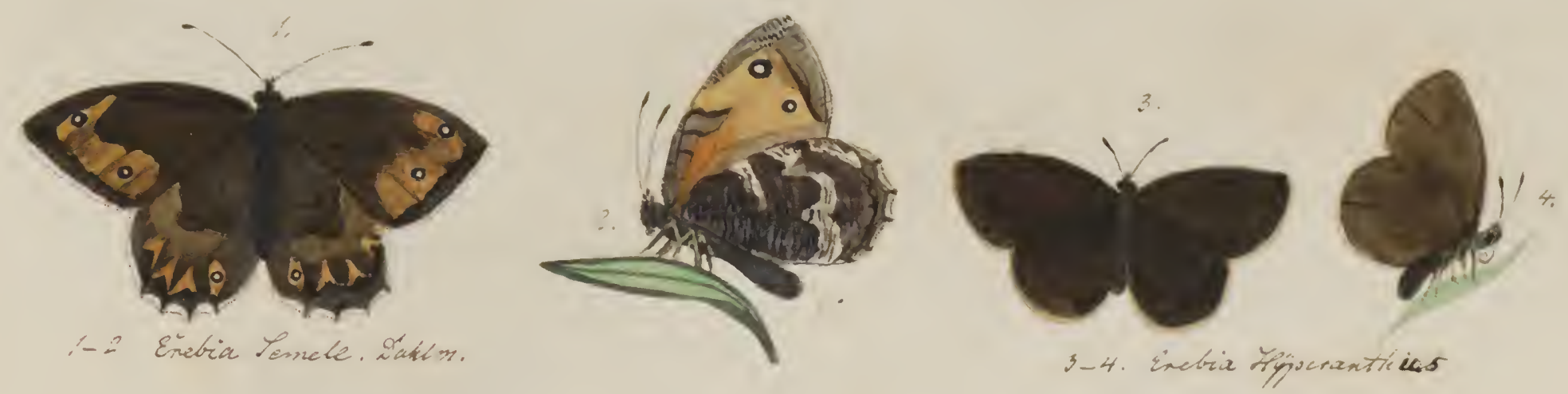

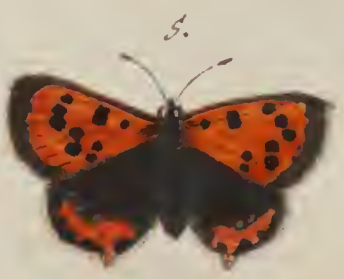

s-6 Aephizrur Mrlacar.
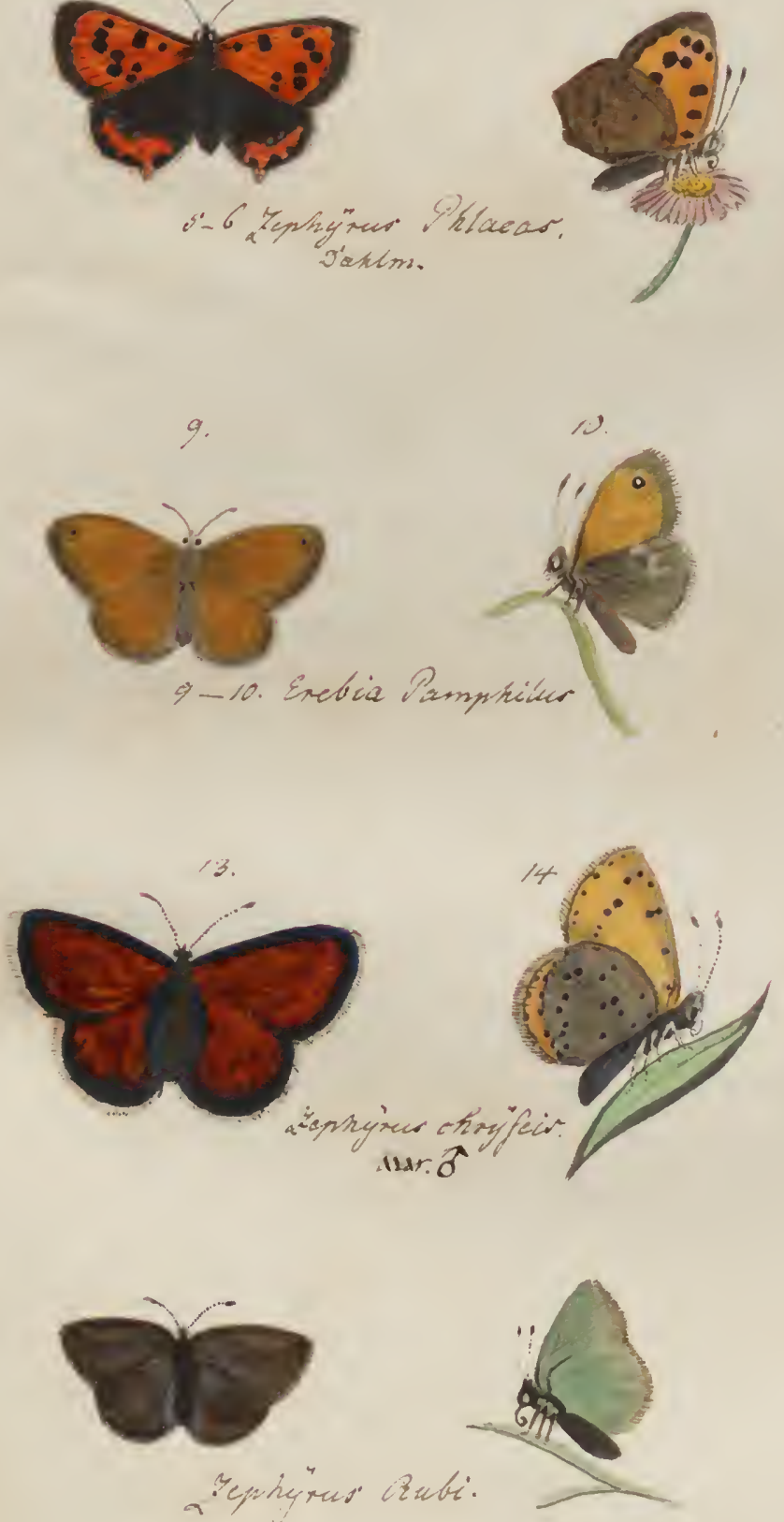

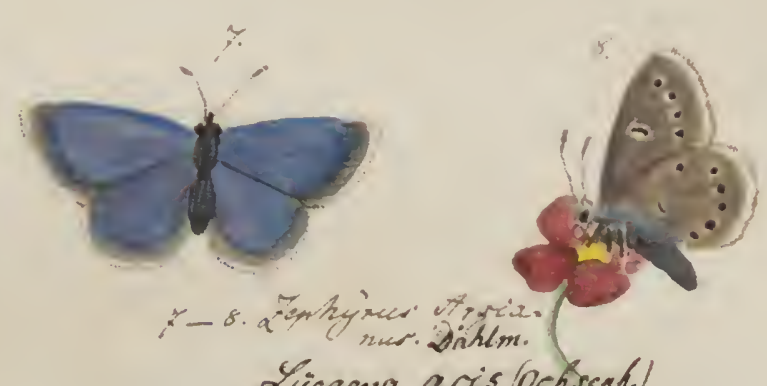

Lysrama acislochosent.।

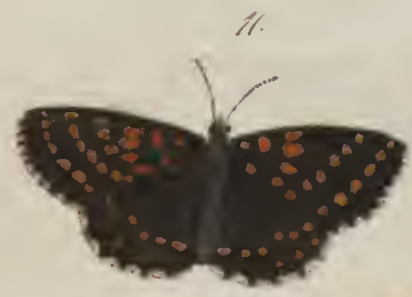

\#-12 7nelitaex

ontirnir:
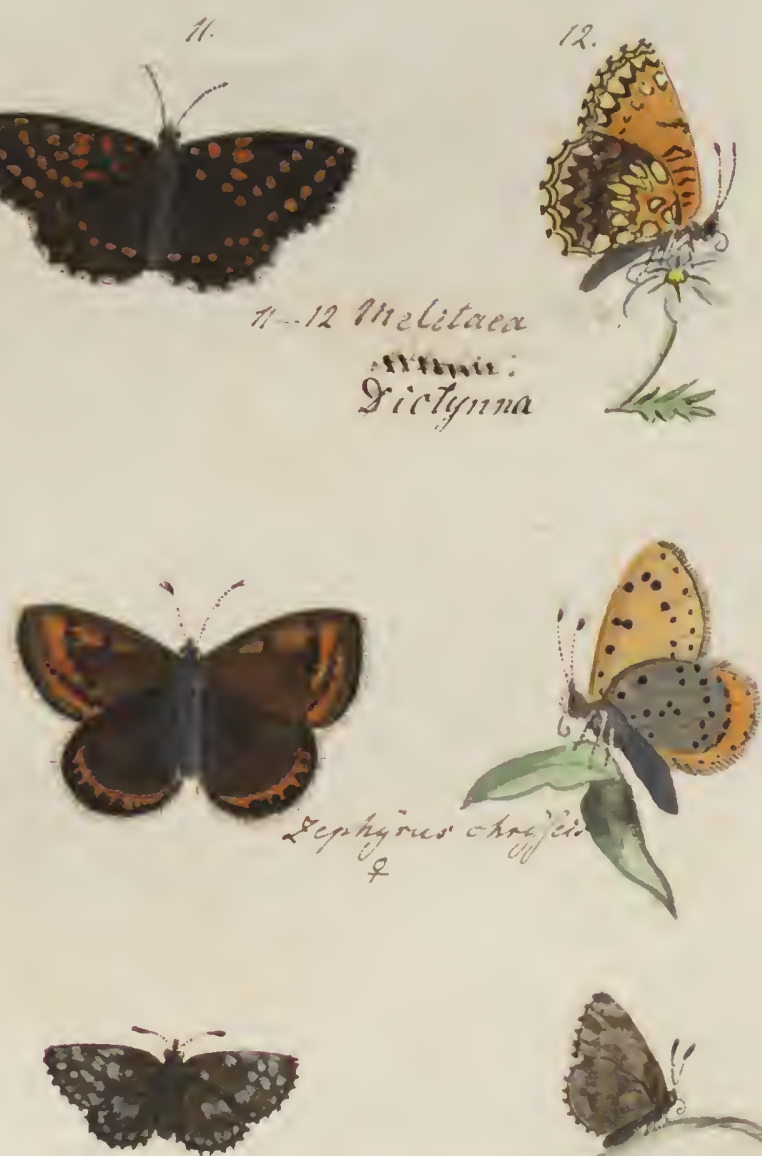

(Yijrichitus Mial vae. Walleng.) 


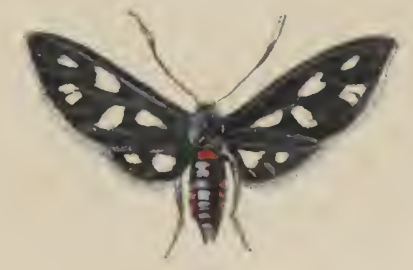

2
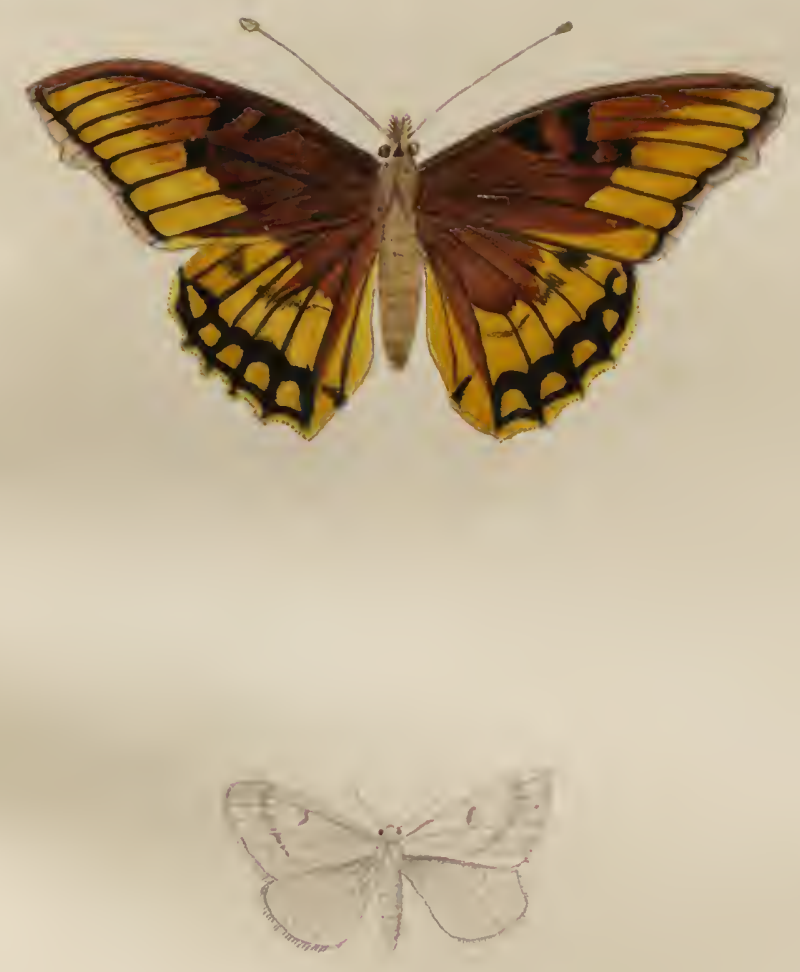

l.

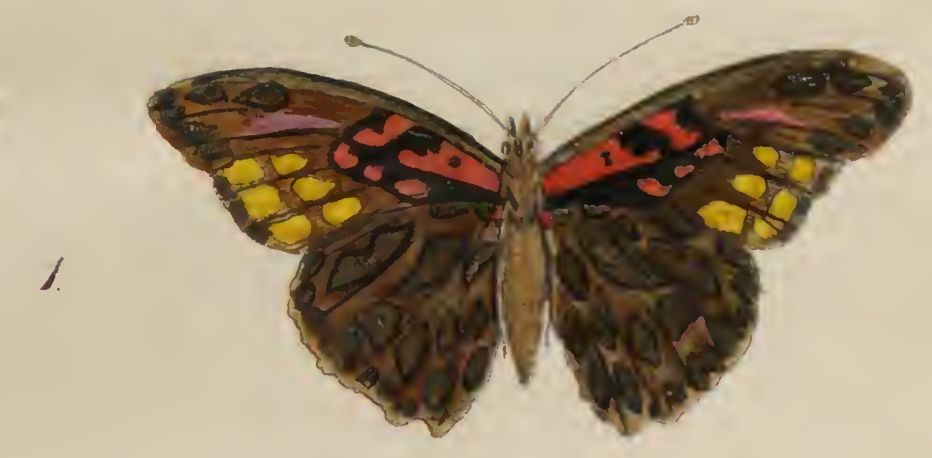

4.
3.
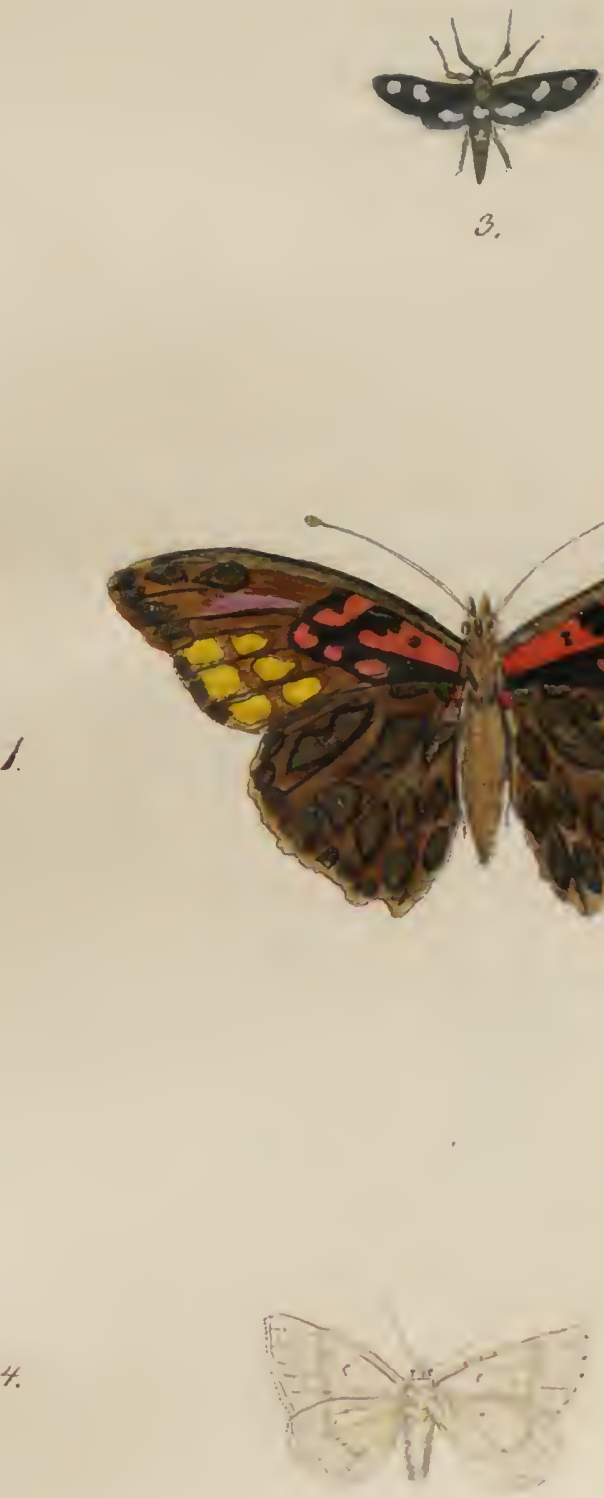

1. Argynuios moneter. Geyer

du mexique.

2. Syntornis Yckulweinie. Ifpetore

Caps de iborme Engéranee.
3. Dessria morculalis. Lertisood.
ae l'Anmérique au ctos.
hreva seotiay
4., Midonia rpobiarice. Lefebure lial di rato, en Yirile.



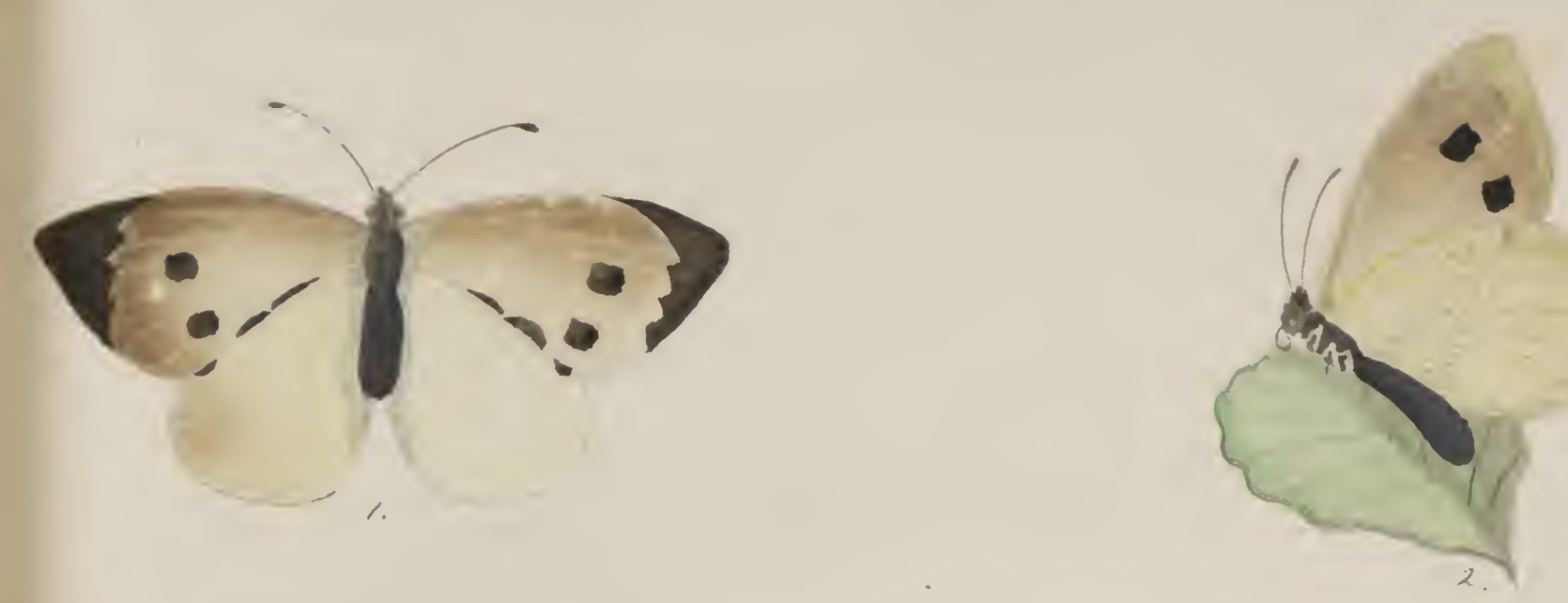

61.
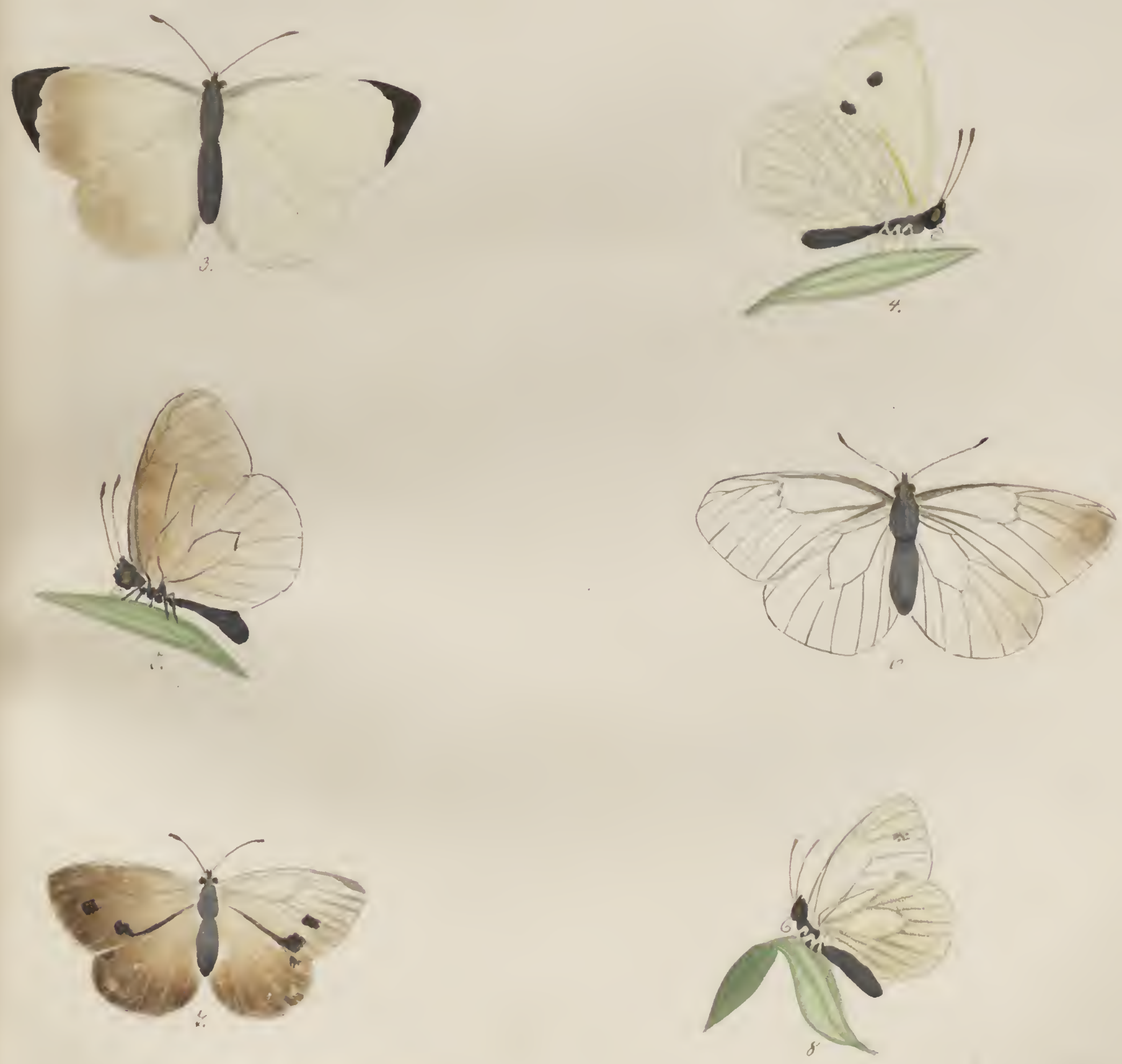

$$
\begin{aligned}
& \text { I-A. Ganoris Brasicae, Dakem. }
\end{aligned}
$$

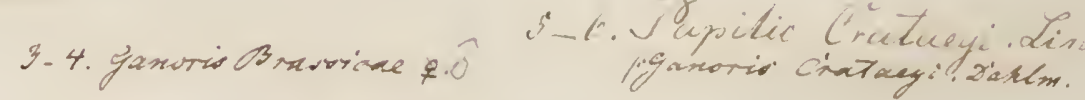

$$
\begin{aligned}
& \text { 7-8. Gonoris Chapi: Garkm. }
\end{aligned}
$$



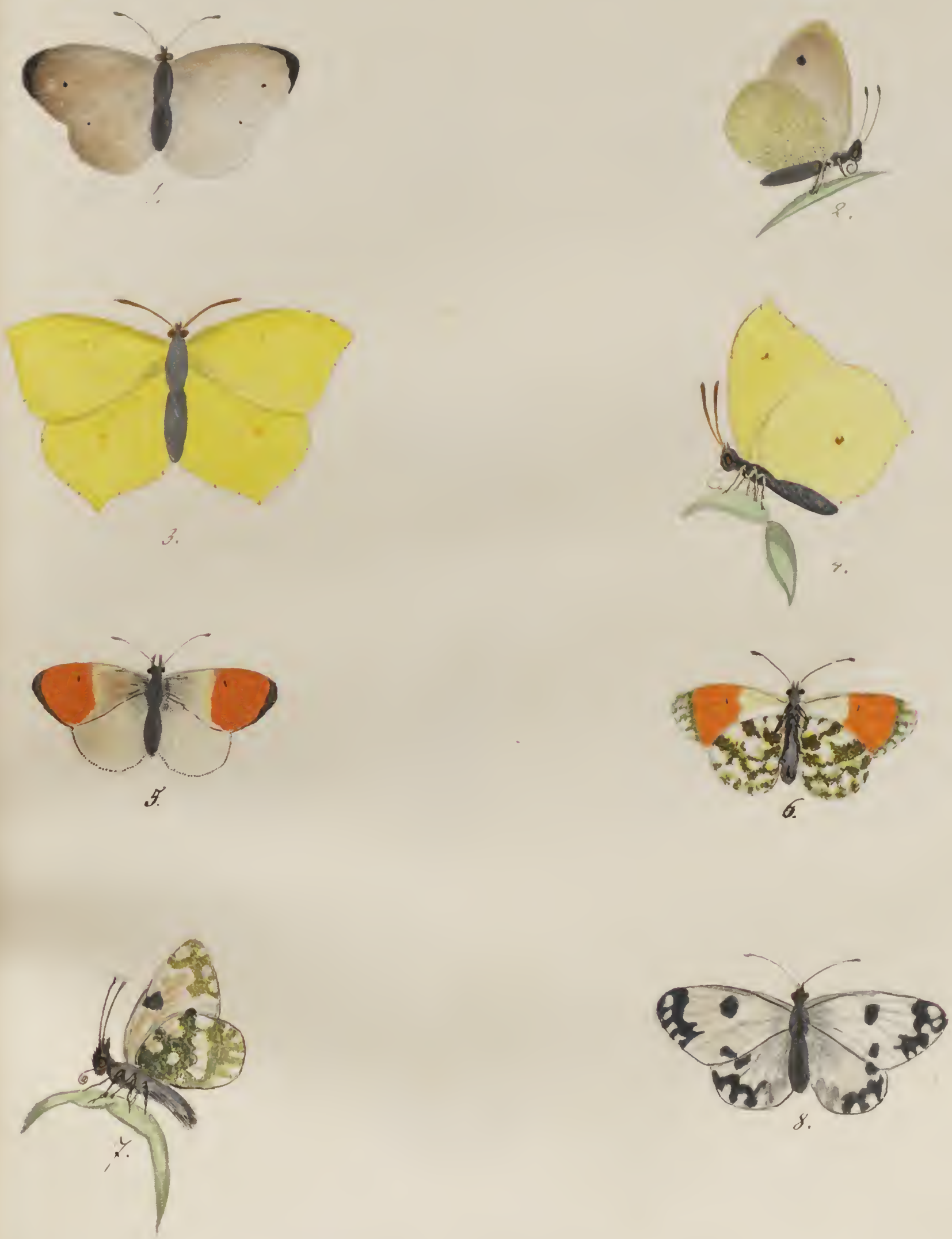

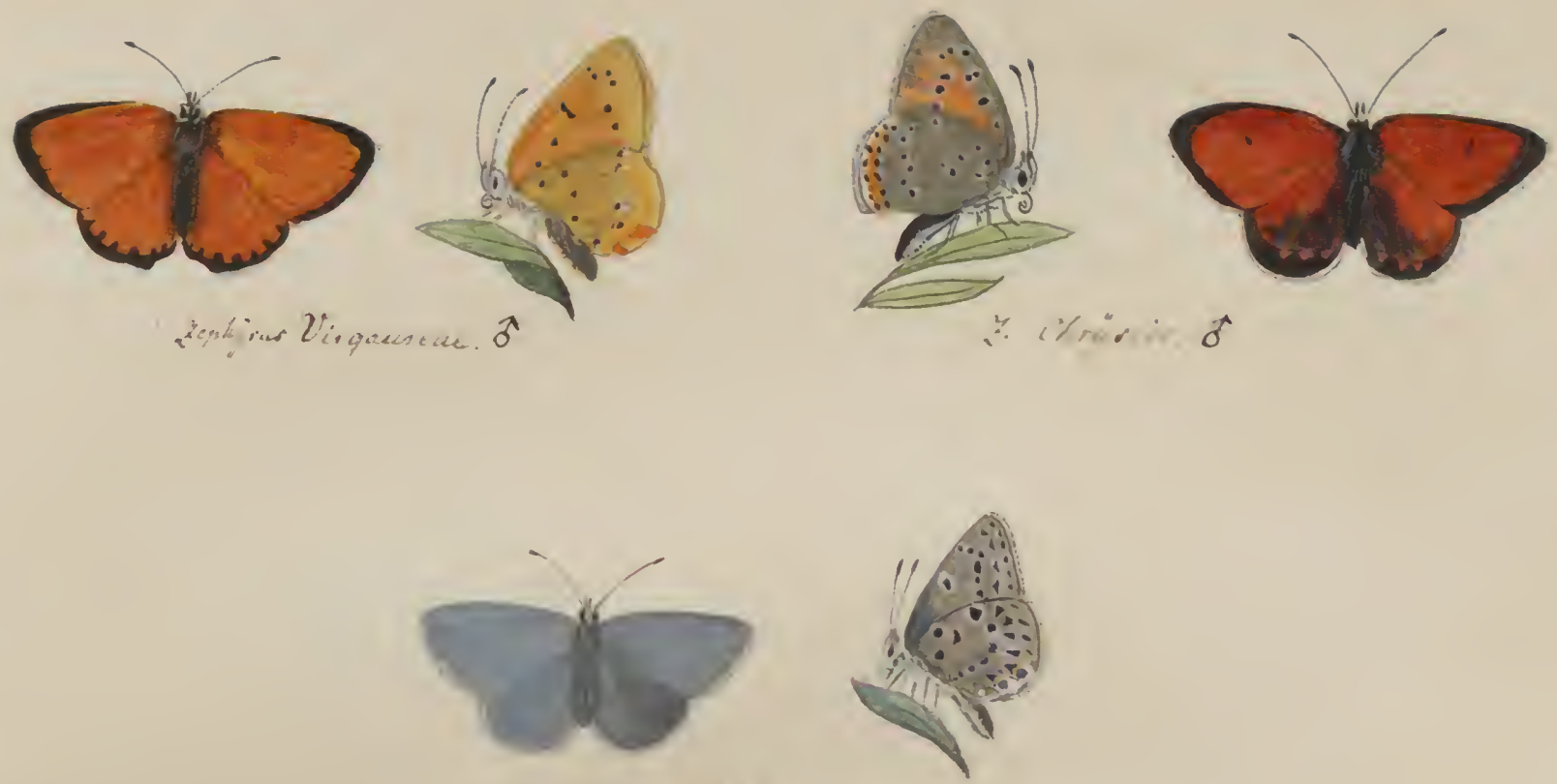

z. uptivite
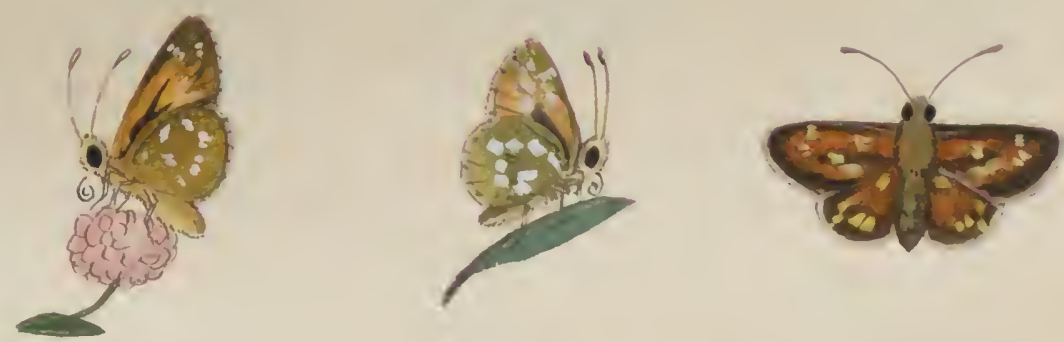

Whoperis cosumx Var

年. consuse fo
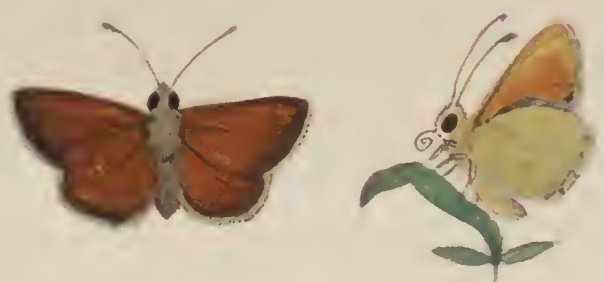

3. Lineula 

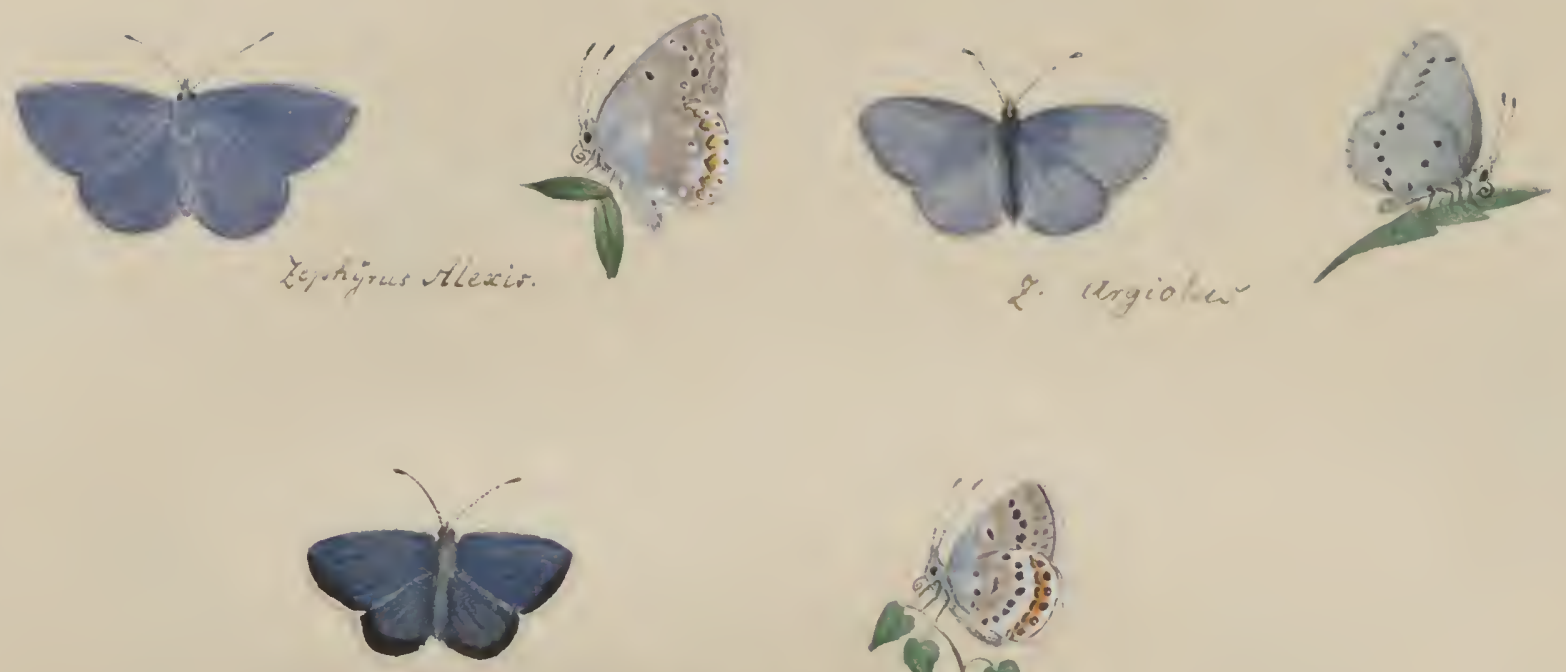

2. Rentes. T.Xinn

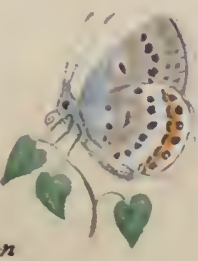

(2ÿraena aegonz. Ruet:!
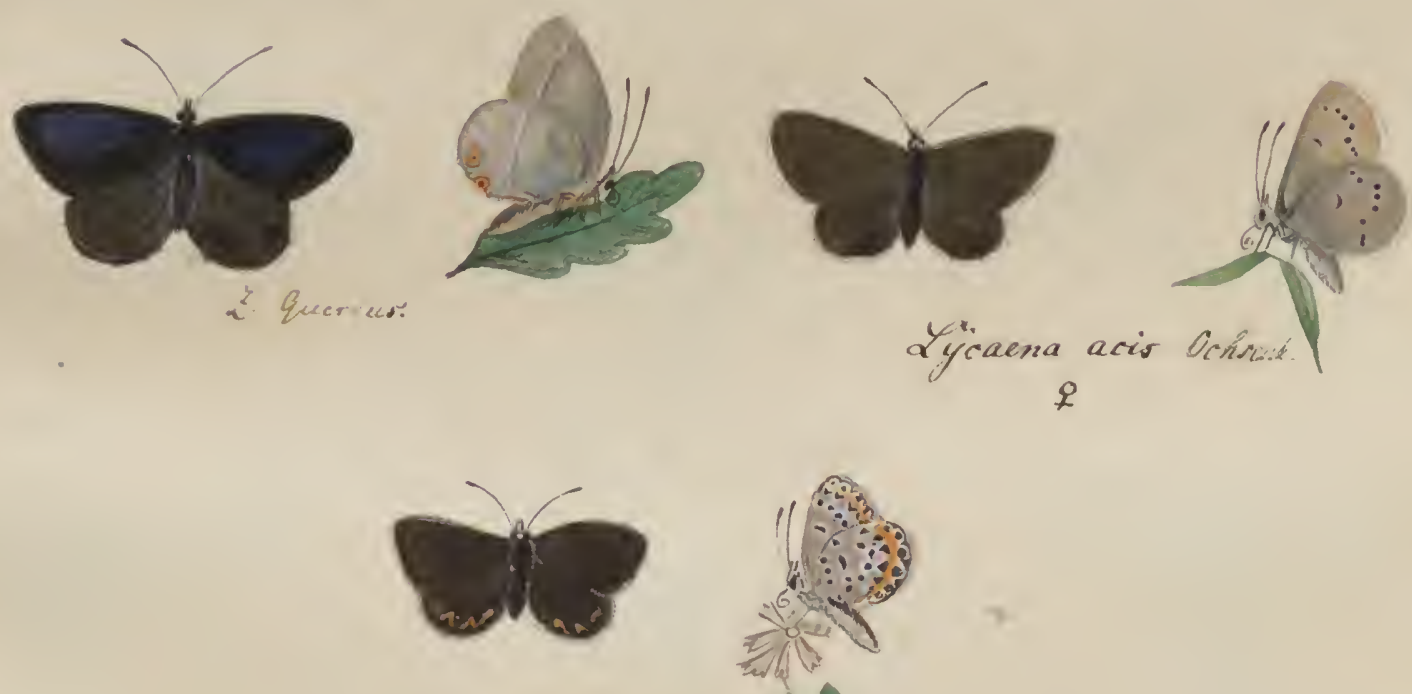

2. aryos
2. acgont?
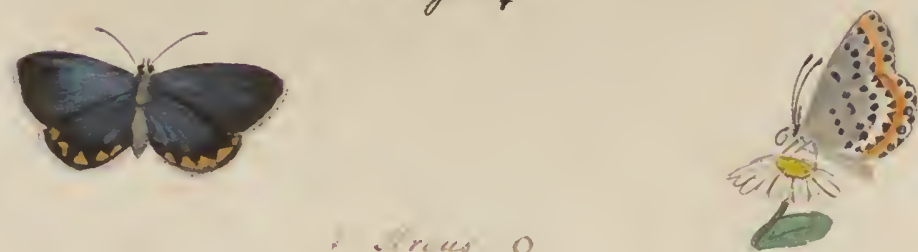

argon.

Yyicaena
?

$q$ 


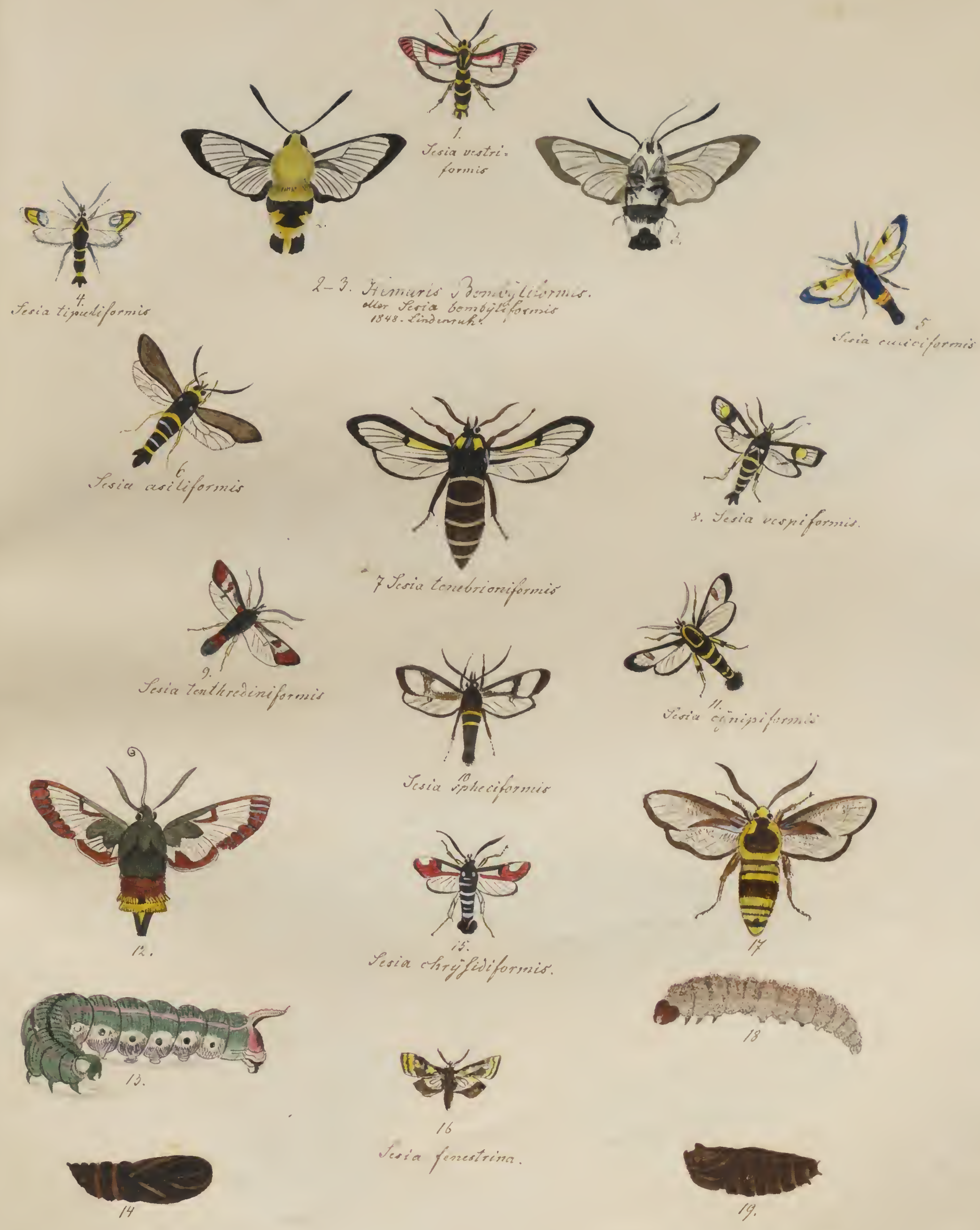

12-14. Tesia fuecifornis 


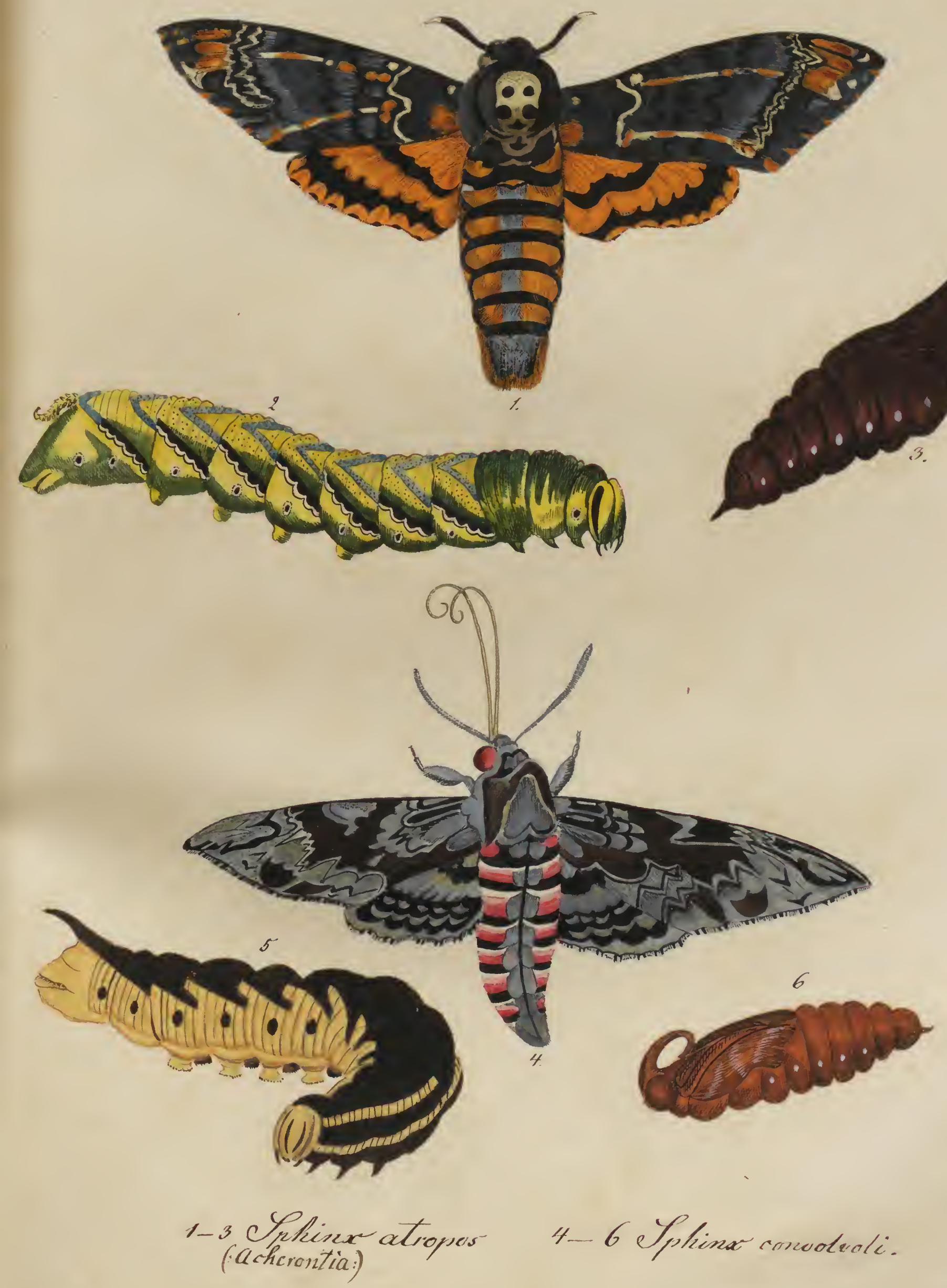



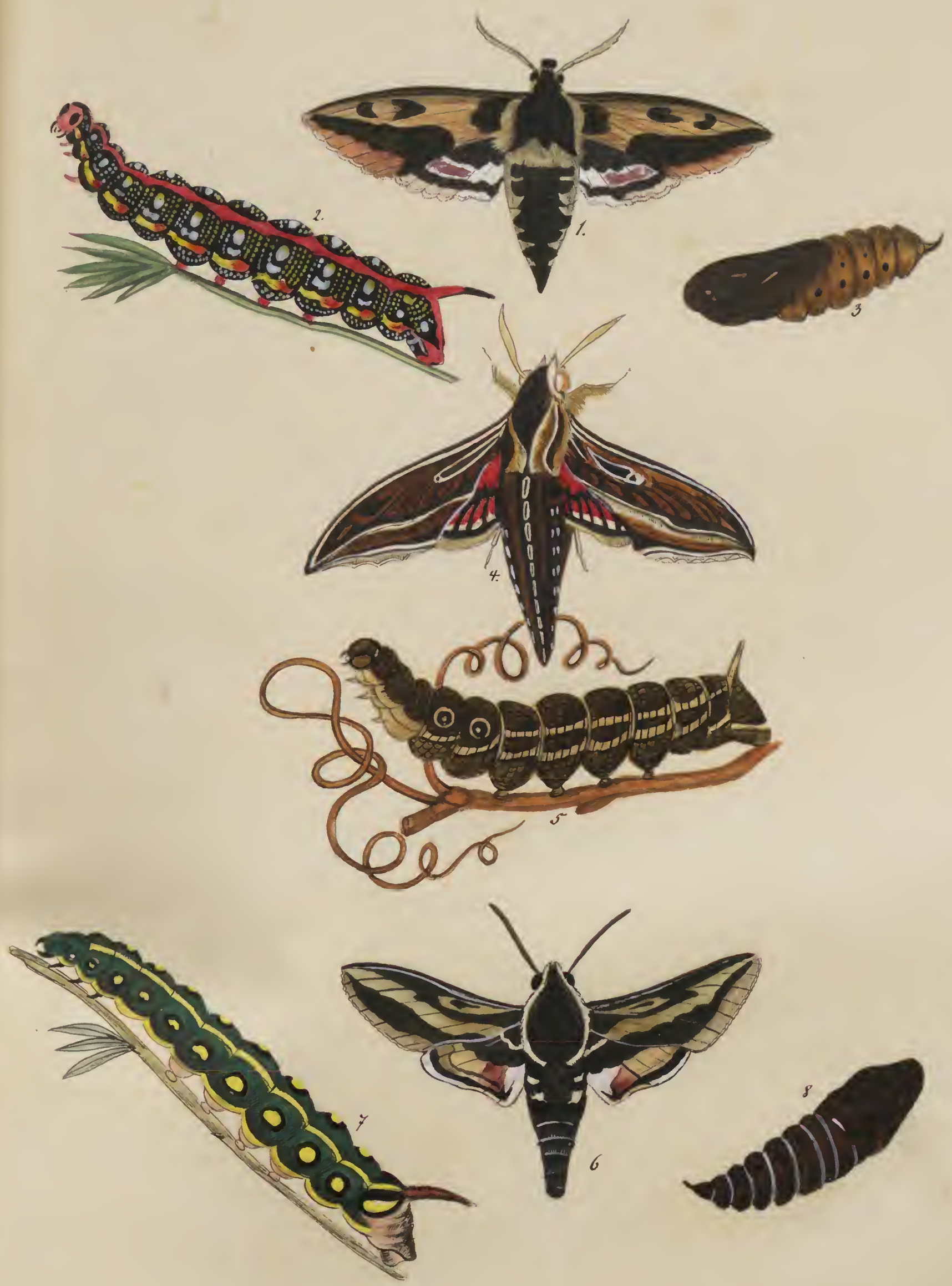

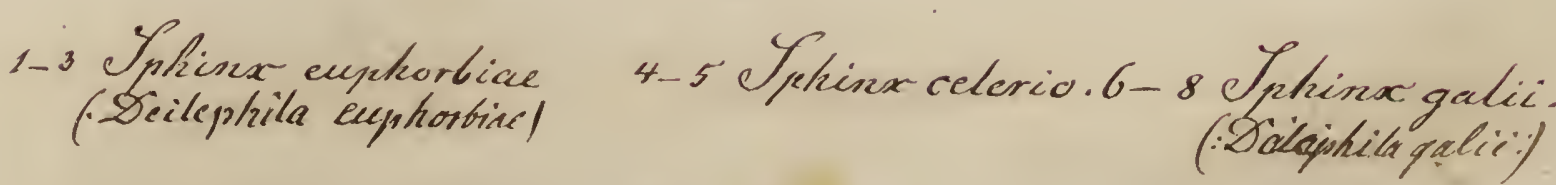




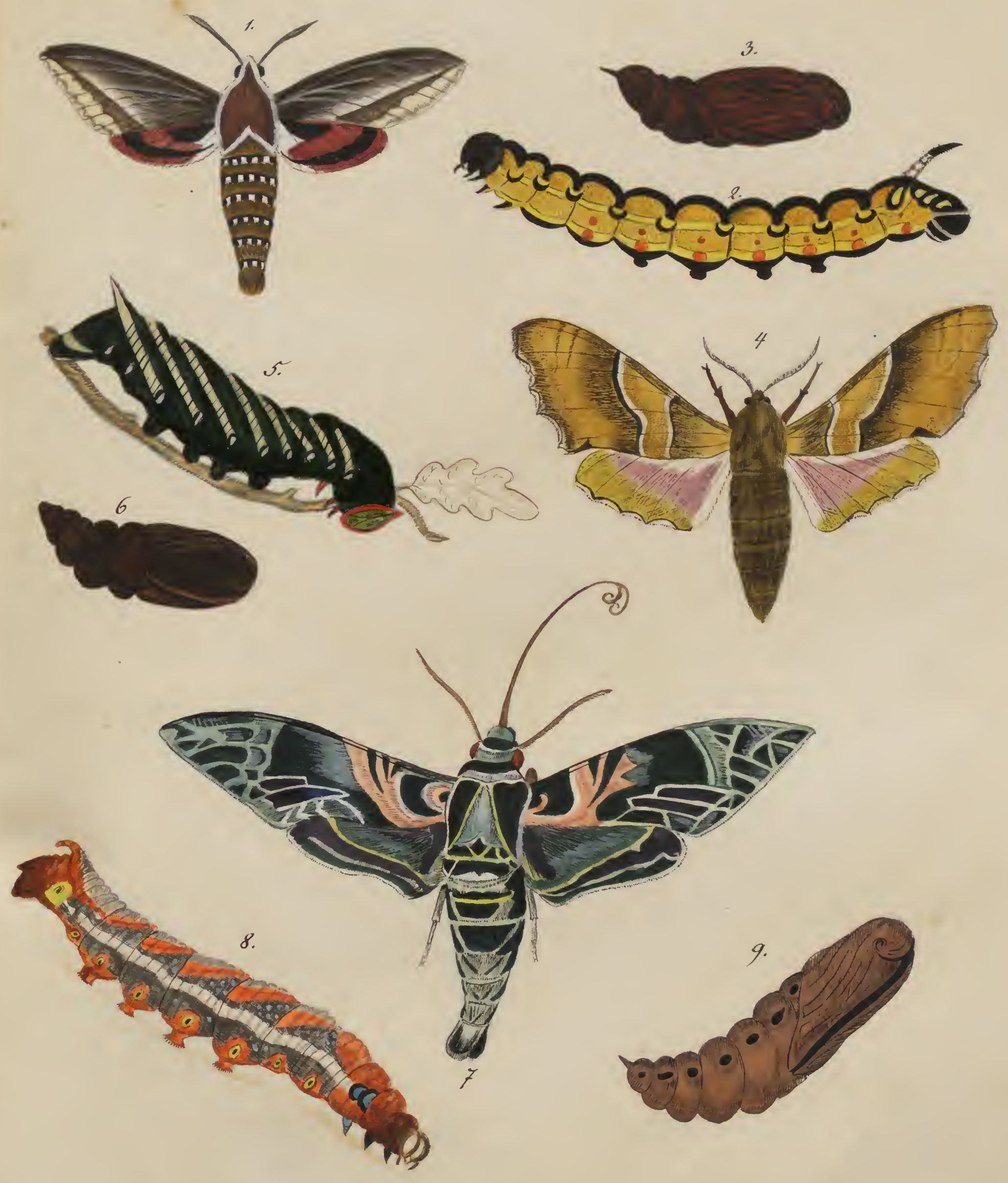

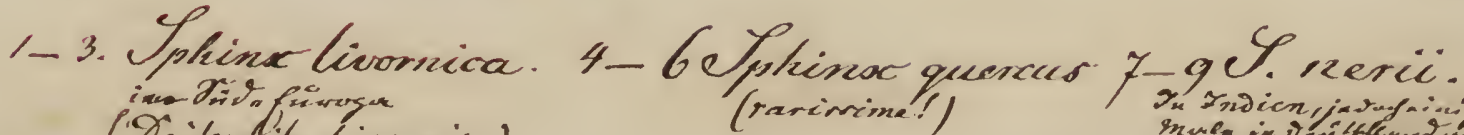

(Diliphtila livornica)

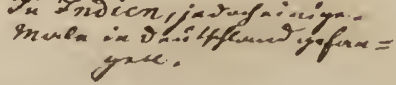




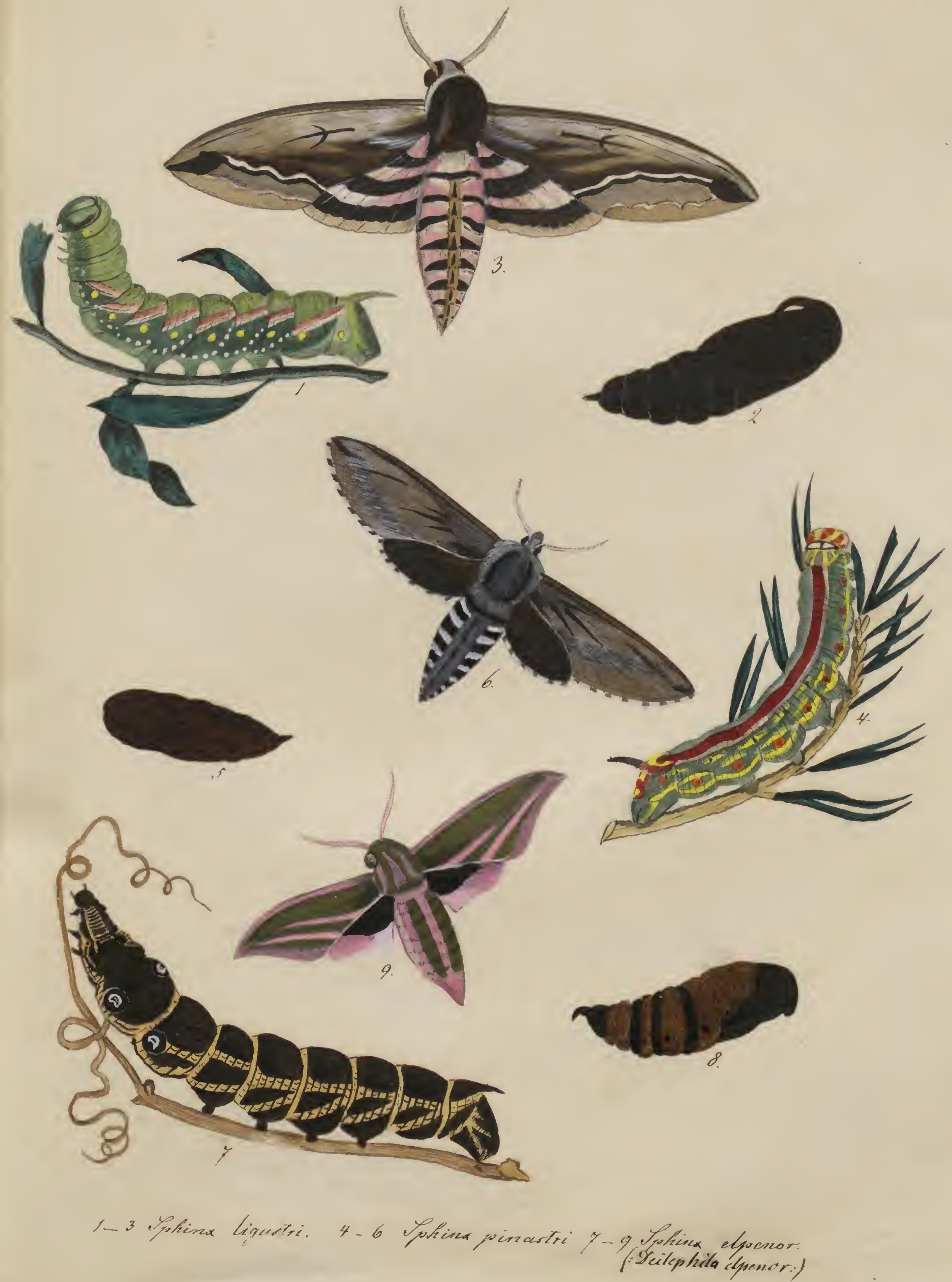



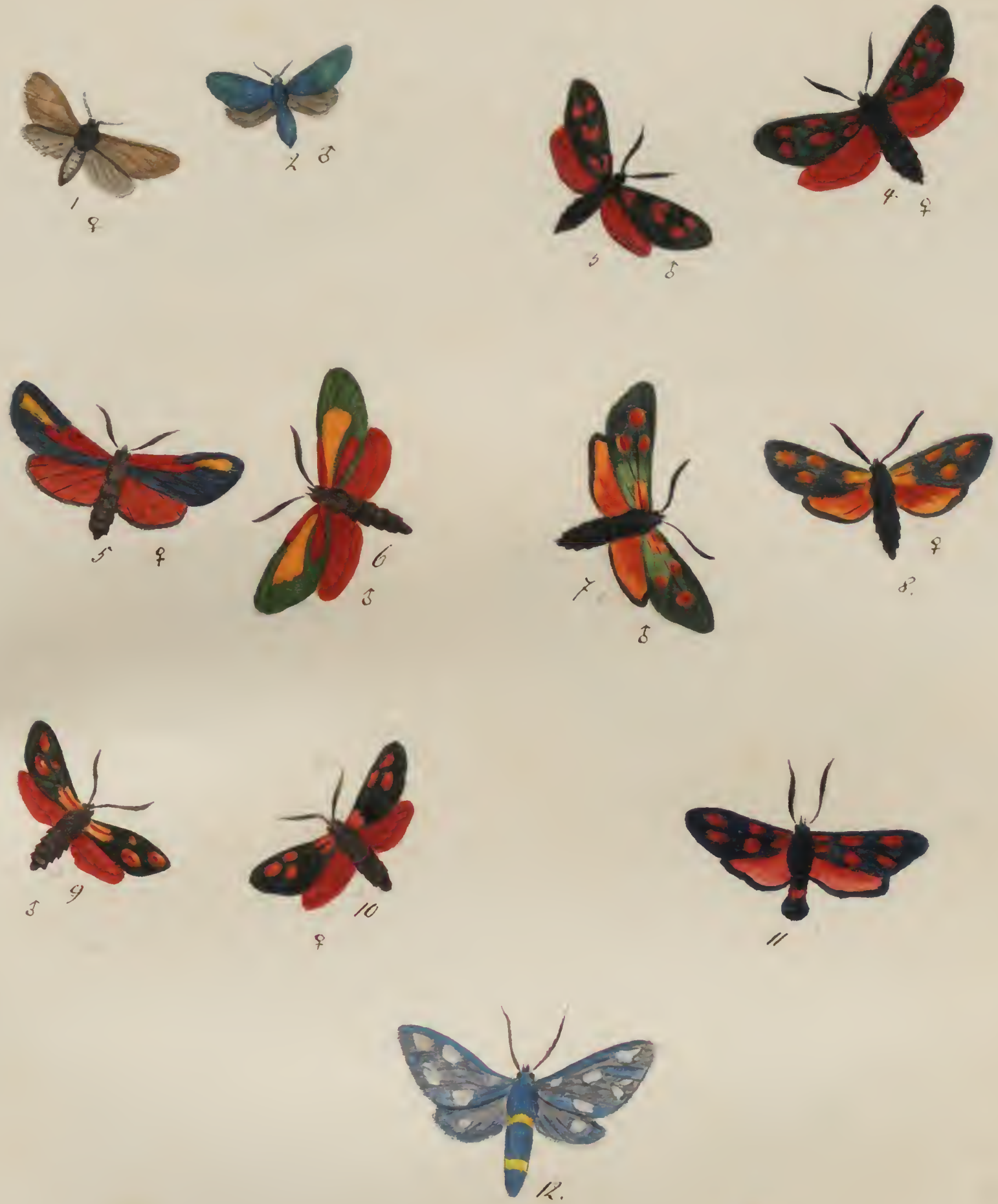

1-2. Zügassa pruni 3-4. iygaena, iligsenoulue.

5 - 6. 25- jilosellac y-8 $y^{2}$ - Conirorae.

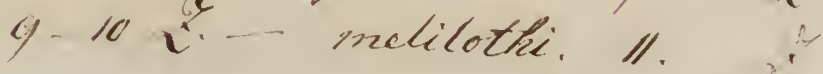
- seusebani. 12. Yyganara phegea. 

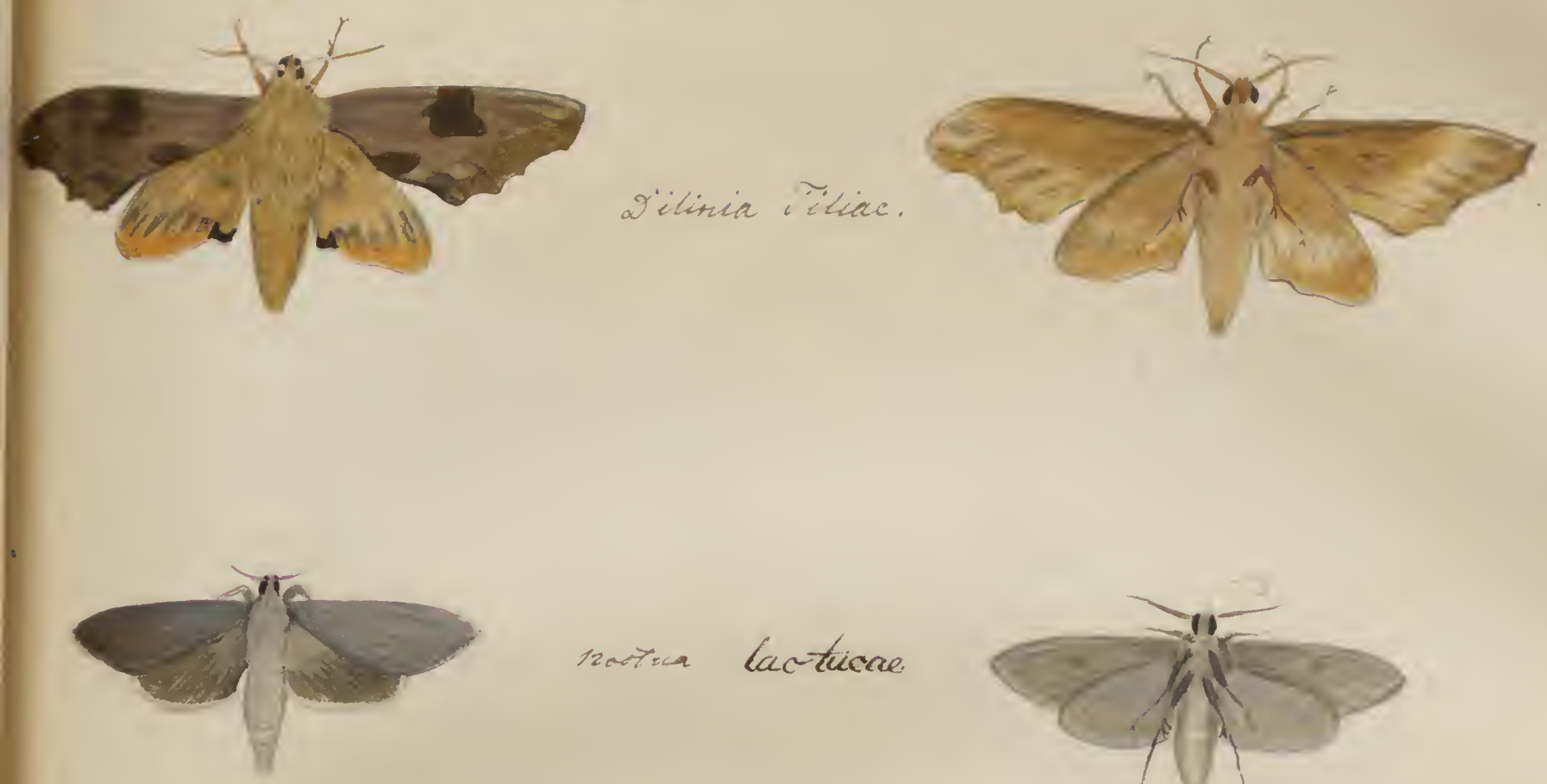

novisa lactucase
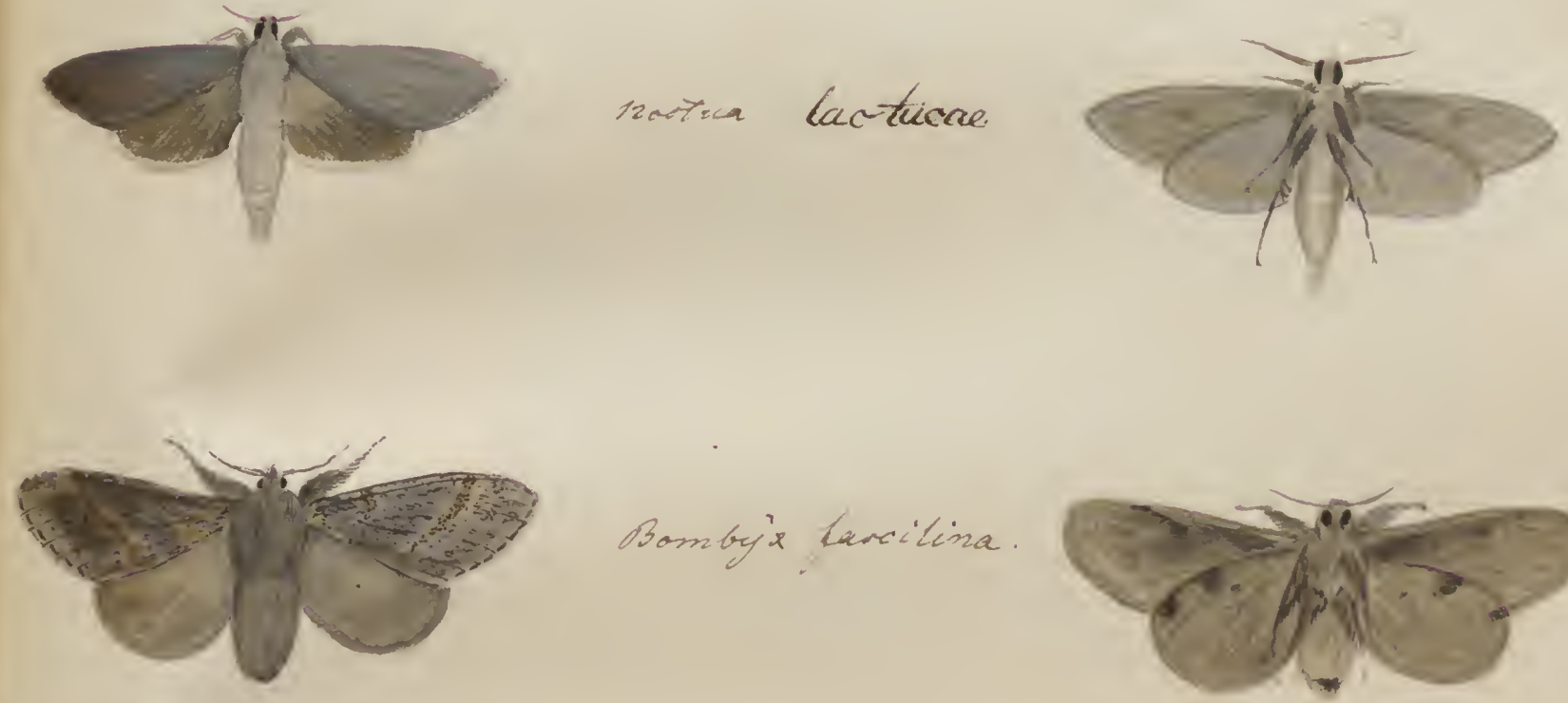

Bomby'x Larilina.
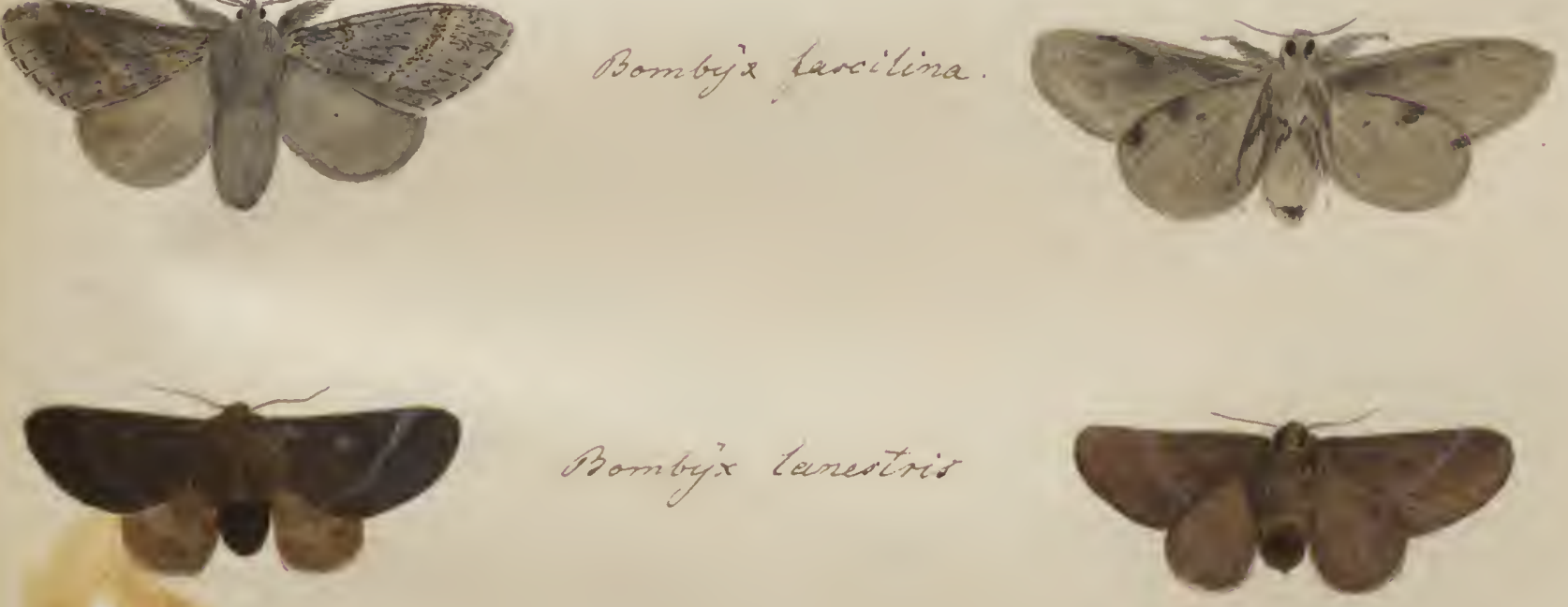

Bambyir lanestrio
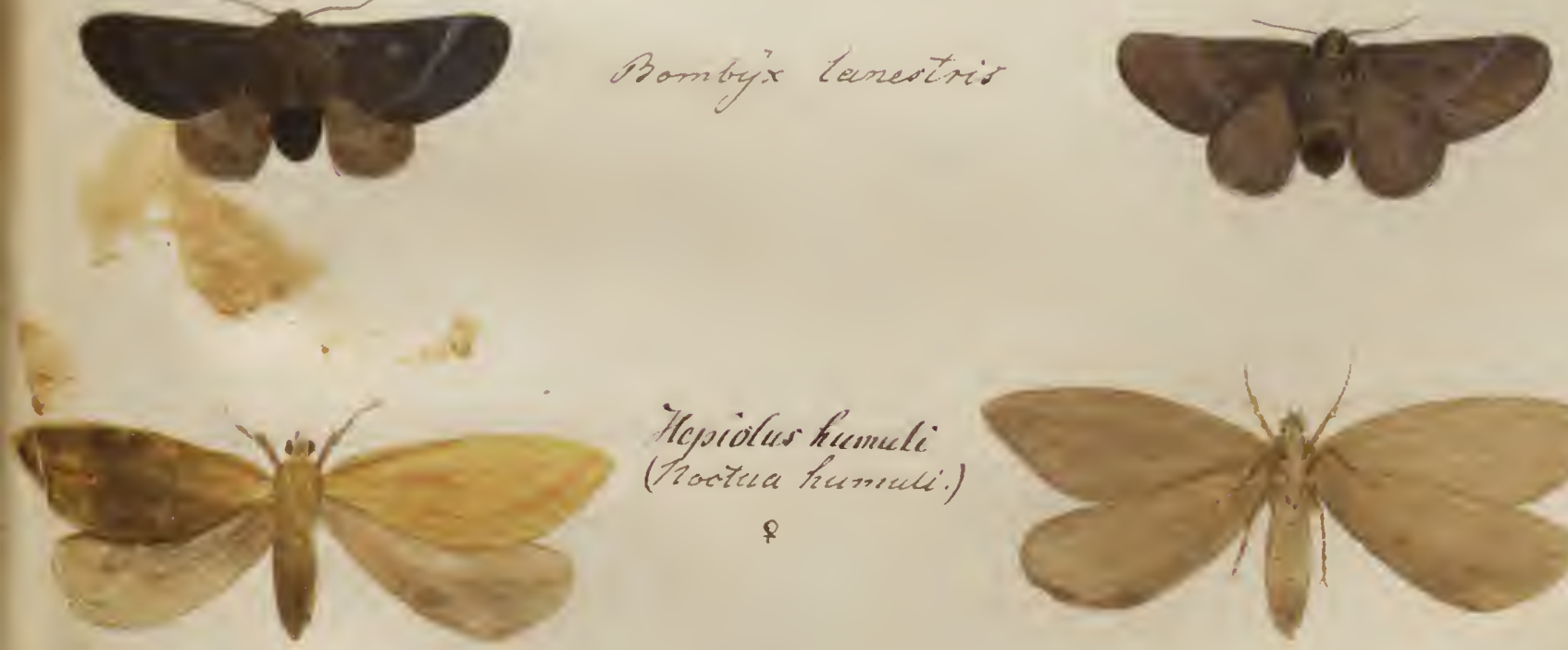

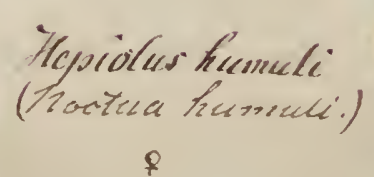

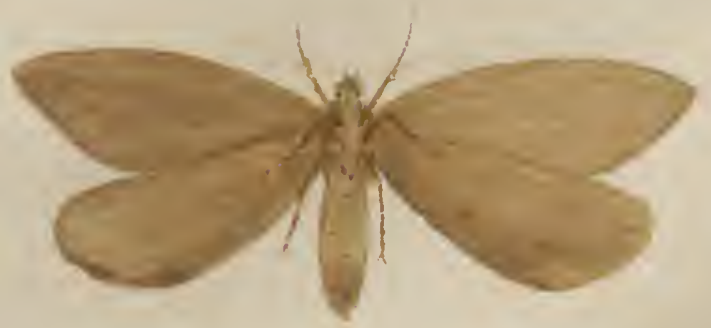



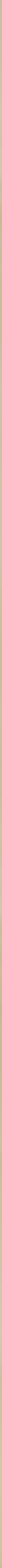


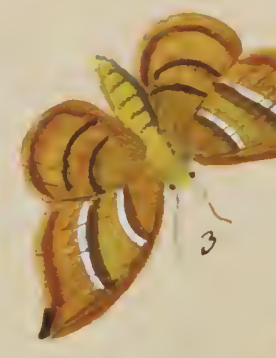

\section{ना1}
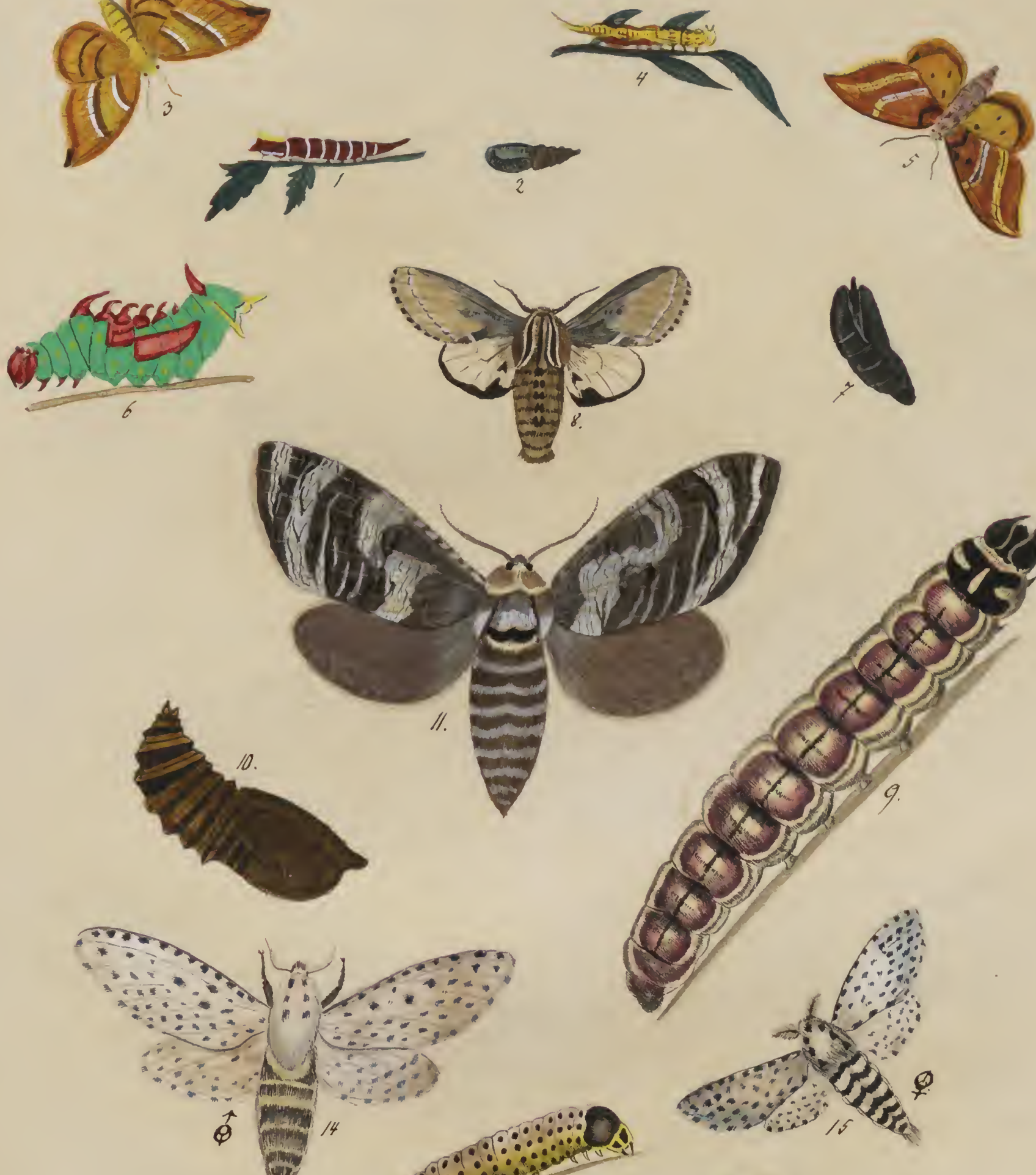

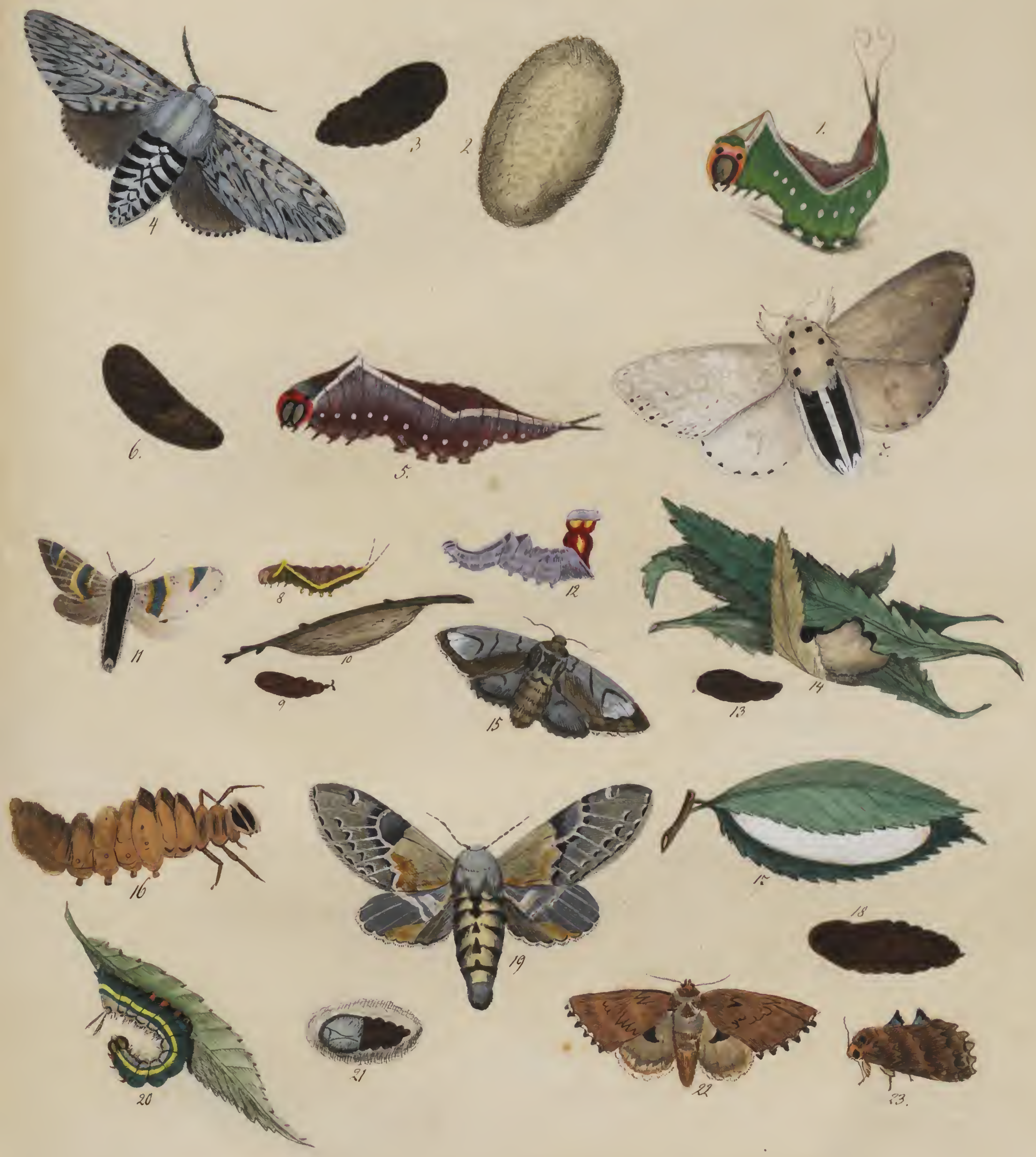

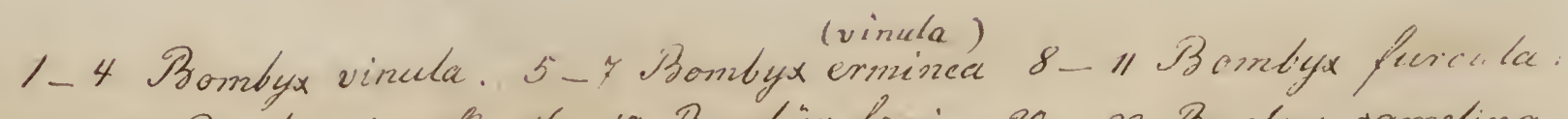

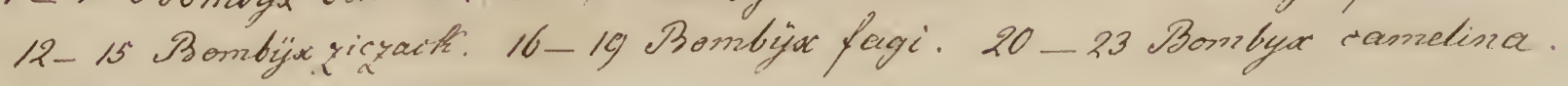



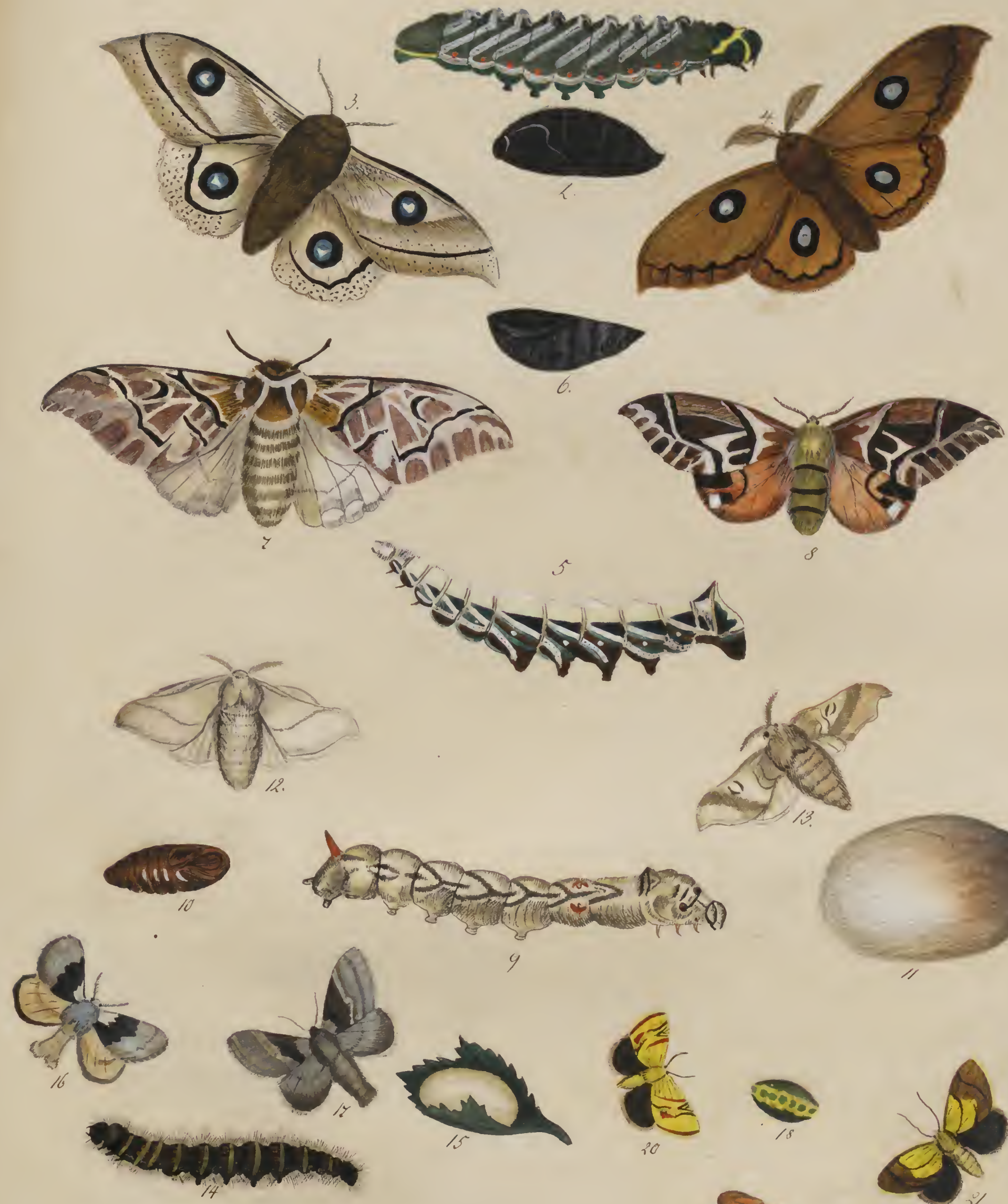

1-4 Bombya tau. 58. Bomblyx versicolor Q 13 "

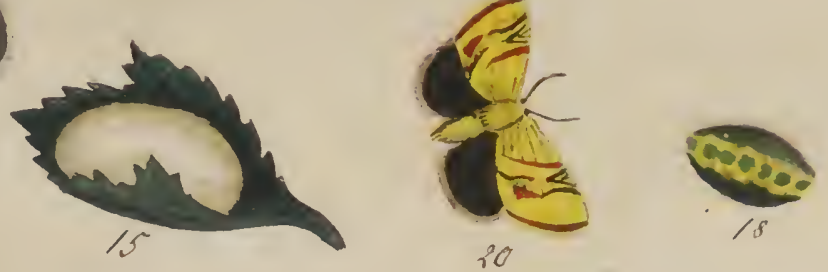

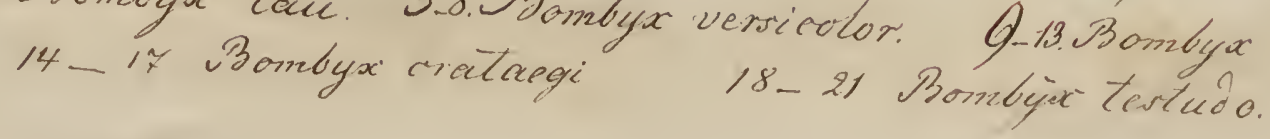




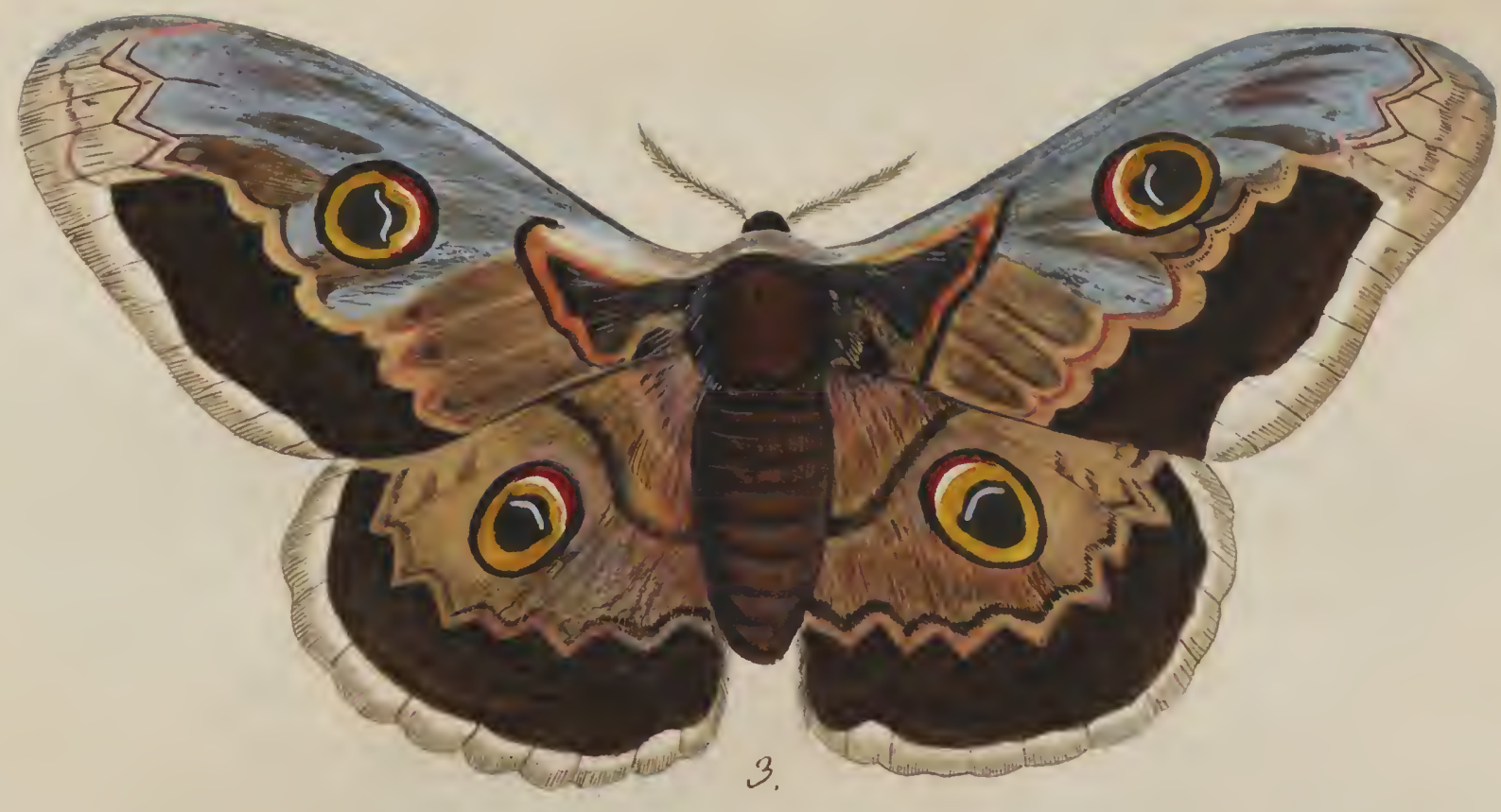

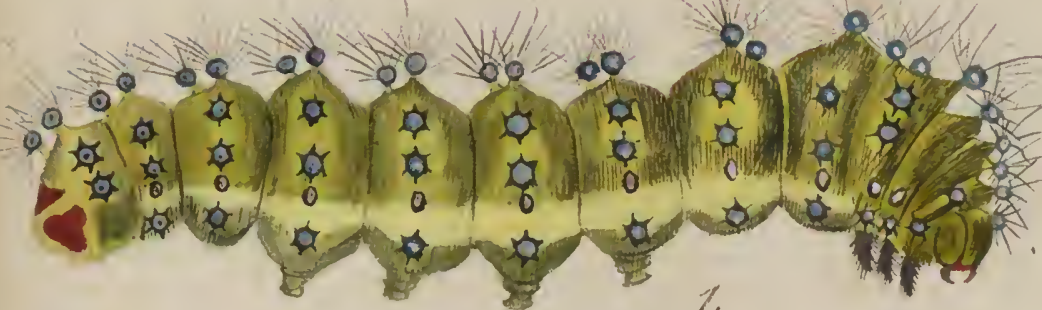
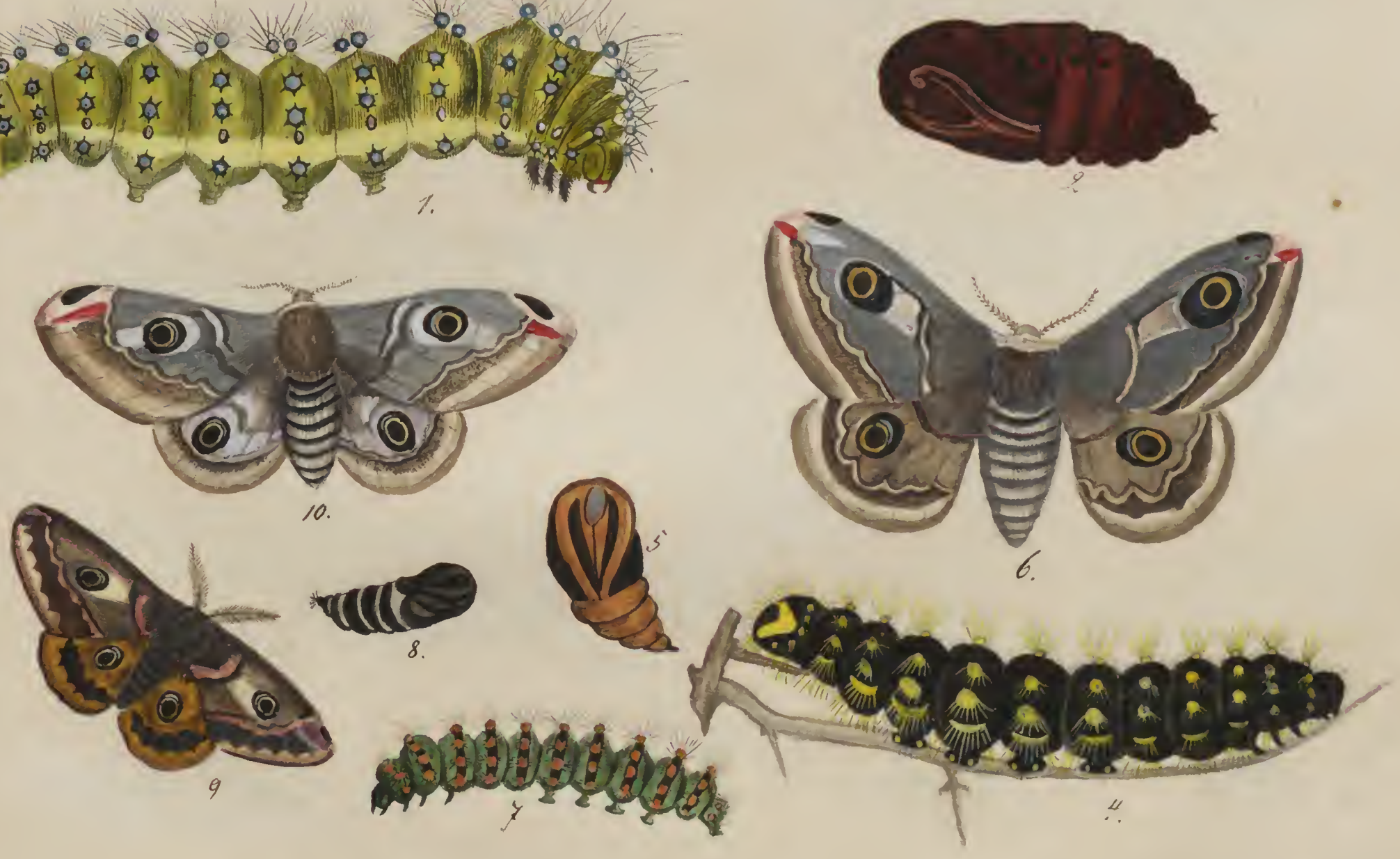

1-3 Bombyx puavonia major 4- B. Bomb. pavonia media. y 19 Bombigx parania minor. 

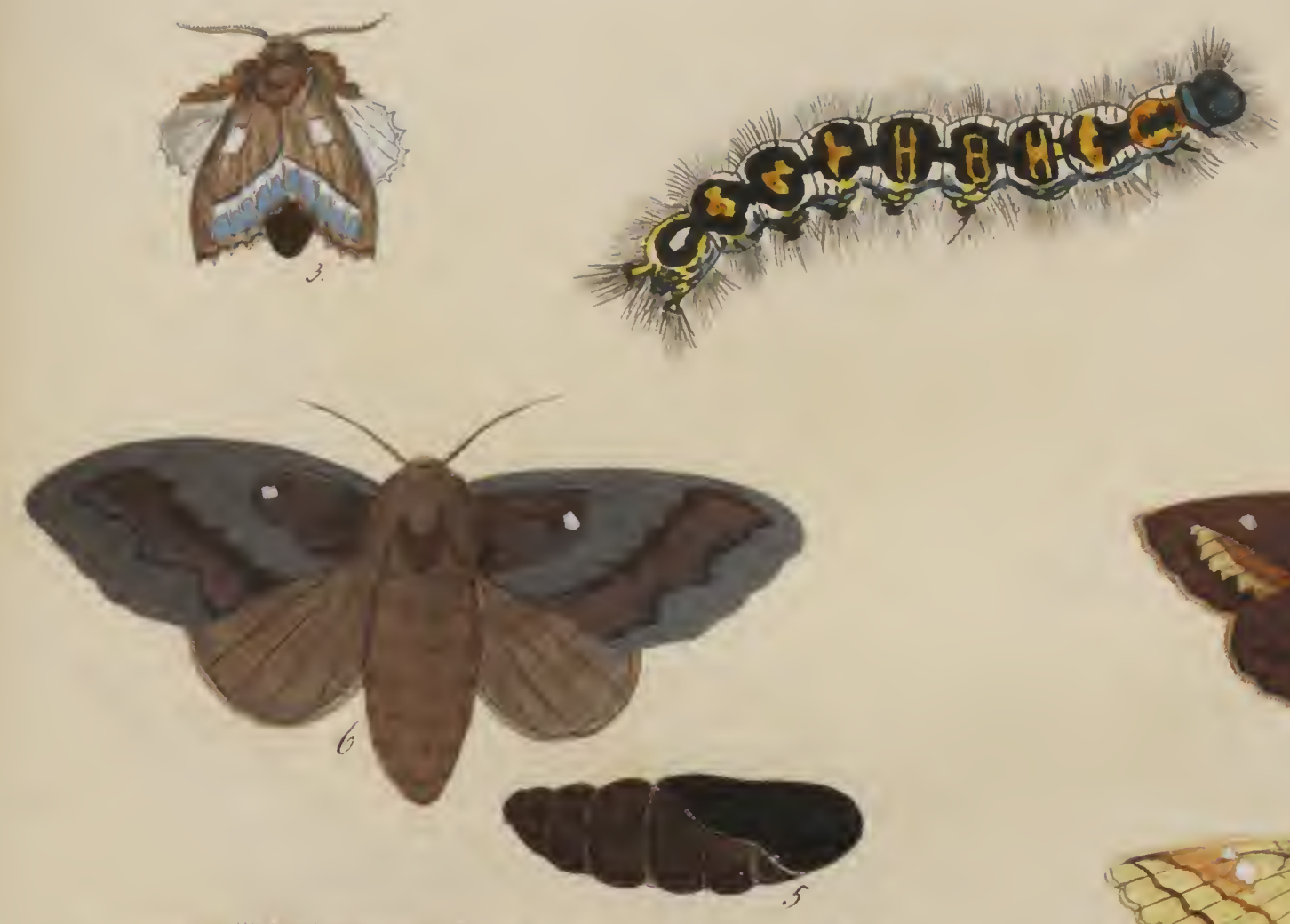

9.
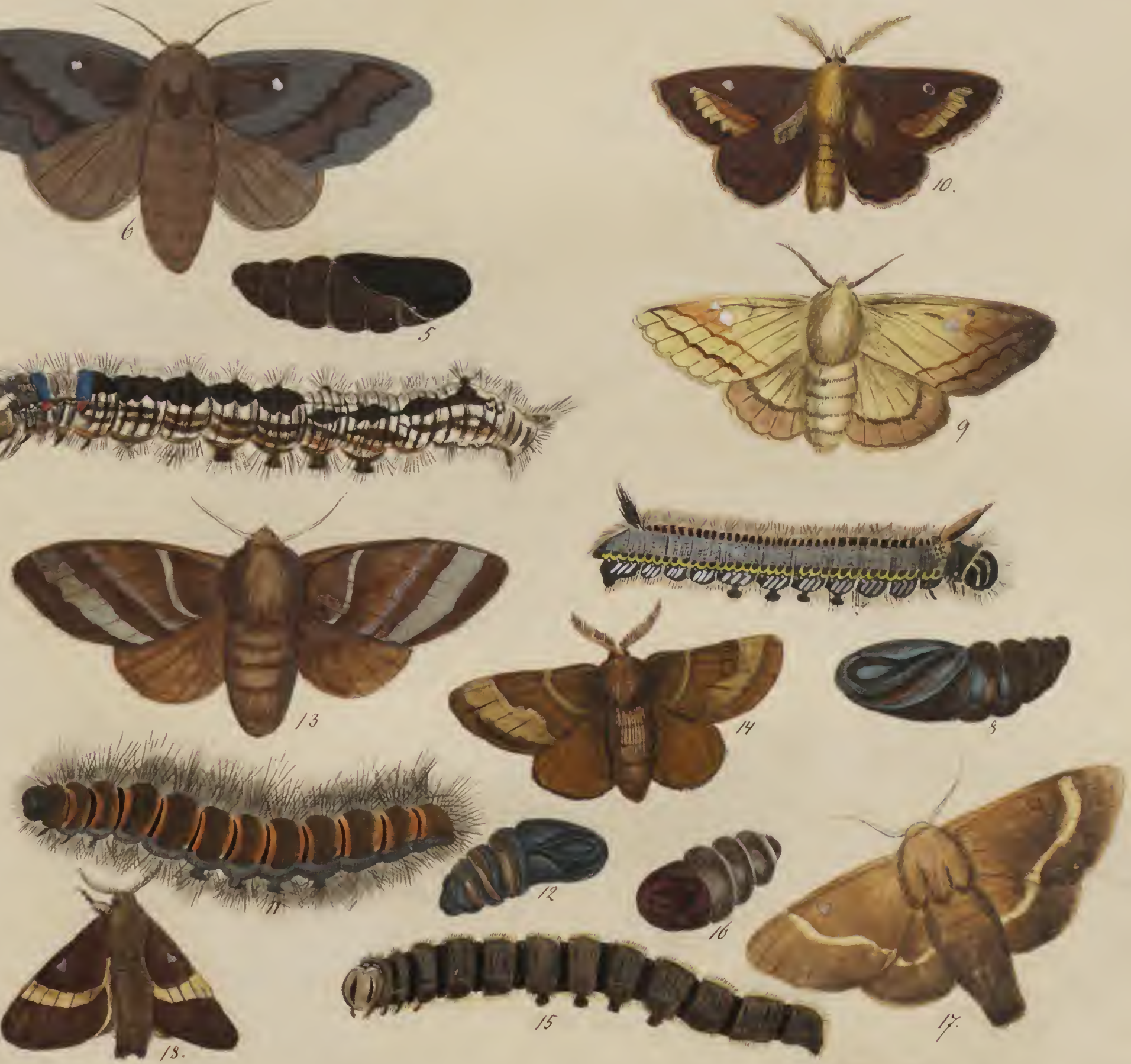

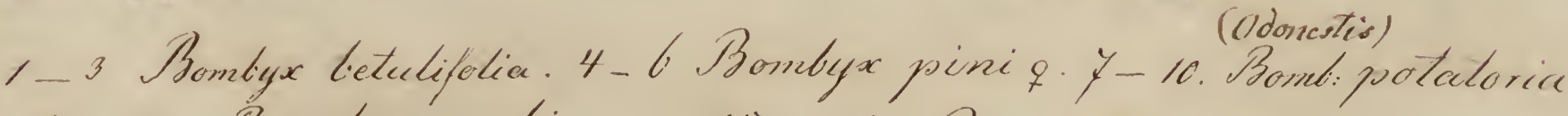
11- 14 Bonbuxi rubi 15- 18. Bonbyx quercus. 

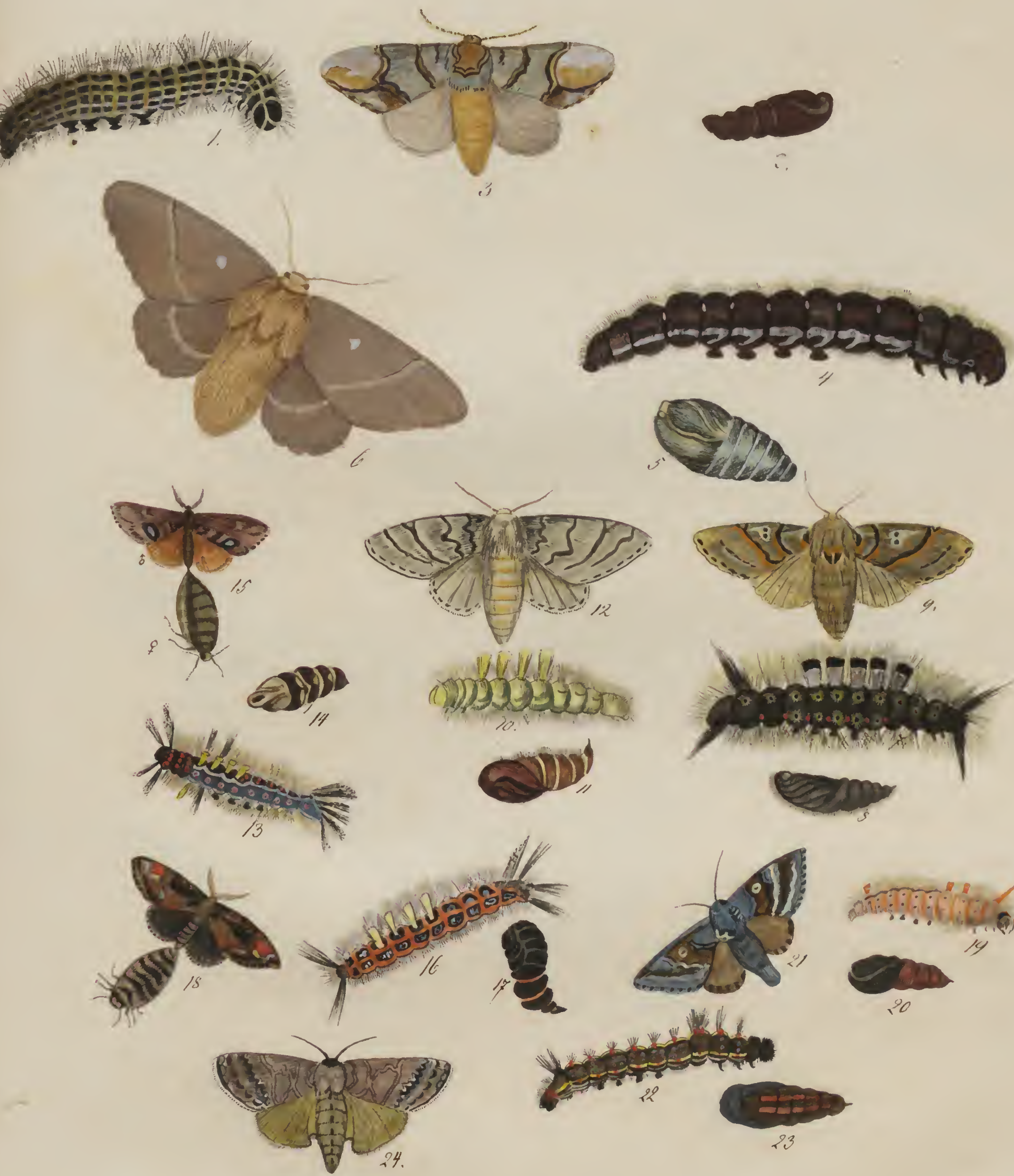

1-3 Bunbyx bueppliala 4-6. B. trifelic y-9. Bombyx farcelina

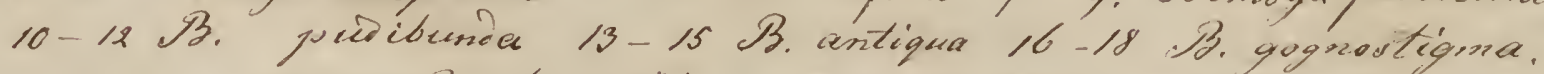

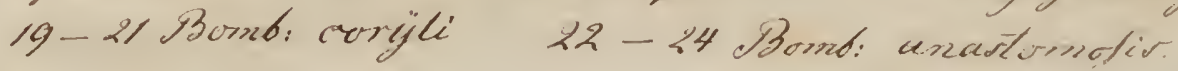



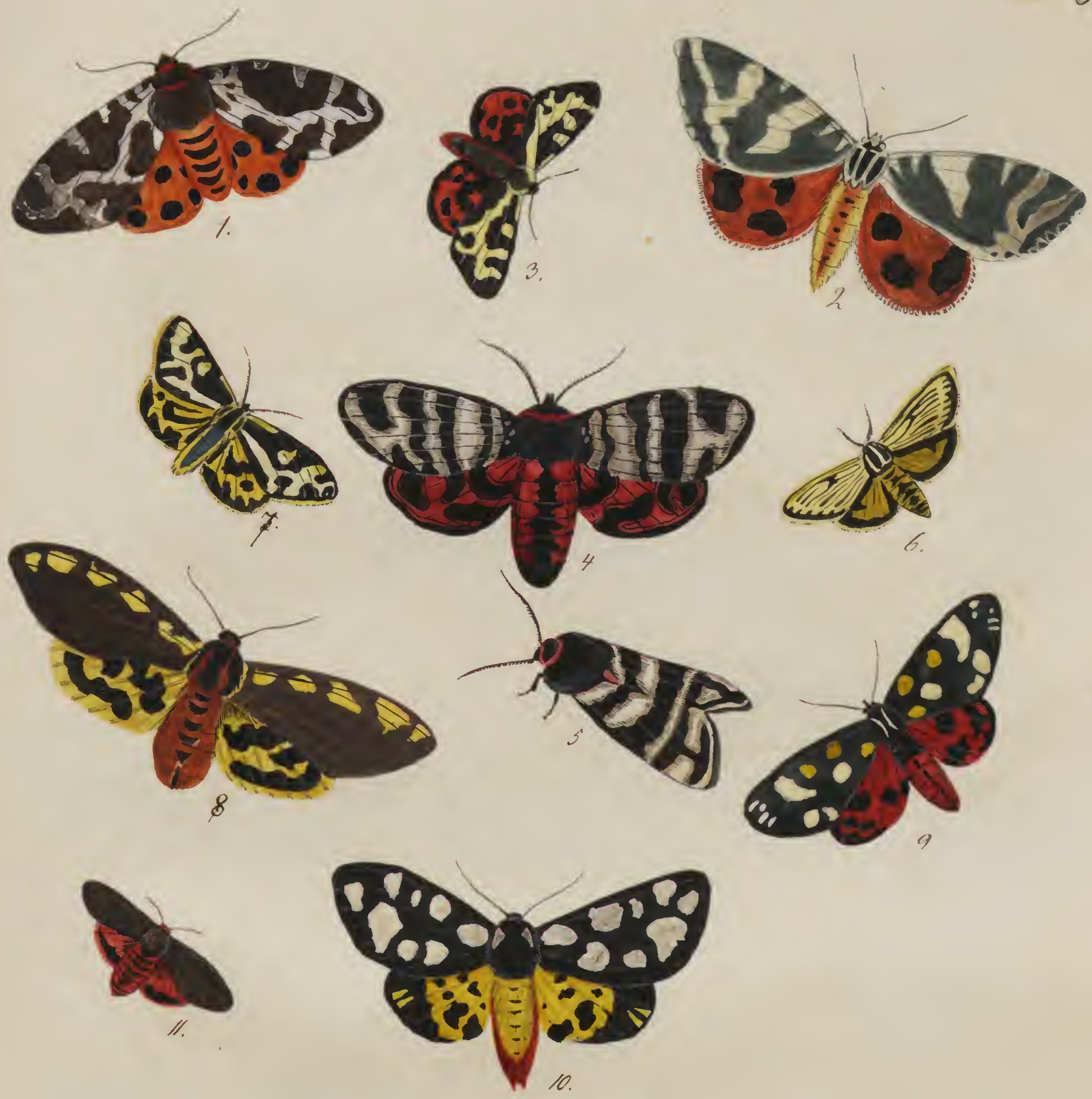

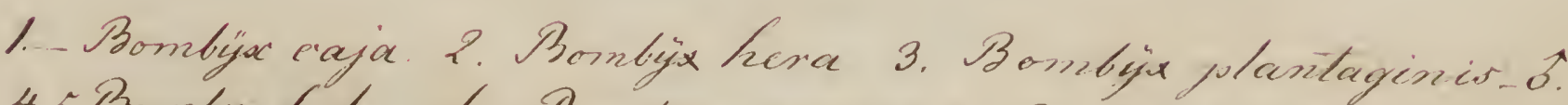

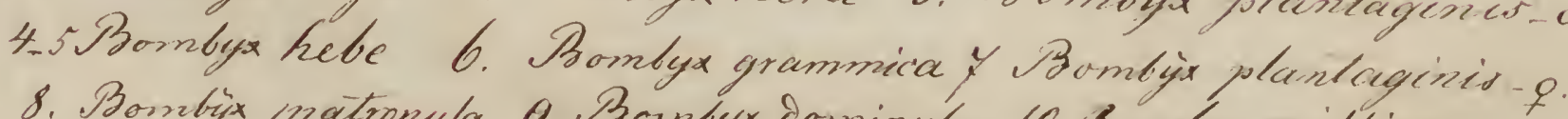
8. Bombigy matronula Q. Bonntyx dominula 10. Bomblyx villica. 11. Bombyar fuliginova. 

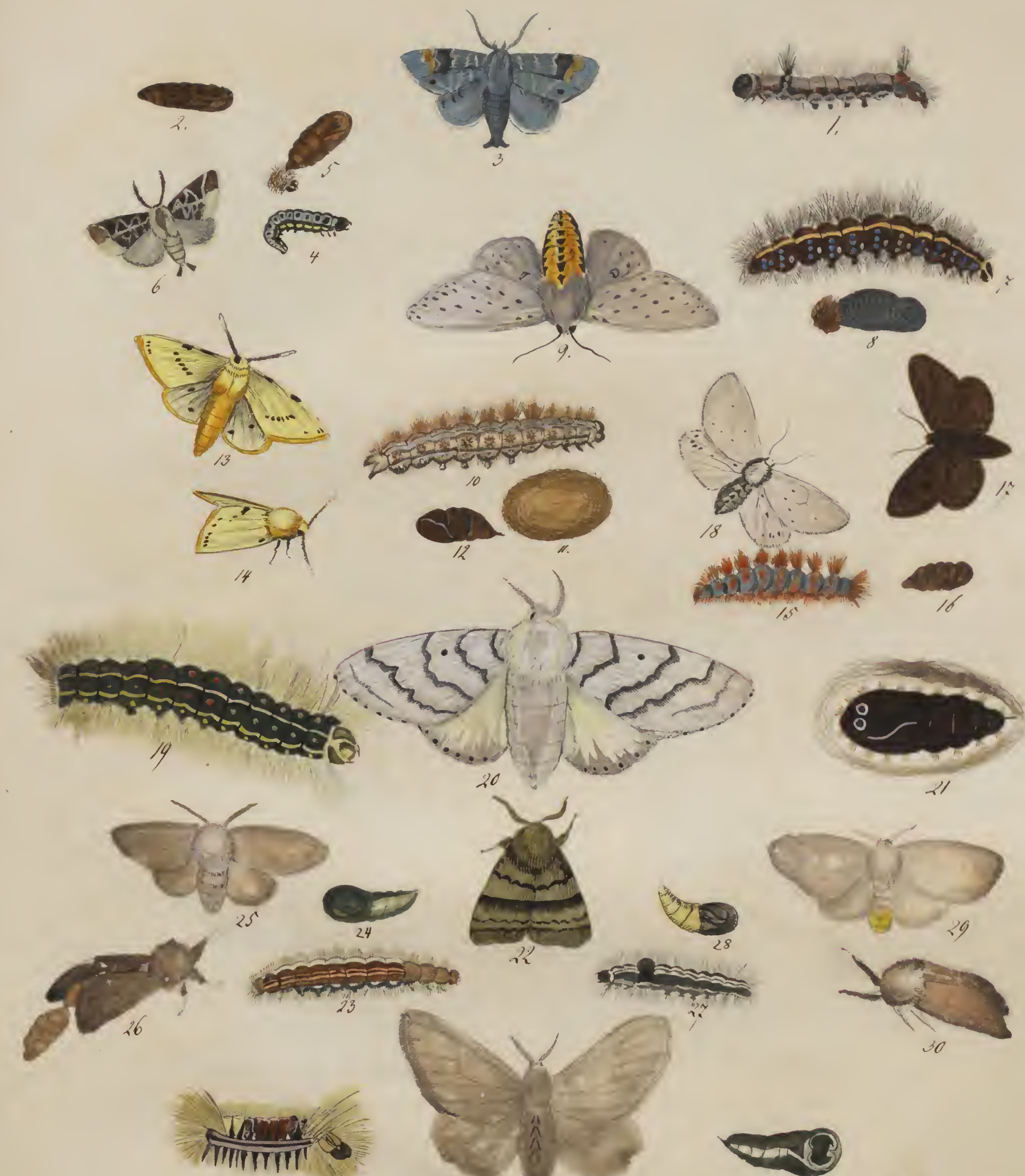

3)

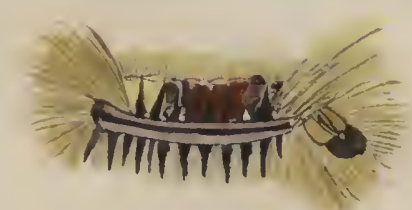

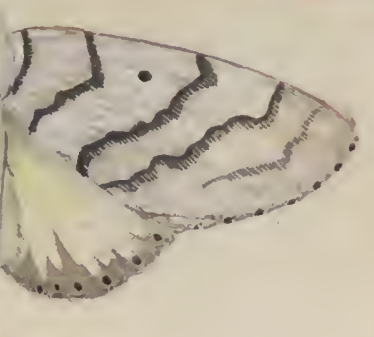
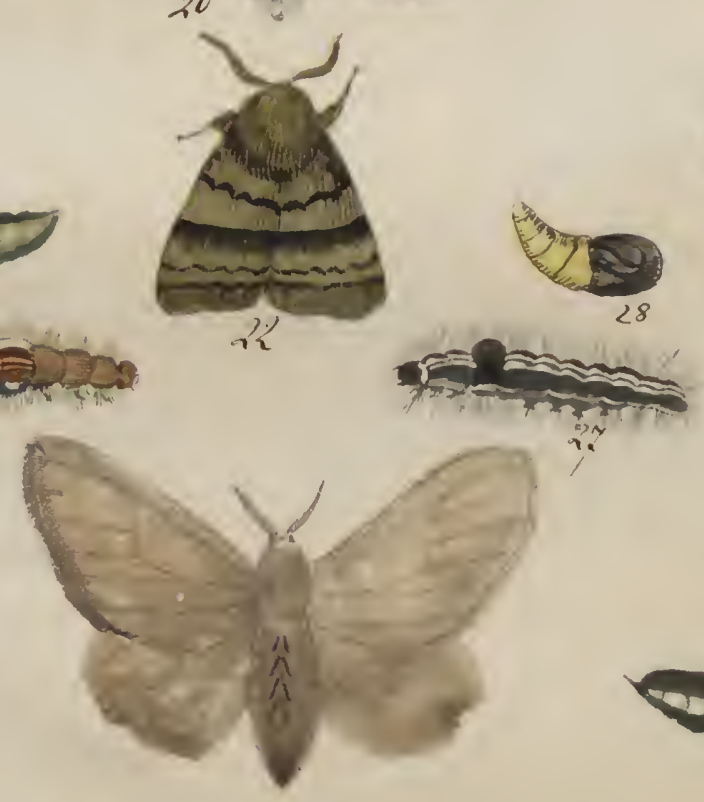

33

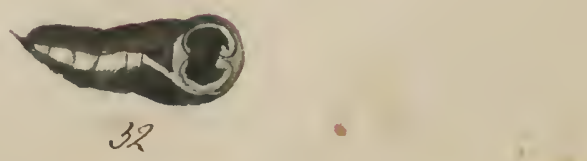

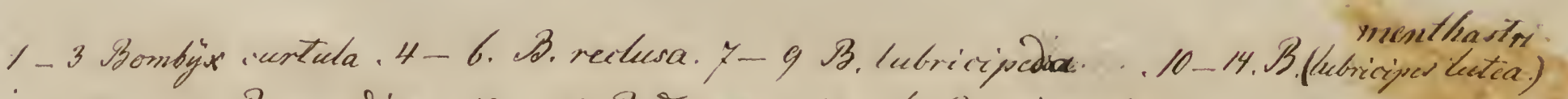
15-18. 3. mendica. 19-22 B. Jispwar. 28-26. 13. cryjurrfioca. 2y-36. Bomby'x aunifua 31-33. Bonby'x V.nigrean 

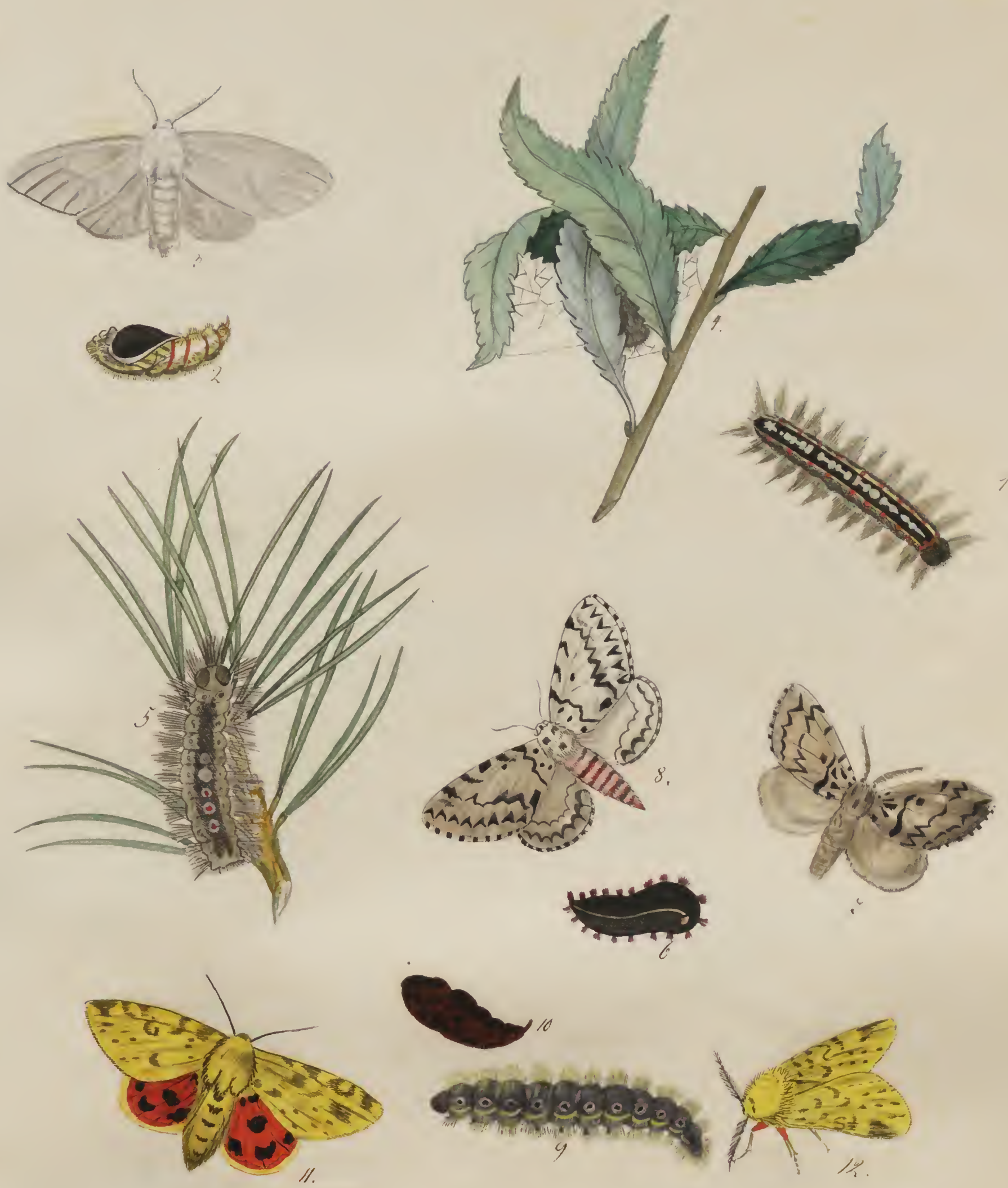

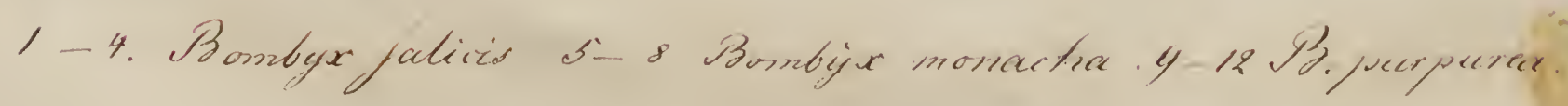



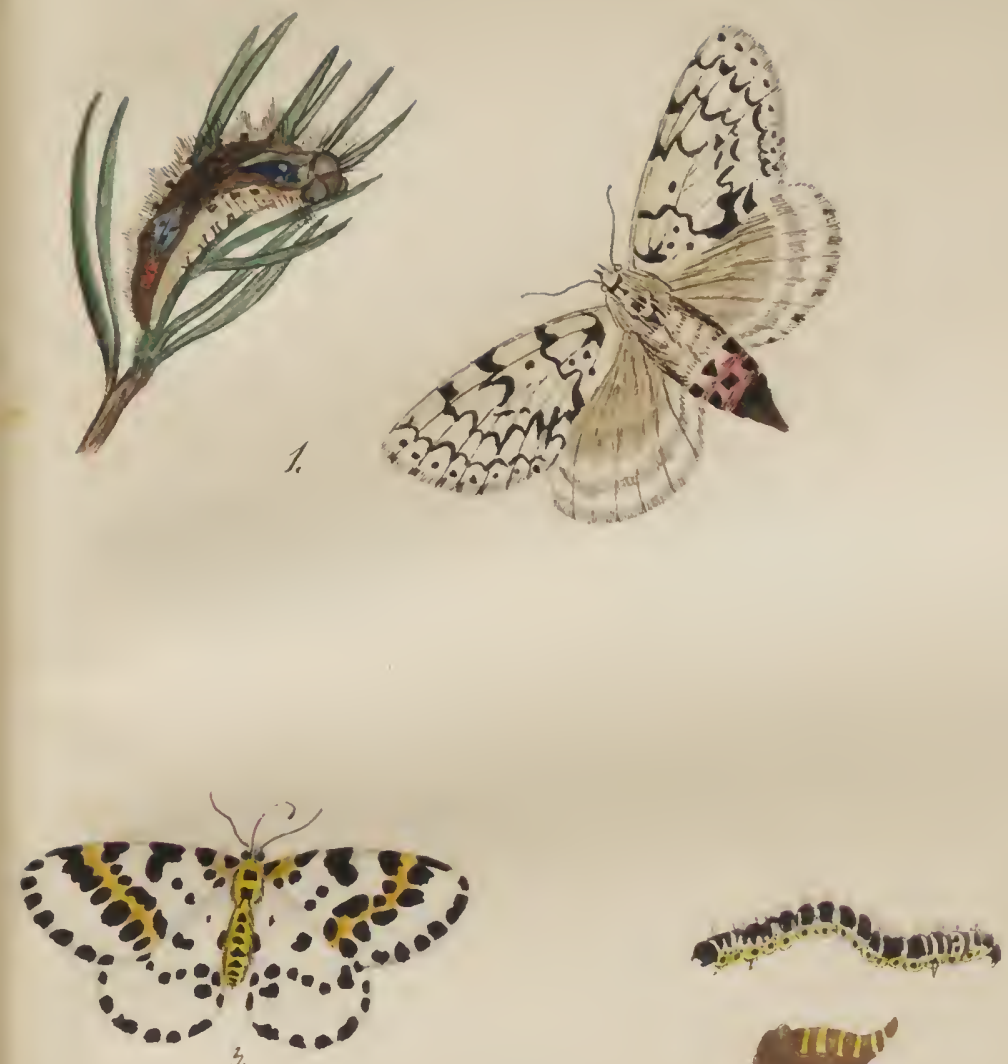

Mtron
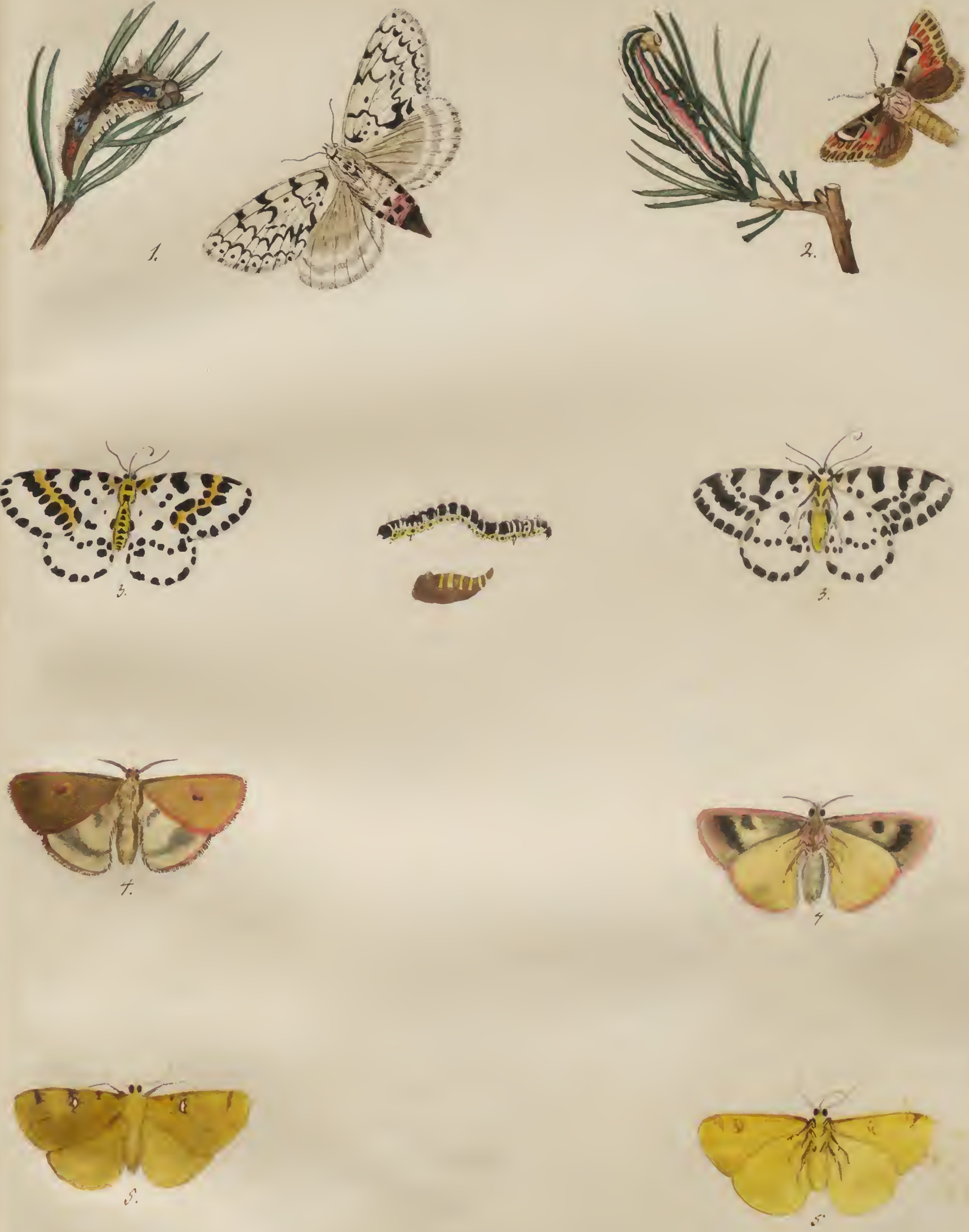

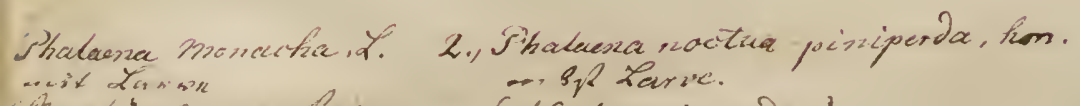
(vem. bix masactia)
(Noctua poinipertu:!
3. Geonutra grosoulariata. 5 yeometra iratusyita. 4. Nenrophita russula. 


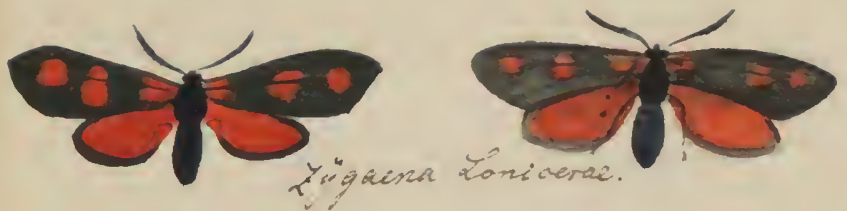

,
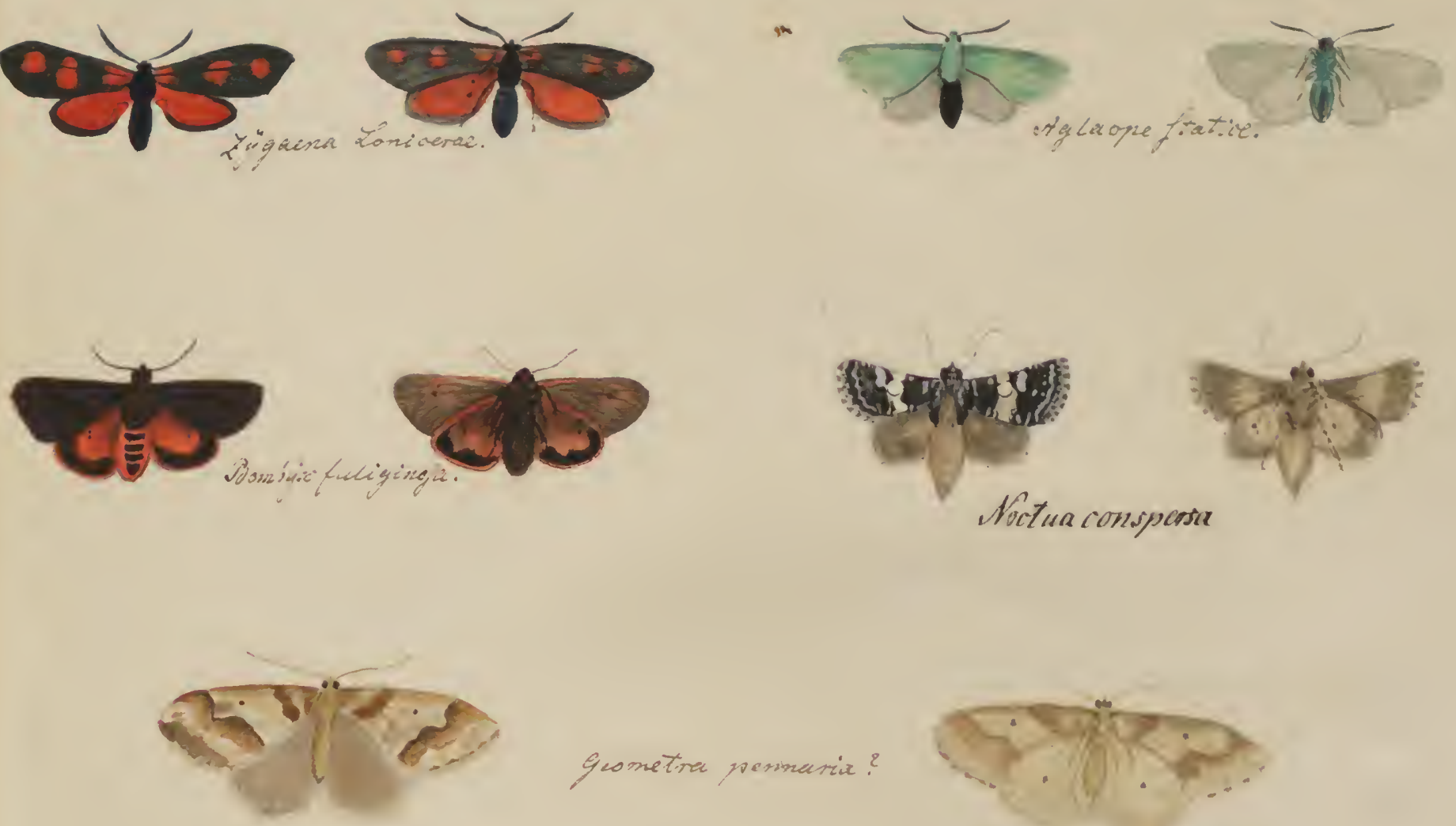

Geometra permarix?
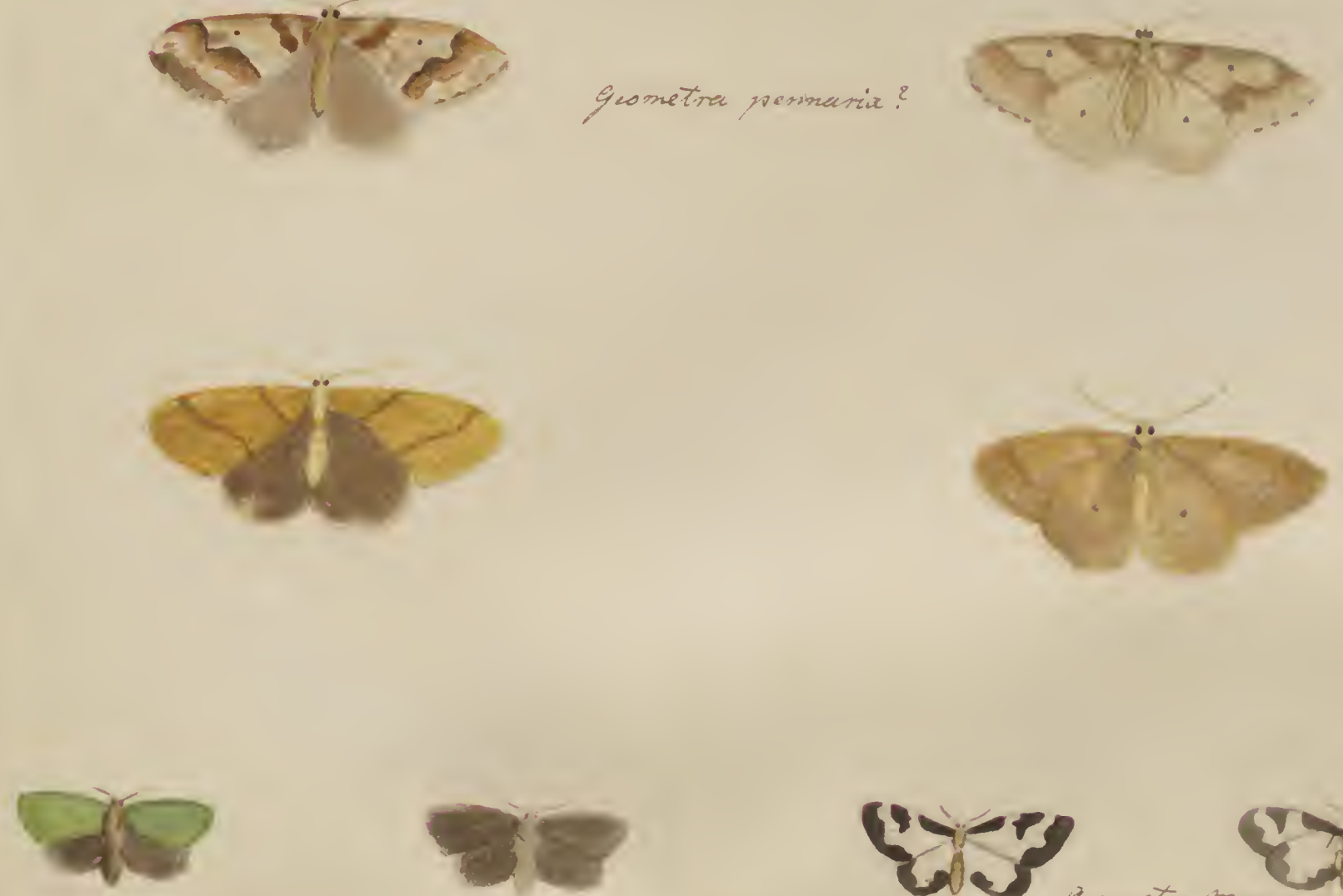

Fortria viridana.
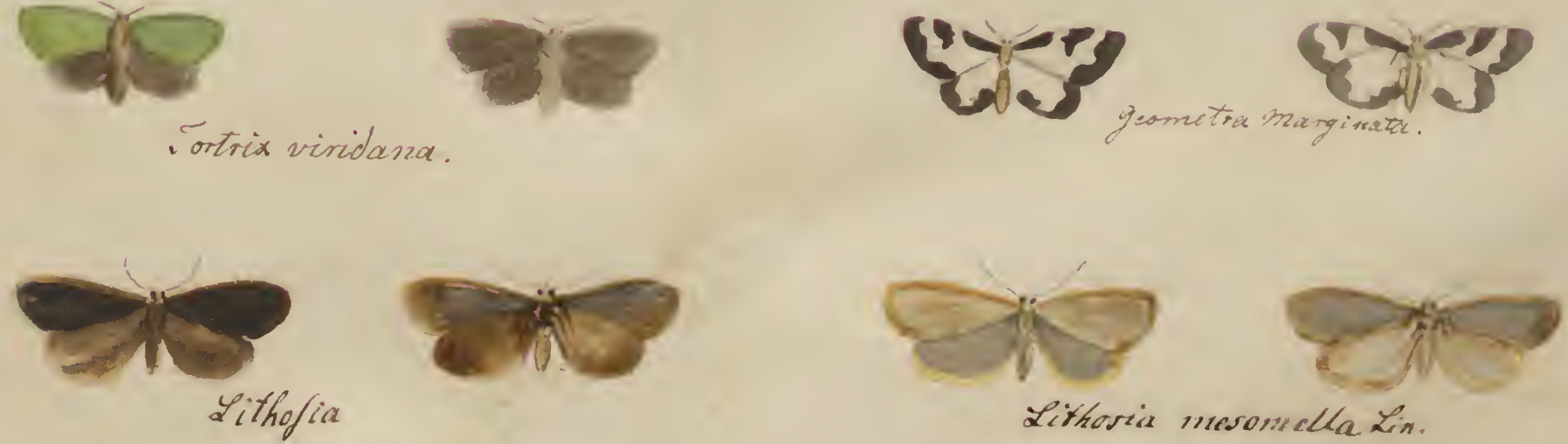

Lithosid mesonsulla Lin. 


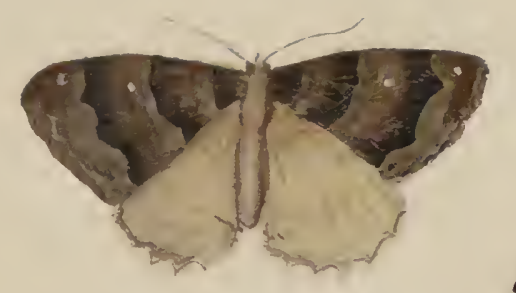

Geomctra bidentata
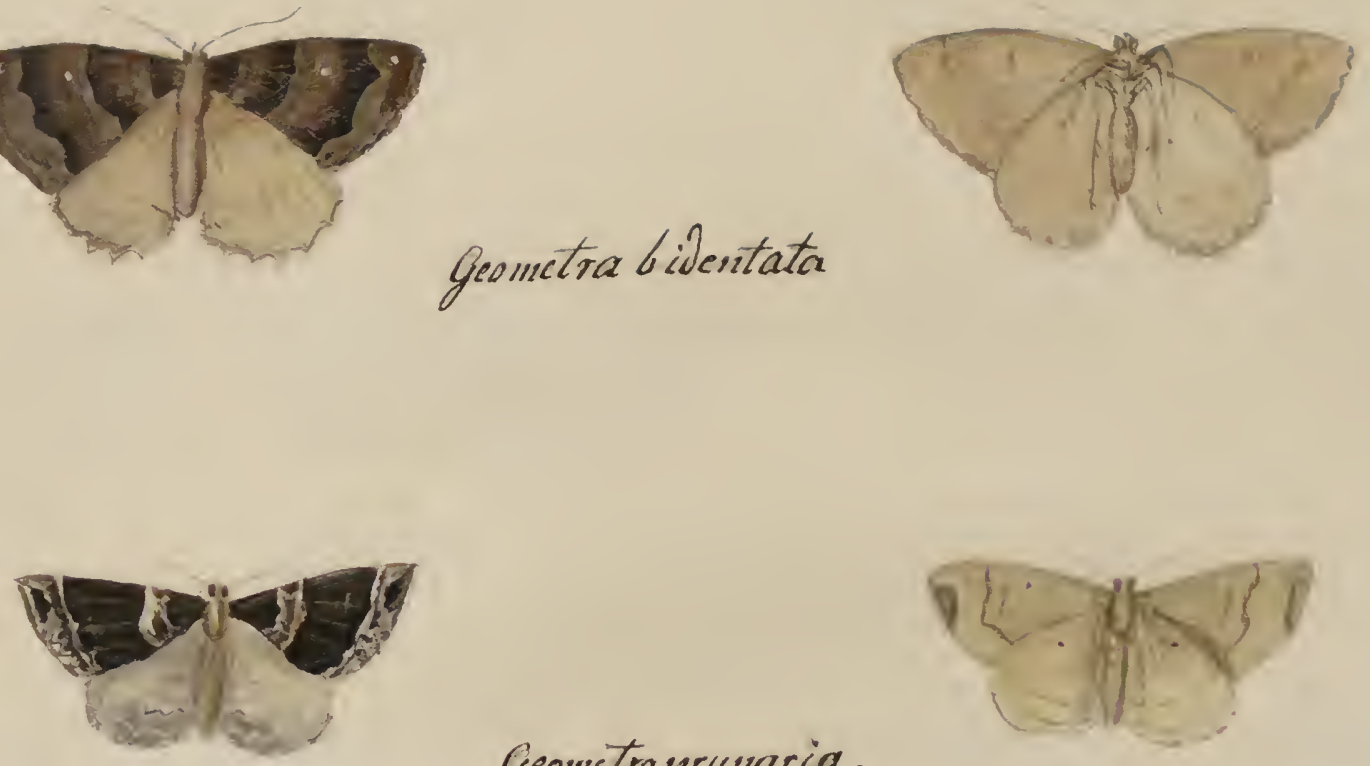

Geometraprunaria.
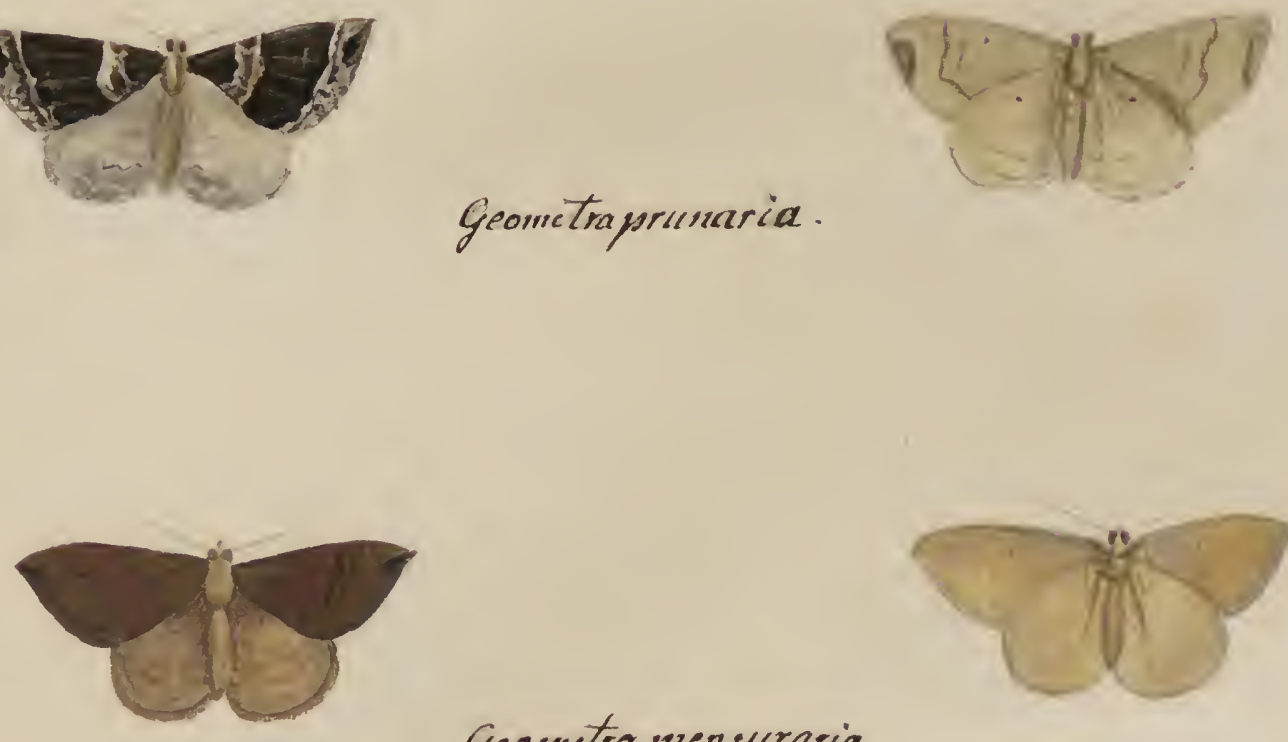

Geometra mensuraria
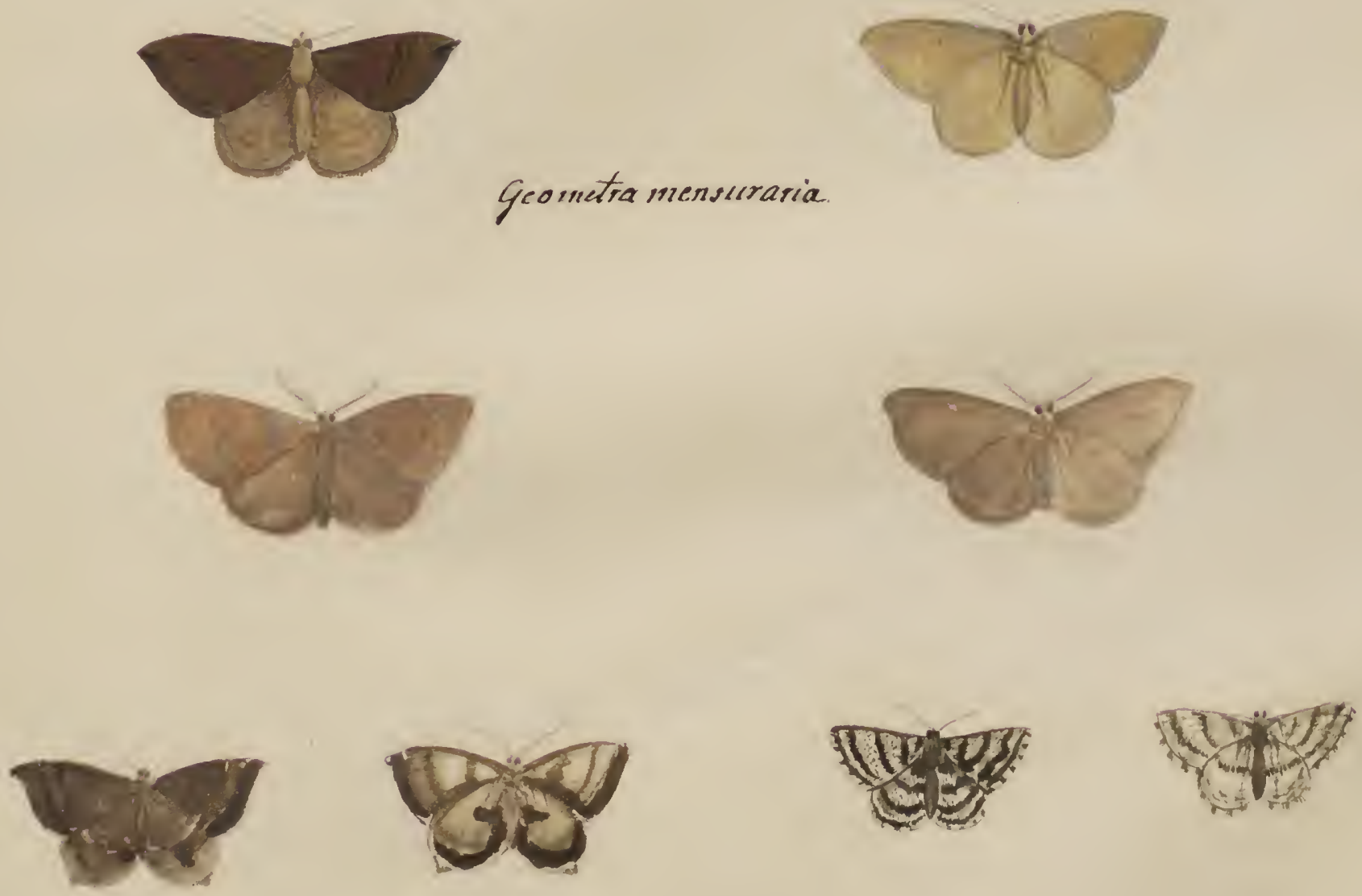


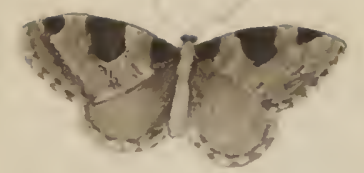

\section{$\theta 0$}
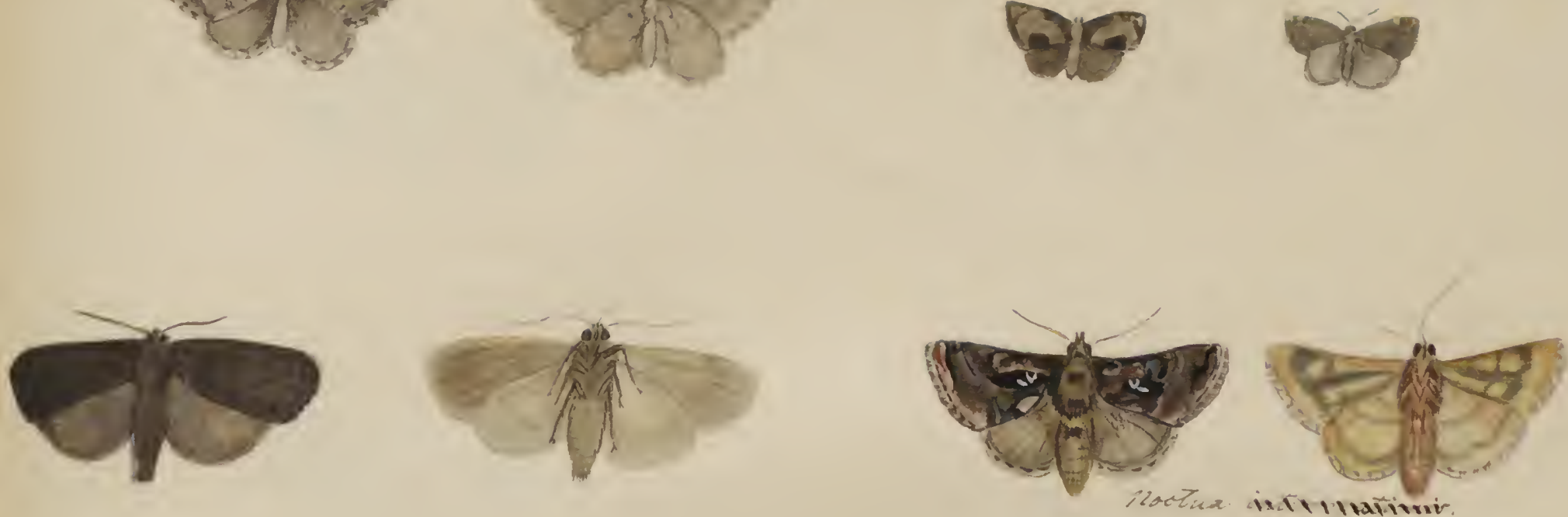
Yota.
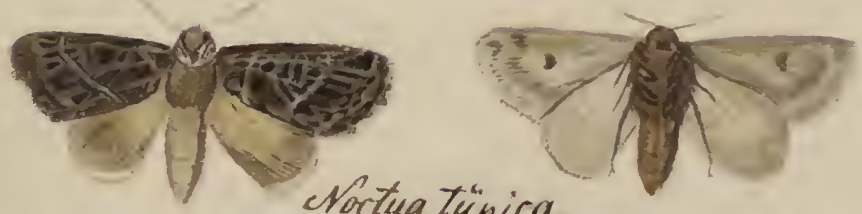
Nortua Typira.
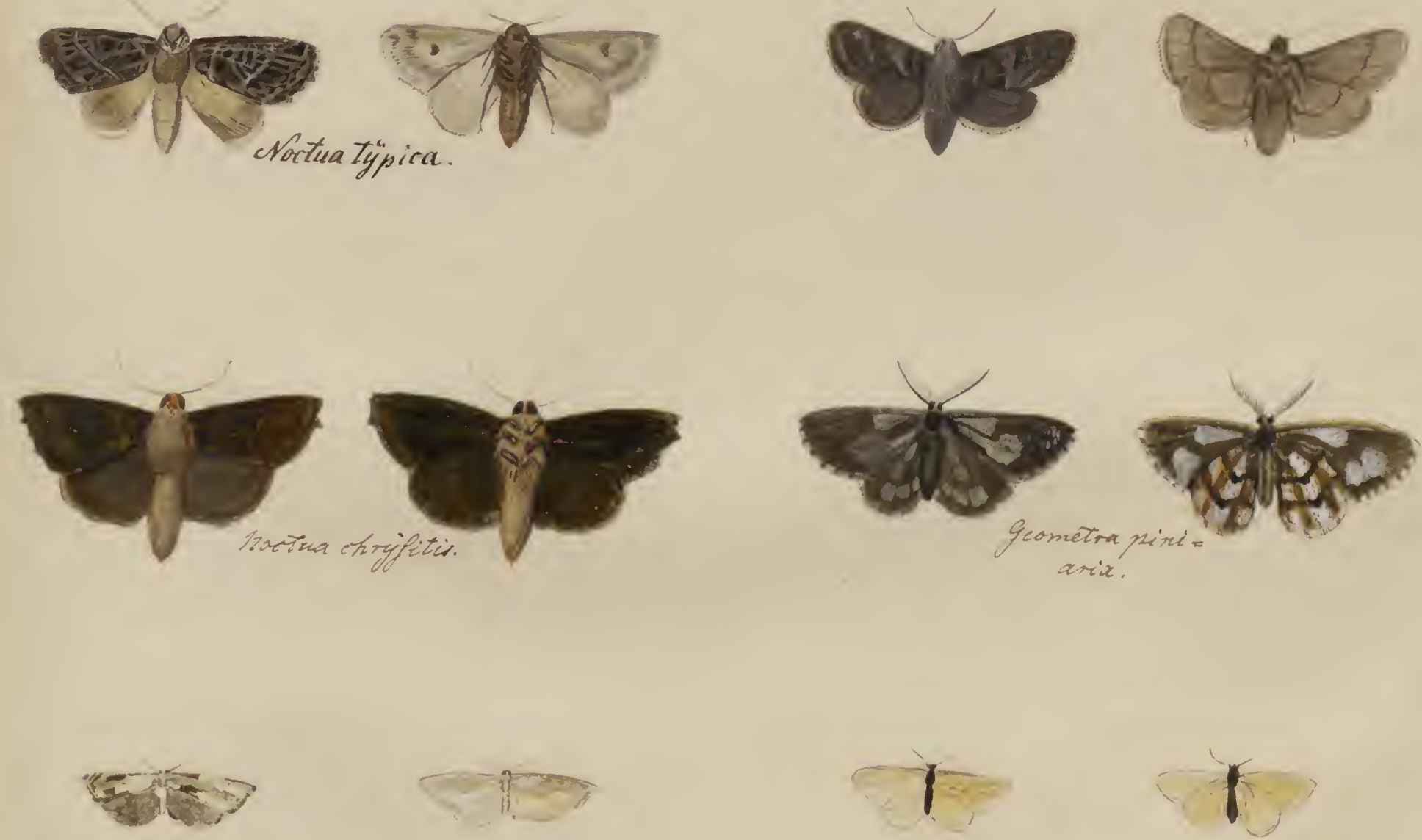

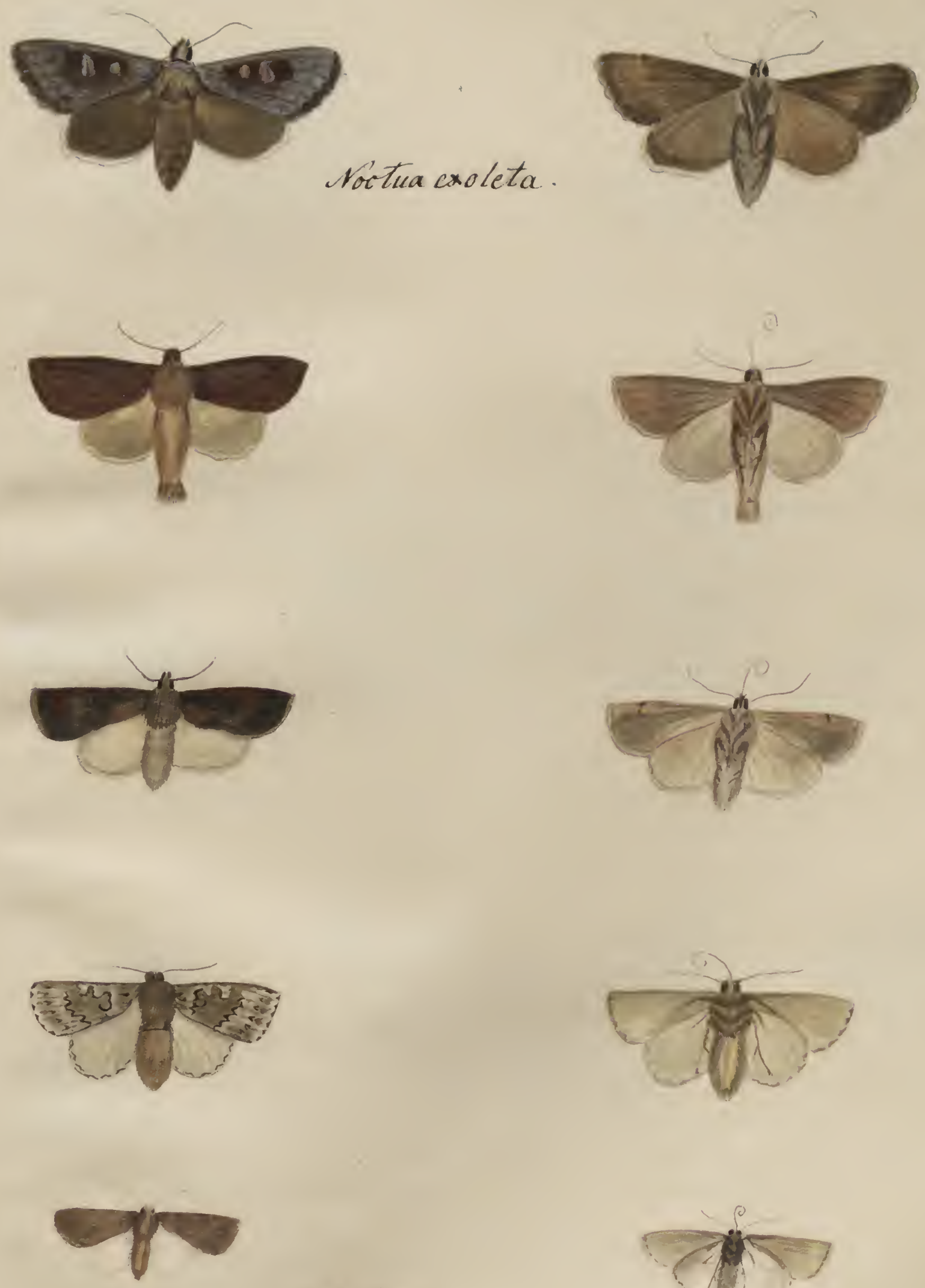

Charadrina

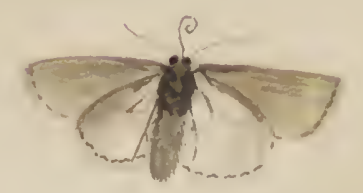



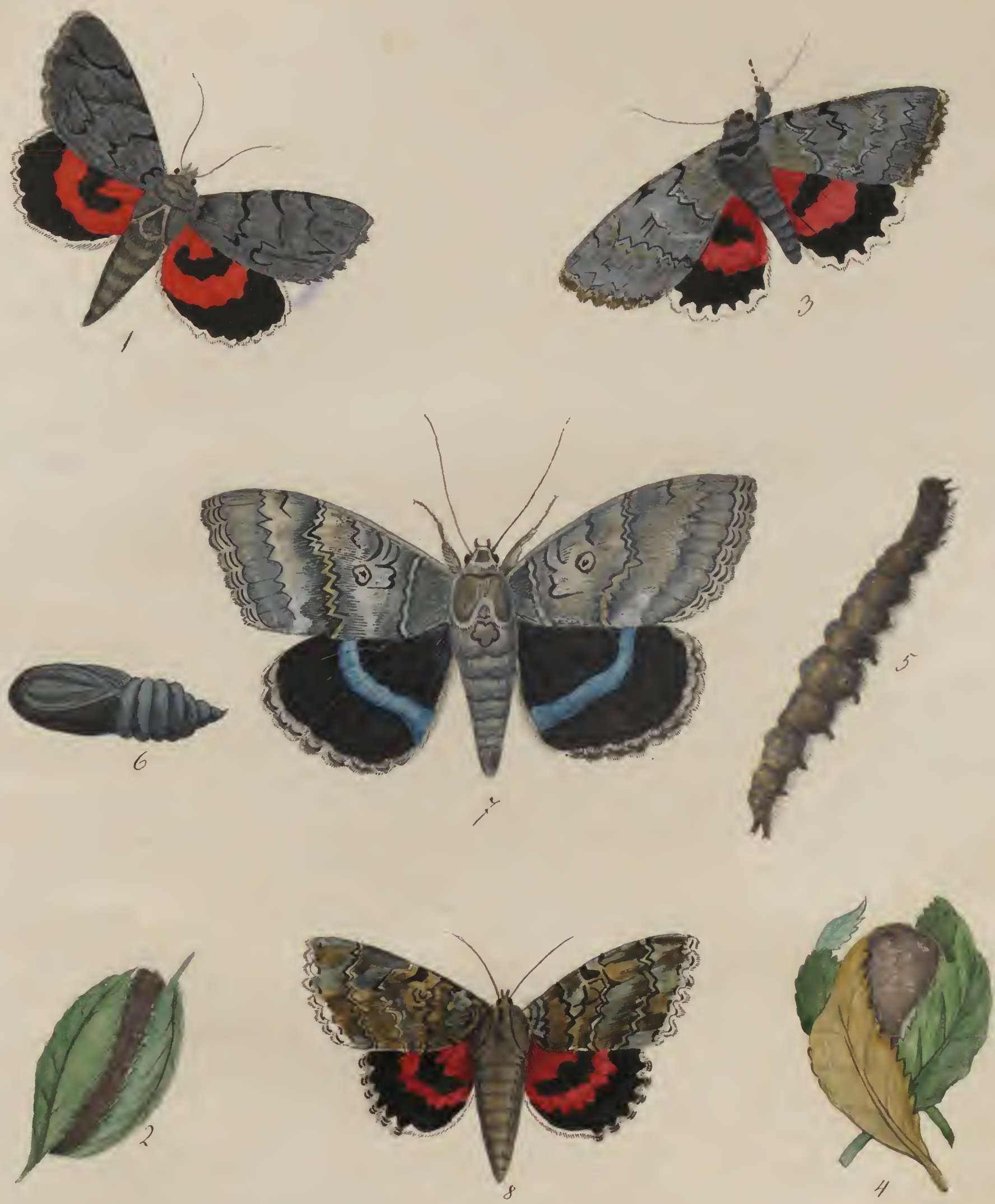

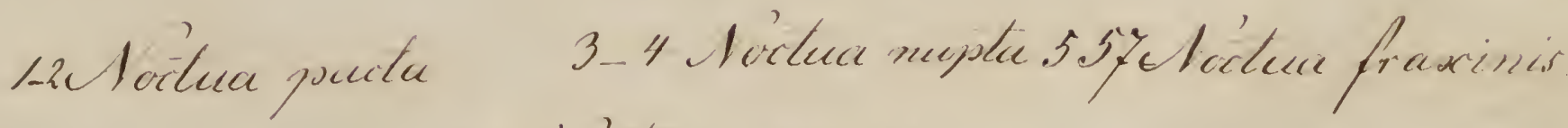
8 c Torlua syousa. 


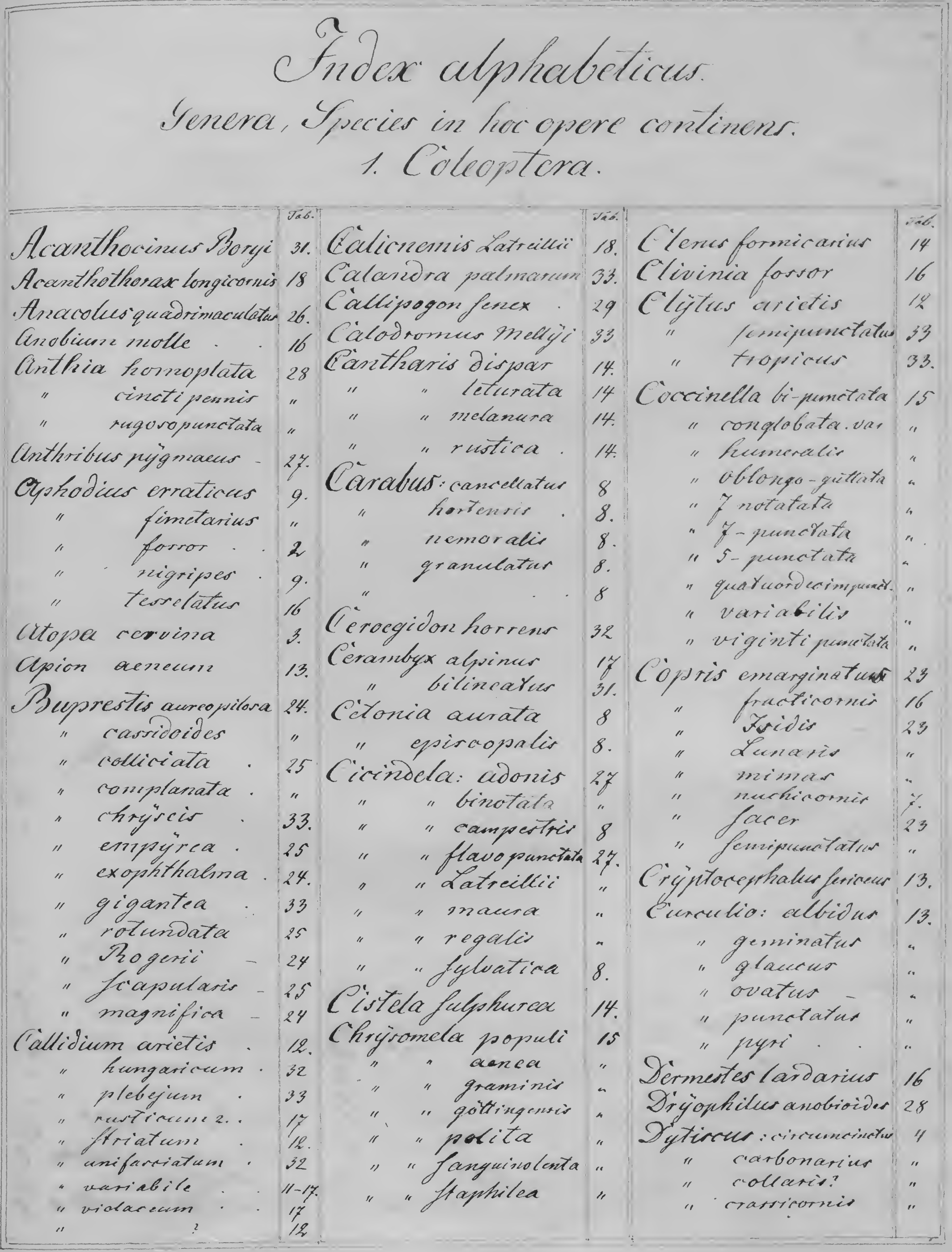




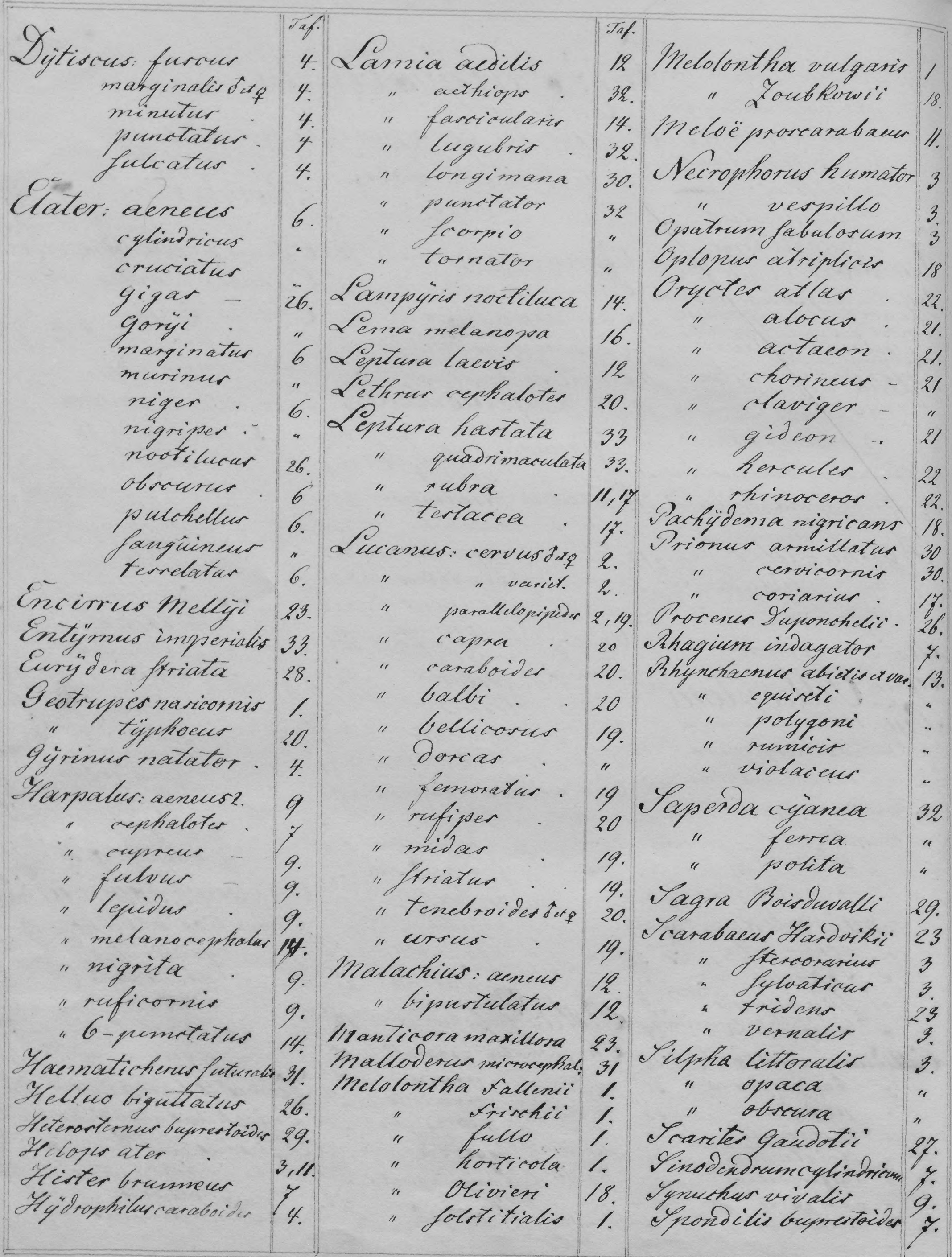


2.

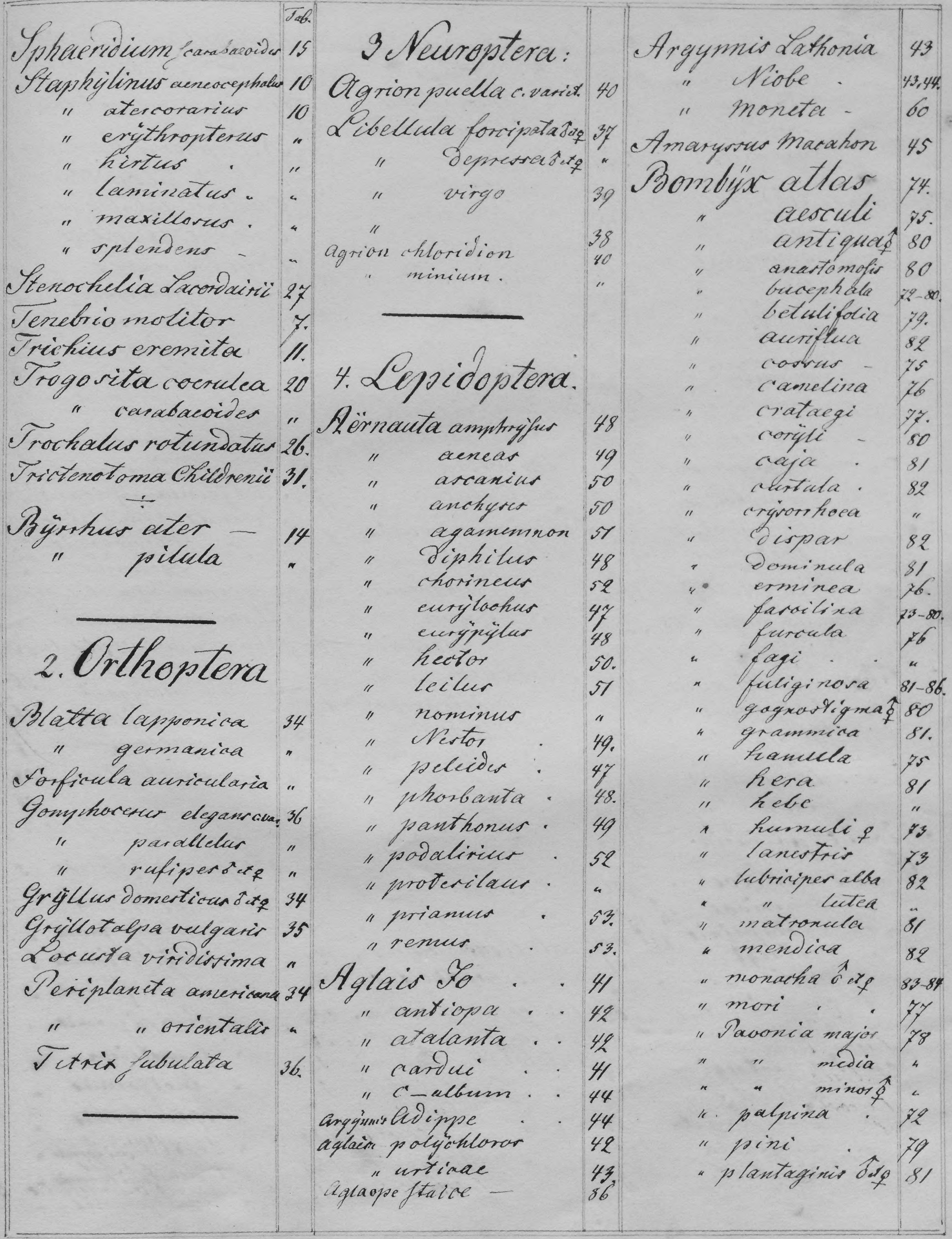




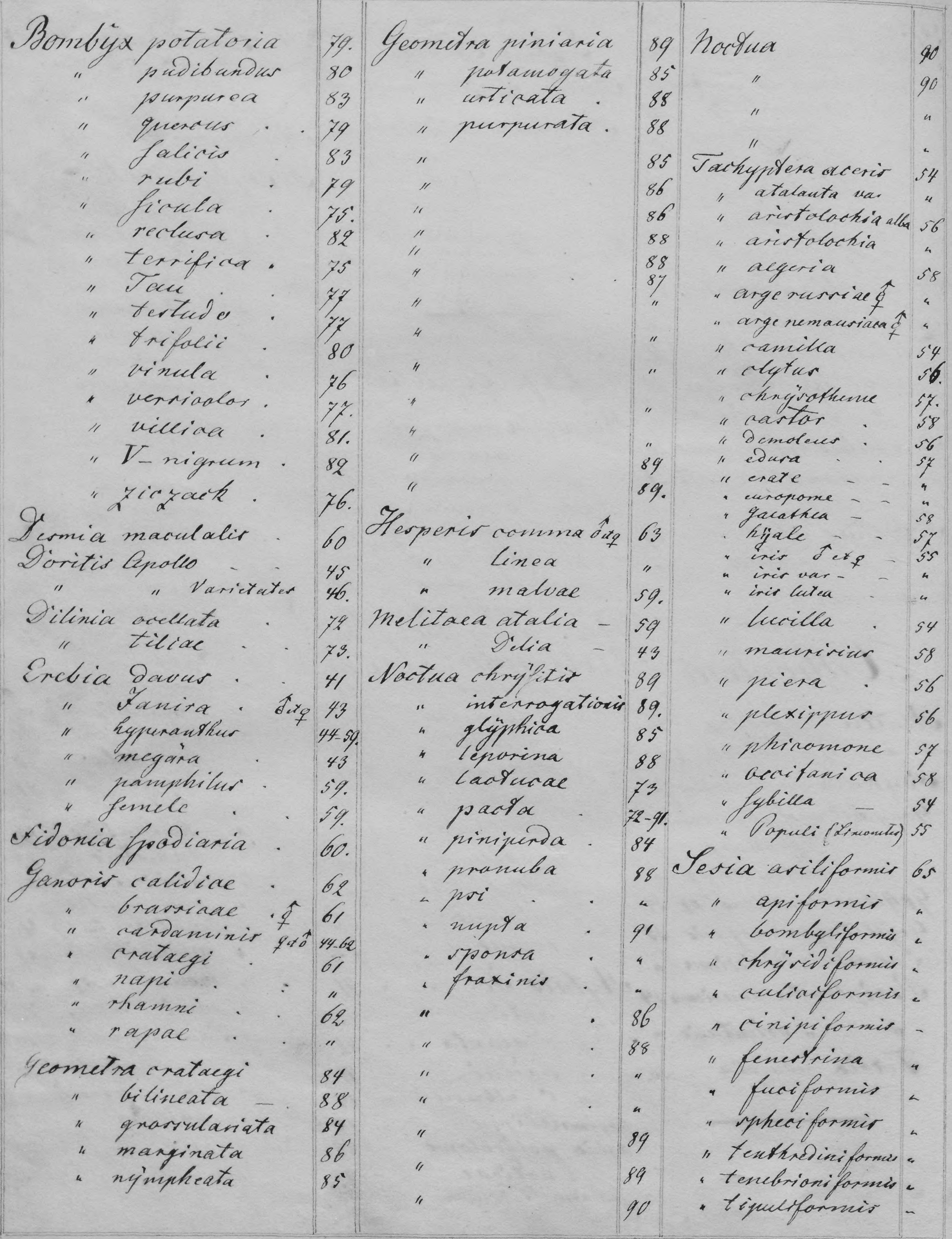




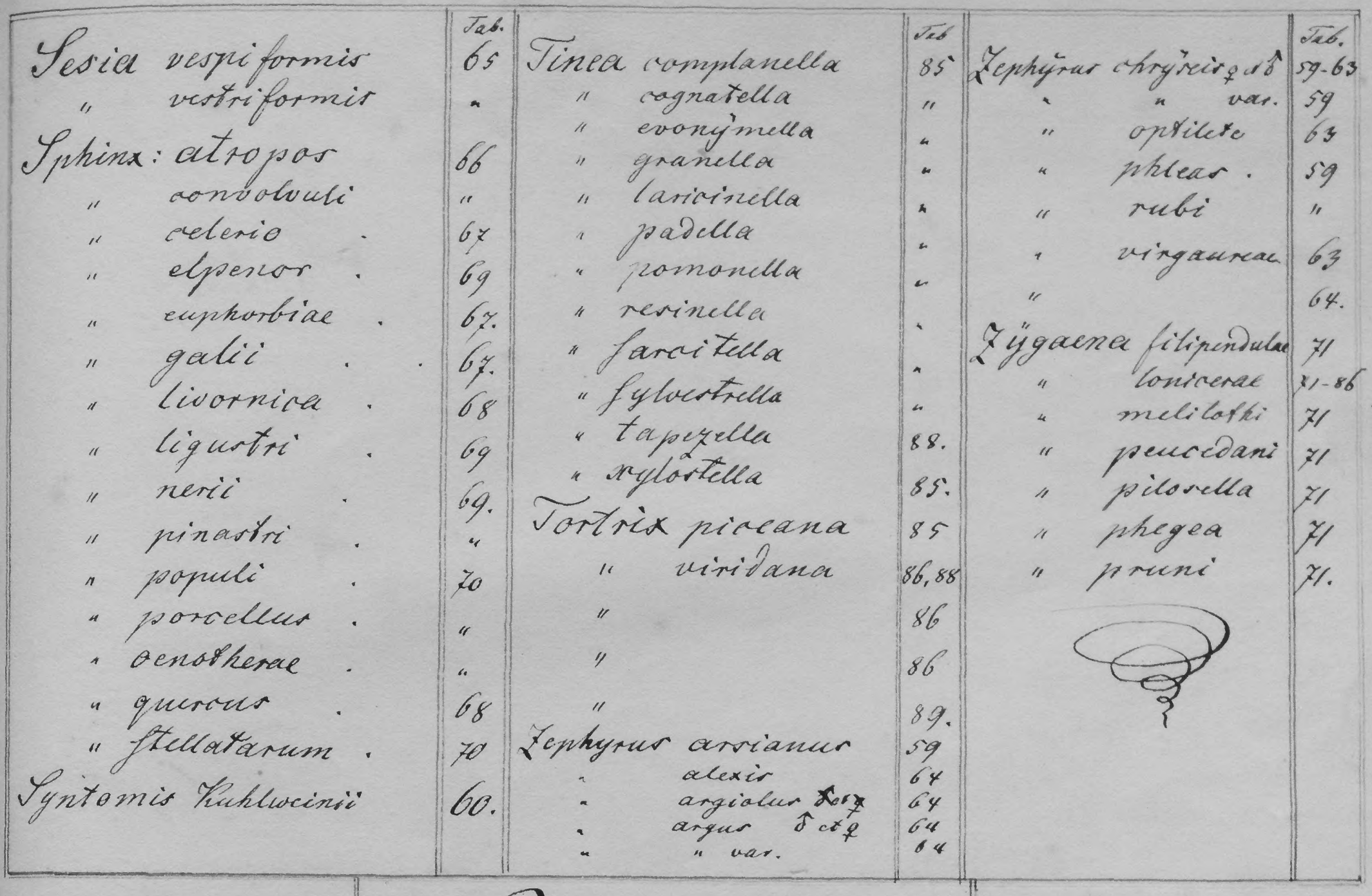

Recapitulatio.

- Cotcopstera... 86 2\%3:

2 Orthoptera . 8. 12

3 Cleuroptera. I. S

4 Lepiopoptera. 25258

Yucurma 124.51: 